Avaliação de manutenibilidade entre as abordagens de web services RESTful e SOAP-WSDL

Ricardo Ramos de Oliveira 



\title{
Avaliação de manutenibilidade entre as abordagens de web services RESTful e SOAP-WSDL
}

\author{
Ricardo Ramos de Oliveira
}

Orientadora: Prof ${ }^{\mathrm{a}}$. Dr ${ }^{\mathrm{a}}$. Renata Pontin de Mattos Fortes

Dissertação apresentada ao Instituto de Ciências Matemáticas e de Computação - ICMC-USP, como parte dos requisitos para obtenção do título de Mestre em Ciências - Ciências de Computação e Matemática Computacional. VERSÃO REVISADA

\author{
USP - São Carlos \\ Junho/2012
}


Ficha catalográfica elaborada pela Biblioteca Prof. Achille Bassi e Seção Técnica de Informática, ICMC/USP, com os dados fornecidos pelo(a) autor(a)

\begin{tabular}{|c|c|}
\hline \multirow[t]{3}{*}{ R48a } & $\begin{array}{l}\text { Ramos de Oliveira, Ricardo } \\
\text { Avaliação de manutenibilidade entre as abordagens } \\
\text { de web services RESTful e SOAP-WSDL / Ricardo Ramos } \\
\text { de Oliveira; orientadora Renata Pontin de Mattos } \\
\text { Fortes. -- São Carlos, } 2012 \text {. } \\
\quad 99 \text { p. }\end{array}$ \\
\hline & $\begin{array}{l}\text { Dissertação (Mestrado - Programa de Pós-Graduação em } \\
\text { Ciências de Computação e Matemática Computacional) -- } \\
\text { Instituto de Ciências Matemáticas e de Computação, } \\
\text { Universidade de São Paulo, 2012. }\end{array}$ \\
\hline & $\begin{array}{l}\text { 1. Avaliação de manutenibilidade. 2. Web services } \\
\text { RESTful e SOAP-WSDL em Java. } 3 \text {. Experimento } \\
\text { controlado. 4. Métricas de softwares. 5. Qualidade } \\
\text { do software. I. Pontin de Mattos Fortes, Renata, } \\
\text { orient. II. Título. }\end{array}$ \\
\hline
\end{tabular}


"A sabedoria do humilde levantará a sua cabeça e o fará sentar-se no meio dos grandes." Ec.11:1

Dedico à minha mãe Luzia, ao meu pai José, a minha irmã Cecília que contribuíram de um modo muito especial para o meu crescimento como ser humano e como profissional Amo todos vocês! 

Agradeço primeiramente a Deus que está sempre do meu lado.

Aos meus pais José e Luzia e a minha irmã Cecília, pessoas que me apoiaram e ajudaram a realizar e concretizar todos os meus sonhos e me ensinaram a lutar pelos meus objetivos. Sempre serei grato a todos vocês.

A todos os meus amigos pelo companheirismo e pelas horas de descontração. Sempre me lembrarei de todos vocês. Obrigado a todos.

A todos do Laboratório do Intermídia e do grupo de pesquisa, pela amizade, pelo agradável convívio, pelas discussões e troca de experiência enriquecedoras. Em especial, aos meus amigos: Robson Vinícius Vieira Sanchez, Willian Massami Watanabe e Rafael Messias Martins pelas inúmeras e valiosas contribuições durante o desenvolvimento do trabalho.

Aos professores, funcionários e estudantes do Instituto Federal de Educação, Ciência e Tecnologia do Sul de Minas Gerais - IFSULDEMINAS, por terem me recebido com muita alegria e felicidade.

A minha orientadora, a professora $\mathrm{Dr}^{\mathrm{a}}$. Renata Pontin de Mattos Fortes, por todo seu caráter, profissionalismo, paciência e dedicação para comigo durante as diversas atividades de pesquisa e andamento deste trabalho.

Por fim, agradeço ao ICMC-USP pela oportunidade e à CAPES pelo apoio financeiro que viabilizou o trabalho. 

Engenharia de Software tem desenvolvido técnicas e méto1 dos para apoiar o desenvolvimento de software confiável, $\perp$ flexível, com baixo custo de desenvolvimento e fácil manutenção. A avaliação da manutenibilidade contribui para fornecer meios para produzir software com alta qualidade. Este trabalho apresenta um experimento controlado para avaliar a manutenibilidade entre as abordagens de web services: RESTful e SOAP-WSDL. Esta avaliação foi conduzida usando 3 programas implementados na linguagem de programação Java e com a mesma arquitetura. Com base na arquitetura projetada, os web services desenvolvidos foram utilizados como objetos em estudos de caso, possibilitando avaliar e comparar a sua manutenibilidade. Os resultados obtidos demonstraram relações entre as informações sobre o custo e a qualidade dos serviços web, que contribuíram para esclarecer os critérios para a obtenção de uma boa relação entre o custo da manutenção e a evolução dos serviços web. Para concluir, os resultados indica que os web services RESTful são mais manuteníveis do lado do servidor, e os web services SOAP-WSDL são mais manuteníveis do lado do cliente. Os estudos realizados no experimento controlado são promissores e podem auxiliar na redução de custo na manutenção dos serviços web, melhorando dessa forma a qualidade do software no geral.

Palavras Chaves: Arquitetura Orientada a Serviços, Avaliação de Manutenibilidade, Web Services RESTful e SOAP-WSDL, Experimento Controlado, Métricas de Software e Qualidade do Software Orientado a Serviço. 


support the development of reliable software, flexible, low development cost and easy maintenance. The evaluation of maintainability contributes in this direction, providing the means to produce software with high quality. This paper presents an controlled experiment to evaluate the maintainability between the approaches of web services: RESTful and SOAP-WSDL. This evaluation was conducted using four programs implemented in the Java programming language, using the same architecture. Based on the designed architecture, Web services were developed as objects used in case studies, allowing to evaluate and compare its maintainability. The results showed relationships between the information on the cost and quality of web services, which contributed to clarify the criteria for obtaining a good relationship between the cost of maintenance and evolution of web services. In conclusion, the results indicate the RESTful web services are more maintainable server side in contrast to the SOAP-WSDL web services are more maintainable client side. Studies in controlled experiments are promising and may help reduce the maintenance cost of web services, thus improving overall software quality.

Keywords: Service Oriented Architecture, Evaluation of Maintainability, Web Services RESTful and SOAP-WSDL, Controlled Experiment, Software Metrics and Quality of Service-Oriented Software. 

$\begin{array}{ll}\text { Agradecimentos } & 7\end{array}$

$\begin{array}{ll}\text { Resumo } & 9\end{array}$

$\begin{array}{ll}\text { Abstract } & \text { i }\end{array}$

1 Introdução 1

1.1 Considerações Iniciais . . . . . . . . . . . . . . . . . . . . . 1

1.2 Contextualização . . . . . . . . . . . . . . . . . . . . 2

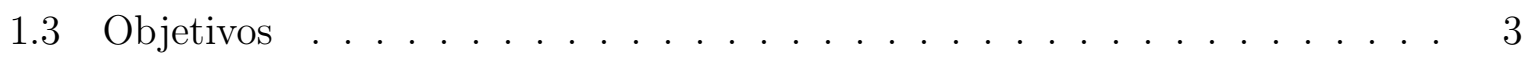

1.4 Estrutura . . . . . . . . . . . . . . . . . . . . 3

2 Fundamentos sobre Web Services 5

2.1 Considerações Iniciais . . . . . . . . . . . . . . . . . . . . 5

2.2 Arquitetura Orientada a Serviços (SOA) . . . . . . . . . . . . . . . . 5

2.3 Conceitos de Web Services . . . . . . . . . . . . . . . . . . . . . 8

2.3.1 Arquitetura de Web Services . . . . . . . . . . . . . . . . 12

2.3.2 Arquitetura RESTful . . . . . . . . . . . . . . . . . . . . . . . . . . . . . . 14

2.4 Os principais Padrões de Web Services . . . . . . . . . . . . . . . 15

2.4 .1 XML-RPC . . . . . . . . . . . . . . . 15

$2.4 .2 \mathrm{JSON} \ldots \ldots \ldots \ldots \ldots \ldots \ldots$

2.4.3 Simple Object Access Protocol (SOAP) . . . . . . . . . . . . . . . 16

2.4.4 Web Service Description Language (WSDL) . . . . . . . . . . . . . 17

2.4.5 Universal Description, Discovery, and Integration (UDDI) . . . . . 18

2.5 Vantagens e Desvantagens das Diferentes Abordagens de Web Services . . 20

2.5.1 Web Services SOAP-WSDL . . . . . . . . . . . . . . . 20

2.5.2 Web Services RESTFul XML . . . . . . . . . . . . . . 21

2.5.3 Web Services RESTFul JSON . . . . . . . . . . . . . . . . . 22

2.5.4 Web Services XML - RPC . . . . . . . . . . . . . . . 23

2.6 A escolha dos Web Services RESTful e SOAP-WSDL . . . . . . . . . . . 25

2.7 Manutenibilidade de Web Services . . . . . . . . . . . . . . . 25

2.8 Considerações Finais . . . . . . . . . . . . . . . . . . . . . . . . . . . . 29 
3 Engenharia de Software Experimental 31

3.1 Considerações Iniciais . . . . . . . . . . . . . . . . . . . . . . . . . . 31

3.2 Engenharia de Software Experimental . . . . . . . . . . . . . . . . 31

3.3 Experimentação na Engenharia de Software . . . . . . . . . . . . . . 33

3.4 Terminologia e Conceitos Básicos . . . . . . . . . . . . . . . 35

3.5 Princípios e Validade . . . . . . . . . . . . . . . . . . . . . . . . . . . . . . . . . . . . . . 37

3.6 Processo de Experimentação . . . . . . . . . . . . . . . . . . . . . 38

3.7 Considerações Finais . . . . . . . . . . . . . . . . . . . . . 40

4 Métricas de Manutenibilidade de Softwares $\quad 41$

4.1 Considerações Iniciais . . . . . . . . . . . . . . . . . . . . . . . . . . 41

4.2 Métricas de Manutenibilidade de Softwares . . . . . . . . . . . . . . . . 42

4.2.1 Utilização de Métricas na Engenharia de Software . . . . . . . . . . 42

4.2.2 O Modelo GQM (Goal/Question/Metric) . . . . . . . . . . . . . . 43

4.2.3 Os Tipos de Métricas de Manutenibilidade . . . . . . . . . . . . . . 45

4.3 Considerações Finais . . . . . . . . . . . . . . . . . . . . . . . . . . 48

5 Definição e Planejamento do Estudo $\quad 49$

5.1 Considerações Iniciais . . . . . . . . . . . . . . . . . . . . . . . . . . . . . . 49

5.2 Experimento Realizado: Definição e Planejamento . . . . . . . . . . . . 50

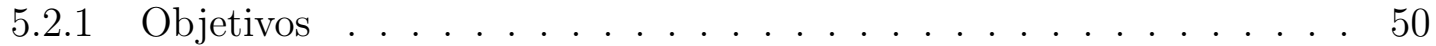

5.2 Metas ........................... 50

5.2 .3 Planejamento . . . . . . . . . . . . . . . . . . 51

5.2 .4 Seleção do Contexto . . . . . . . . . . . . . . . . . 51

5.2 .5 Hipóteses . . . . . . . . . . . . . . . . . . . . 51

5.3 Seleção dos Indivíduos . . . . . . . . . . . . . . . . . . . . . . . 53

5.3 .1 Variáveis . . . . . . . . . . . . . . . . . . . . 54

5.3 .2 Descrição da Instrumentação do Experimento . . . . . . . . . . . . . . . 55

5.3 .3 Validade . . . . . . . . . . . . . . . . . 56

5.4 Considerações Finais . . . . . . . . . . . . . . . . . . . 57

6 Preparação do Ambiente e Execução do Experimento 59

6.1 Considerações Iniciais . . . . . . . . . . . . . . . . . . . . . . . . . . . 59

6.2 Preparação do Experimento . . . . . . . . . . . . . . . . . . 60

6.2.1 O Ambiente de Manutenção . . . . . . . . . . . . . . . . . . . 60

6.2.2 Descrição dos Web Services RESTful e SOAP-WSDL . . . . . . . . 61

6.3 Execução do Experimento . . . . . . . . . . . . . . . . . 63

6.4 Considerações Finais . . . . . . . . . . . . . . . . . . . . . . . 71

7 Análise dos Resultados e Avaliação da Hipótese $\quad 73$

7.1 Considerações Iniciais . . . . . . . . . . . . . . . . . . . . . . . . . . . . . . . . . . . . . . . .

7.2 Resultados no Lado do Servidor . . . . . . . . . . . . . . . . . . . . . . 74

7.3 Resultados no Lado do Cliente . . . . . . . . . . . . . . . . . . . 77

7.4 Comparação dos Resultados . . . . . . . . . . . . . . . . . . 79

7.4.1 Comparação no Lado do Servidor . . . . . . . . . . . . . . . . . . 79

7.4 .2 Comparação no Lado do Cliente . . . . . . . . . . . . . . . . . . . . . . . . 81

7.5 Considerações Finais . . . . . . . . . . . . . . . . . . 82 
8 Conclusão $\quad \mathbf{8 5}$

8.1 Caracterização da Pesquisa Realizada . . . . . . . . . . . . . . . . . . 85

8.2 Contribuições . . . . . . . . . . . . . . . . . . . 86

8.2.1 Produção Científica . . . . . . . . . . . . . . . 86

8.3 Dificuldades e Limitações . . . . . . . . . . . . . . . . . . . . . . . . . . 87

8.4 Trabalhos Futuros . . . . . . . . . . . . . . . . . . . . . . 88

$\begin{array}{ll}\text { Referências } & 89\end{array}$

$\begin{array}{ll}\text { A Base de Dados Utilizada no Experimento } & 97\end{array}$

B Modelo Inicial e Provisório da Arquitetura 99 



\section{Lista de Figuras}

2.1 Interação Provedor-Consumidor $($ Bih, 2006) $\ldots \ldots \ldots \ldots$

2.2 Modelo básico de SOA $($ Bih, 2006) $\ldots \ldots \ldots \ldots$

2.3 Pilha conceitual de web services (Cerami, 2002) . . . . . . . . . . . . . . . 12

2.4 Pilha conceitual de web services (IBM, 2009) . . . . . . . . . . . . . . . 13

2.5 Arquitetura de web services . . . . . . . . . . . . . . . . . . . . 13

2.6 Estrutura de uma mensagem SOAP (Snell et al., 2002) . . . . . . . . . . 17

2.7 Estrutura de um documento WSDL (Weerawarana et al., 2005) . . . . . . 19

2.8 Custos de desenvolvimento e de manutenção (Sommerville, 2007) . . . . . 27

2.9 Redes de Fornecimento de Serviço (Kajko-Mattsson, 2005) . . . . . . . . . 29

3.1 Apresentação dos conceitos de um experimento (Wohlin et al., 2000). . . . 36

3.2 O processo de experimentação e suas fases (Wohlin et al., 2000) . . . . . . 39

4.1 O processo principal da abordagem GQM (Solingen, 1999) . . . . . . . . . 44

4.2 Abordagem GQM utilizada no experimento controlado (Basili et al., 1994) 44

4.3 Níveis do modelo GQM . . . . . . . . . . . . . . . . . . . . . . 45

6.1 Projeto Netbeans dos web services RESTful e SOAP-WSDL . . . . . . . . 62

6.2 Linhas de Código de cada Projeto Provedor e Cliente RESTful e SOAP-WSDL utilizados no experimento . . . . . . . . . . . . . . 63

6.3 Número de Classes de cada projeto Provedor e Cliente RESTful e SOAP-WSDL utilizados no experimento . . . . . . . . . . . . . . 63

6.4 Número de Métodos de cada projeto Provedor e Cliente RESTful e SOAP-WSDL utilizados no experimento . . . . . . . . . . . . . . . . 64

6.5 Média da Complexidade Ciclomática de cada Provedor e Cliente RESTful e SOAP-WSDL utilizados no experimento . . . . . . . . . . . . . 64

6.6 Arquitetura utilizada no experimento . . . . . . . . . . . . . . 65

6.7 Questionário aplicado aos alunos no $1^{\circ}$ dia do curso de web services . . . . 67

$6.82^{\circ}$ dia do curso de web services . . . . . . . . . . . . . . . . . . 68

6.9 Organização do Experimento no $2^{\circ}$ dia de curso . . . . . . . . . . . . . 69

$6.103^{\circ}$ dia do curso de web services . . . . . . . . . . . . . . . . . 70

6.11 Organização do Experimento no $3^{\circ}$ dia de curso . . . . . . . . . . . . 71

A.1 Banco de Dados utilizado no experimento controlado . . . . . . . . . . 98 
B.1 Arquitetura inicial e provisória do experimento controlado . . . . . . . . . 99 


\section{Lista de Tabelas}

4.1 Categoria das Métricas . . . . . . . . . . . . . . . . . . . . . . . 42

4.2 Métricas de Halstead (Halstead, 1977) . . . . . . . . . . . . . . . . 46

4.3 Subcaracterísticas da Norma ISO/IEC 9126 (ISO9126, 2003) . . . . . . . . 48

7.1 Tabela de dados referentes às Tarefas 1 e 2 do servidor RESTful . . . . . . 75

7.2 Estatística básica referente à Tarefa 1 do servidor RESTful . . . . . . . . . 75

7.3 Estatística básica referente à Tarefa 2 do servidor RESTful . . . . . . . . . . 75

7.4 Tabela de dados referentes às Tarefas 1 e 2 do servidor SOAP-WSDL . . . 76

7.5 Estatística básica referente à Tarefa 1 do servidor SOAP-WSDL . . . . . . 76

7.6 Estatística básica referente à Tarefa 2 do servidor SOAP-WSDL . . . . . . 77

7.7 Tabela de dados referentes às Tarefas 1 do cliente RESTful . . . . . . . . . 77

7.8 Estatística básica referente à Tarefa 1 do cliente RESTful . . . . . . . . . . 78

7.9 Tabela de dados referentes à Tarefa 1 do cliente SOAP-WSDL . . . . . . . 78

7.10 Estatística básica referente à Tarefa 1 do cliente SOAP-WSDL . . . . . . . 78

7.11 Teste- $T$ da Tarefa 1 do lado do Servidor . . . . . . . . . . . . . . . 80

7.12 Teste- $T$ da Tarefa 2 do lado do Servidor . . . . . . . . . . . . . . . . 81

7.13 Teste- $T$ da Tarefa 1 do lado do Cliente . . . . . . . . . . . . . . . . . 82 



\section{Lista de Siglas}

API - Application Programming Interface

B2B - Business to Business

B2C - Business to Consumer

CORBA - Common Object Request Broker Architecture

DCOM - Distributed Component Object Model

ESB - Enterprise Service Bus

FLOSS - Free/Libre Open Source Software

GQM - Goal-Question-Metric

HTML - HyperText Markup Language

HTTP - HyperText Transfer Protocol

IBM - International Business Machines

IDE - Integrated Development Environment

IETF - Internet Engineering Task Force

JSON - JavaScript Object Notation

KPI - Key Process Indicator

LAN - Local Area Network

MIME - Multipurpose Internet Mail Extensions

OMM - Open Source Maturity Model

Qualipso - Quality Plataform for Open Source

REST - Representational State Transfer 
RMI - Remote Method Invocation

RPC - Remote Procedure Call

SOA - Service-Oriented Architecture

SOAP - Simple Object Access Protocol

Spago4Q - SpagoBI for Quality

SQL - Structured Query Language

TWE - Trustworthy Elements

UDDI - Universal Description, Discovery, and Integration

URI - Uniform Resource Identifier

W3C - World Wide Web Consortium

WAN - Wide Area Network

WS-Addressing - Web Service Addressing

WS-Reliable - Web Service Reliable

WS-Security - Web Service Security

WSDL - Web Service Definition Language

XML - Extensible Markup Language 


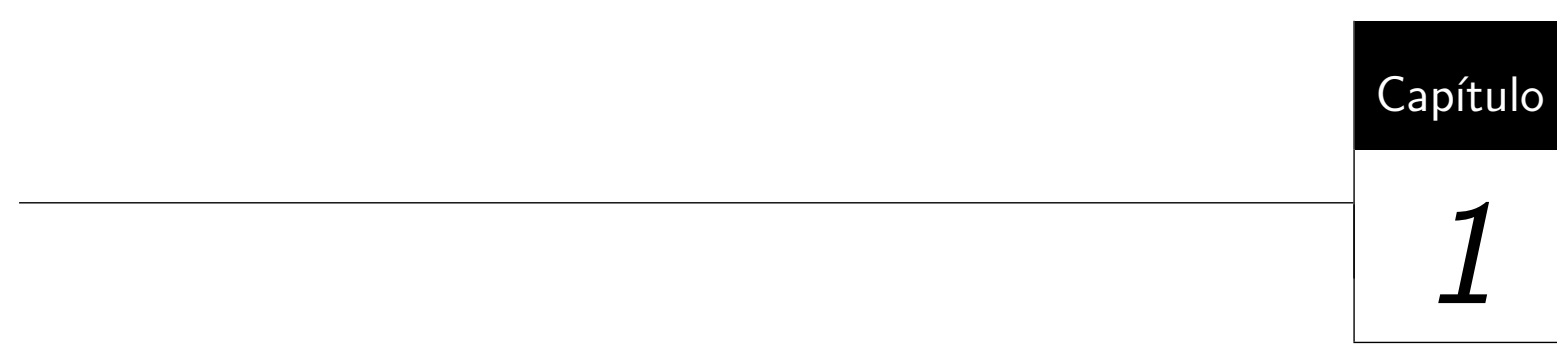

\section{Introdução}

\subsection{Considerações Iniciais}

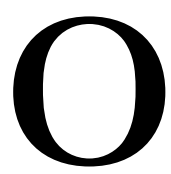

s web services constituem uma tecnologia emergente da Arquitetura Orientada a Serviços (SOA) (Perepletchikov e Ryan, 2011). Sua grande popularidade ocorreu devido à adoção de protocolos e padrões abertos, tais como HTTP e XML, visando solucionar o problema de integrar aplicativos de sistemas heterogêneos presentes em tecnologias como CORBA, DCOM e RMI (Stal, 2002). A interoperabilidade possibilita que os sistemas escritos em diferentes linguagens de programação, desenvolvidos por fornecedores distintos e em sistemas operacionais diversos possam se comunicar (Meng et al., 2009).

Por meio de uma interface especificada em WSDL ( Web Service Description Language) que descreve o serviço web em XML, a comunicação entre web services pode ser realizada. A WSDL é apenas um dos padrões da $\mathrm{W} \mathrm{C}^{1}$ que instanciado permite um avanço na comunicação entre aplicações distribuídas. Porém, como softwares que são, os web services são inerentemente vulneráveis e sujeitos a constantes mudanças, oferecendo um novo desafio para Engenharia de Software. A partir da perspectiva de evolução e manutenção, há muitas questões que devem ser examinadas, incluindo critérios de evolução e manutenção de processos, produtos e funções envolvidas nos processos, e as mudanças organizacionais necessárias para a adoção de web services (Kajko-Mattsson, 2004).

\footnotetext{
${ }^{1}$ World Wide Web Consortium (W3C) http://www.w3.org/
} 
A evolução e manutenção dos web services podem ser muito caras para muitas organizações de software. Eles têm que manter engenheiros altamente qualificados, e fazer reorganizações necessárias dentro de suas empresas. Sendo assim, uma falha de um web service pode afetar substancialmente a produtividade das organizações. Atualmente, a tecnologia de web services carece de um suporte para a manutenção. A longo prazo, uma organização pode ter sérios problemas de manutenção do serviço (Kajko-Mattsson e Tepczynski, 2005).

Além disso, a construção de aplicações distribuídas em um ambiente dinâmico como a web é muito complexa principalmente quando o foco de uma aplicação deve considerar a manutenibilidade entre a interação das entidades envolvidas em uma Arquitetura Orientada a Serviços (cliente, provedor, broker, repositório de informações sobre serviços).

Portanto, a evolução durante o ciclo de desenvolvimento de software é inevitável, necessitando de manutenção e aprimoramento dos sistemas de software ao longo do ciclo de vida dos sistemas. Como o software evolui, as mudanças realizadas sobre ele devem ser cuidadosamente gerenciadas de forma a controlar as atividades relacionadas à modificação do projeto, correção de bugs, a adaptação do ambiente, e assim por diante (Wei-Chung $\mathrm{Hu}$ e Jiau, 2010).

\subsection{Contextualização}

Em 1990, Henry e Humphrey (Henry e Humphrey, 1990) realizaram um experimento controlado que compara a capacidade de manutenção de dois sistemas funcionalmente equivalente, a fim de explorar a alegação de que os sistemas desenvolvidos com linguagens orientadas a objetos são mais facilmente mantido do que aqueles programados com linguagens procedurais.

Em 2007 Kumar et al. (Avadhesh Kumar e Grover, 2007) estudou o impacto da manutenibilidade nos sistemas Orientado a Aspecto (OA) e nos sistemas Orientado a Objetos (OO) e concluiu que os sistemas $\mathrm{AO}$ são mais manuteníveis do que os sistemas OO. No futuro, esta técnica pode ser usado para comparar a manutenção de diferentes sistemas OA.

Atualmente no ano passado Perepletchikov e Ryan (Perepletchikov e Ryan, 2011) realizaram um experimento controlado para avaliar o impacto do acoplamento na manutenção de Softwares Orientados a Serviço. 


\subsection{Objetivos}

O objetivo deste mestrado foi avaliar a manutenibilidade entre as abordagens de web services RESTful e SOAP-WSDL. O experimento realizado é promissor e contribui para o baixo custo e a alta qualidade do software desenvolvido, melhorando dessa forma a qualidade dos softwares orientados à serviços no geral. Segundo o trabalho de Kajko-Mattsson (Kajko-Mattsson, 2005) foram identificadas questões que são únicas em evolução e manutenção do sistema de serviços web. Além disso, existem poucos estudos relacionados a manutenibilidade aplicados no contexto de Softwares Orientado a Serviço. Desse modo o experimento controlado não pretende ser definitivo, mas sim fornecer evidências sobre as questões estudadas e que posteriormente possam ser utilizadas como referência para novos estudos na área. Vale ressaltar, que o experimento controlado pode ser replicado com um número maior de participantes.

Os resultados mostraram que existem diferenças entre a gestão dos sistemas de softwares convencionais e sistemas web services, devido ao baixo acoplamento, maior flexibilidade e reutilização dos serviços. Sendo assim, é preciso encontrar novas metodologias de Engenharia de Software para desenvolvimento, evolução e manutenção. Portanto, foi desenvolvida uma arquitetura adequada e todo um conjunto de web services apropriado que possibilitassem avaliar e comparar a manutenibilidade entre as abordagens de web services RESTful e SOAP-WSDL.

\subsection{Estrutura}

Este trabalho está organizado em oito capítulos. Este capítulo introduziu a área de pesquisa apresentando a motivação necessária para a realização deste trabalho. O Capítulo 2 apresenta os principais conceitos relacionados com os web services e a evolução e manutenção de web services, incluindo a arquitetura e as principais tecnologias na área. No Capítulo 3 são descritos os principais conceitos sobre Engenharia de Software Experimental. No Capítulo 4 são apresentadas as métricas de manutenibilidade de softwares e nos Capítulo 5, 6 e 7 são descritos todos os processos da Engenharia de Software Experimental utilizados durante as etapas do experimento realizado, discutindo os objetivos e a metodologia utilizada. Assim como, serão apresentados a análise dos resultados e a avaliação da hipótese. O Capítulo 8 apresenta as conclusões e as contribuições deste trabalho no decorrer deste projeto. Por fim, são listadas as referências bibliográficas utilizadas ao longo deste documento e os apêndices. 



$=$

\section{Fundamentos sobre Web Services}

\subsection{Considerações Iniciais}

$\mathrm{N}$

este capítulo são apresentados os principais conceitos sobre web services, incluindo suas arquiteturas e as principais tecnologias utilizadas. Os conceitos apresentados neste capítulo fornecem um embasamento teórico para o desenvolvimento do presente trabalho. Inicialmente, conceitos básicos sobre Arquitetura Orientada a Serviços são apresentados, representando a base para os princípios da tecnologia de web services. A seguir, diversos aspectos envolvendo web services são considerados, desde sua definição, suas principais características, até uma descrição mais detalhada sobre os padrões fundamentais de web services.

Como o foco deste trabalho foi avaliar a manutenibilidade entre as abordagens de web services RESTful e SOAP-WSDL, na Seção 2.7 essa propriedade será descrita.

Por fim, este capítulo aborda as questões sobre o desenvolvimento e modificações para cada uma das diferentes abordagens de web services, assim como suas vantagens e desvantagens.

\subsection{Arquitetura Orientada a Serviços (SOA)}

A Arquitetura Orientada a Serviços (SOA) é um conjunto de funcionalidades bem definidas em forma de serviços disponibilizados na rede. É importante destacar que a ar- 
quitetura SOA estabelece a implementação de componentes como serviços modulares que podem ser descobertos e usados pelos clientes, além de fornecer um repositório para publicação e descoberta de serviços, possibilitando a transparência de localização (R. Fraser e Woodcock, 2007).

Devido ao baixo grau de dependência entre os serviços, o acoplamento é fraco, possibilitando a manutenção dos serviços sem prejudicar a lógica do negócio (Colan, 2003). Portanto, a adoção de uma Arquitetura Orientada a Serviços facilita a adaptatividade de sistemas, permitindo a construção de sistemas altamente dinâmicos na medida em que os serviços podem ser substituídos ou melhorados. SOA promove também a reusabilidade de seus serviços, e permite que tais serviços sejam compostos, formando lógicas de processos mais elaboradas, ao mesmo tempo, evitando desperdício de recursos. O baixo acoplamento da arquitetura oferece vantagens como flexibilidade, escalabilidade e tolerância a falhas (Josuttis, 2007).

De acordo com Erl (Erl, 2005) os oito princípios fundamentais da arquitetura SOA são:

- Acoplamento fraco: os serviços mantêm uma relação que minimiza as dependências e exige apenas o conhecimento um do outro.

- Reusabilidade: a lógica é dividida em serviços com a intenção de promover a reutilização.

- Contrato de Serviço: serviços de adesão a um acordo de comunicações, tal como definido coletivamente por uma ou mais descrições de serviço relacionadas aos documentos.

- Autonomia: os serviços têm controle sobre a lógica que encapsulam.

- Abstração: além do que está descrito no contrato, os serviços permitem esconder a lógica do mundo exterior.

- Composição: as coleções de serviços podem ser coordenadas e reunidas a partir da composição de serviços.

- Descoberta: os serviços são projetados para serem externamente bem descritos, encontrados e avaliados através dos mecanismos de descoberta.

- Sem estado: os serviços minimizam o armazenamento de informações específicas de uma atividade.

A infraestrutura da Arquitetura Orientada a Serviços baseia-se em duas entidades: consumidores e provedores de serviços. Tais entidades estão relacionadas com conceitos 
fundamentais de troca de mensagens entre servidores e clientes em um sistema distribuído. Um provedor possui características semelhantes a um servidor que disponibiliza serviços na rede, enquanto consumidores são considerados clientes que utilizam os serviços disponíveis por provedores de serviços. Uma entidade também pode assumir ambos os papéis ao mesmo tempo, caracterizando a composição de serviços. Uma interação básica entre tais entidades é ilustrada na Figura 2.1. Nessa figura um programa do consumidor de serviço envia, pela rede, uma requisição ao provedor de serviço, o qual retorna, pela rede, a resposta àquela requisição para o devido consumidor de serviço.

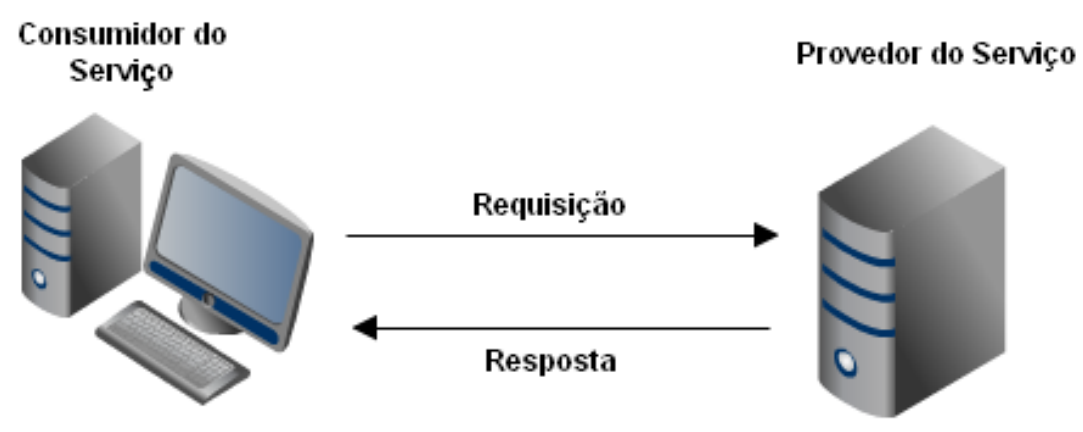

Figura 2.1: Interação Provedor-Consumidor (Bih, 2006)

Um outro elemento fundamental da arquitetura SOA é o registro de serviços ou diretório central de serviços que interage tanto com o servidor, quanto com o consumidor. Essa interação é estabelecida de forma que um provedor possa registrar/publicar os serviços em um determinado diretório, assim como um consumidor utiliza este registro para consultar e encontrar o serviço requisitado. Podemos fazer uma analogia às páginas amarelas de uma lista telefônica, na qual um cliente busca o telefone por tipo de serviço, e os provedores de serviço podem publicar seus serviços. Sendo assim, em um simples modelo de SOA, podem ser definidos três tipos de entidades básicas: consumidores, provedores e registradores de serviços (broker), exercendo as operações de publicação, registro e acesso. A Figura 2.2 ilustra este processo em SOA. Nessa figura, o registro de serviços broker, conhecido também por diretório central de serviços possibilita que o fornecedor interaja com o diretório para registrar/publicar serviços no diretório, além de permitir também que um consumidor encontre o serviço que ele gostaria de requisitar.

O backbone $e^{1}$ de execução da arquitetura SOA é conhecido por ESB (Enterprise Service Bus) que trata aplicativos como serviços, estabelecendo padrões de conectividade, troca de mensagens e fornecendo apoio a tarefas, tais como transações, segurança, métricas de desempenho, configuração dinâmica, e descoberta de serviço (Papazoglou et al., 2007).

\footnotetext{
${ }^{1} \mathrm{O}$ backbone, tradução de "espinha dorsal", é uma rede principal por onde passam os dados dos clientes da internet. Por ser a rede principal, o backbone captura e transmite informações de várias redes menores que se conectam a ele.
} 


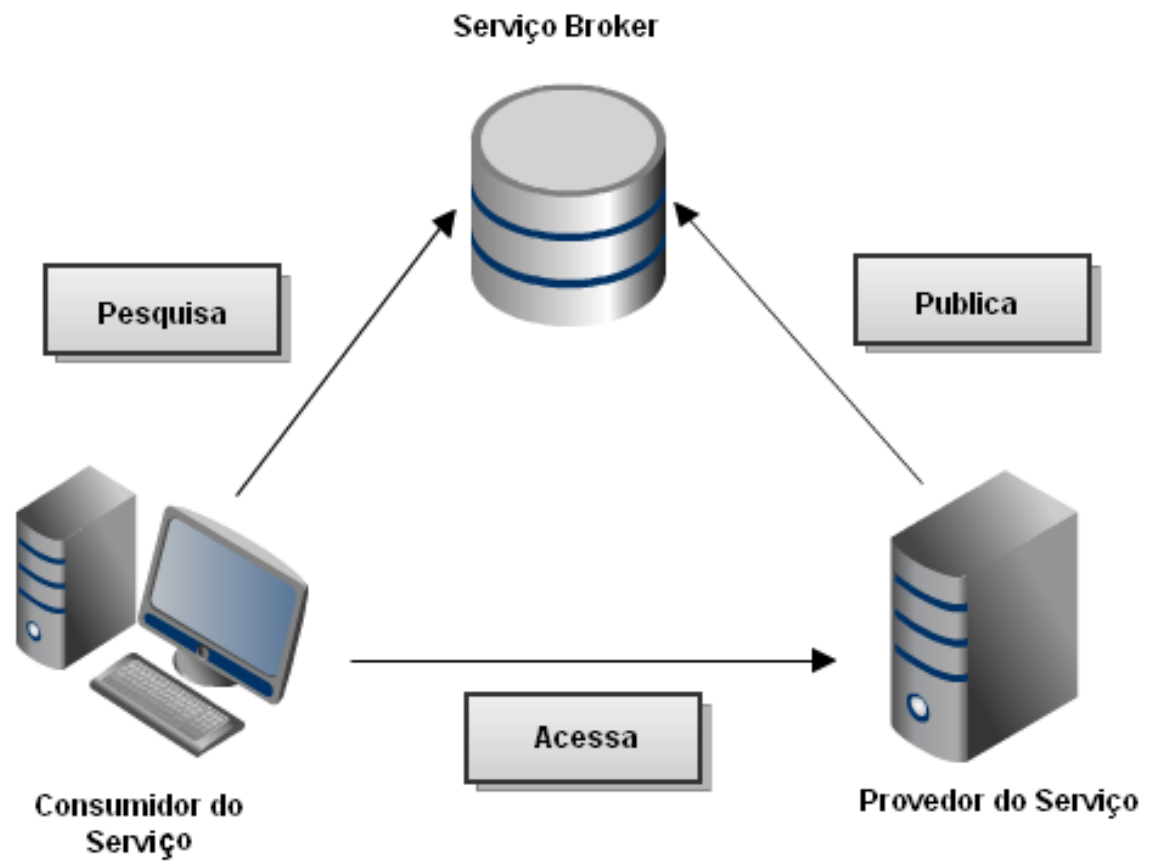

Figura 2.2: Modelo básico de SOA (Bih, 2006)

Atualmente, as tecnologias mais utilizadas para integração de aplicações heterogêneas são os web services, devido ao uso de padrões abertos baseados em XML, que possibilitam implantar os princípios da arquitetura SOA. A Seção 2.3 apresenta os principais conceitos de web services, assim como sua relação com a arquitetura SOA.

\subsection{Conceitos de Web Services}

Antes de definir um web service é importante destacar que um web service é composto por duas estruturas: o serviço (W3C, 2004a) e a descrição do serviço (W3C, 2007).

O serviço consiste num módulo de software instalado numa plataforma computacional com acesso à rede e oferecido pelo "provedor de serviços". Um serviço existe para ser usado por um consumidor, podendo funcionar também como um cliente de outro serviço.

A descrição do serviço (DS) contém os detalhes da interface e da implementação de um serviço, o que inclui os tipos de dados, operações, informação de ligação (binding), e localização de rede. Pode ainda incluir metadados e informação de categorização para facilitar as atividades de descoberta e utilização por consumidores do serviço. A DS pode ser publicada num registrador de serviço para tornar o respectivo serviço conhecido em um determinado contexto.

A definição mais aceita pela comunidade da Tecnologia da Informação (TI) é da World Wide Web Consortium (W3C) onde os web services são um sistema de software projetado para apoiar interações máquina-para-máquina interoperáveis pela rede, fornecendo uma 
interface descrita em um formato processável por máquina (especificamente a WSDL). Outros sistemas interagem com o web service de maneira prescrita por sua descrição usando mensagens SOAP, normalmente transmitidas através de HTTP com uma serialização XML em conjunto com outros padrões da web (W3C, 2004a). Todos esses protocolos englobando o UDDI são responsáveis por estabelecer uma simples conexão entre os web services. Cada tecnologia envolvida é descrita a seguir:

- XML ${ }^{2}$ (eXtensible Markup Language) é uma linguagem genérica e padronizada de marcação, isto é, uma linguagem capaz de descrever uma organização lógica, estruturada dos dados através de tags definidas. O XML além de ser popular e amplamente aceito é a base principal para o desenvolvimento dos web services (BASCI, 2009). Exemplo de um livro em XML:

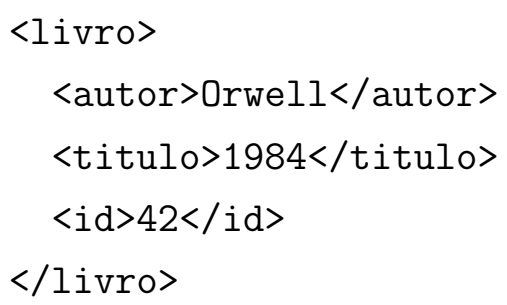

- XML Schema3 ${ }^{3}$ Um XML schema descreve a estrutura de um documento XML, é uma linguagem que também costuma ser designada por XML Schema Definition (XSD). O XML Schema é um sucessor do Document Type Definition (DTD) que permitem ter tipos de dados. Exemplo de um arquivo XML Schema de um livro:

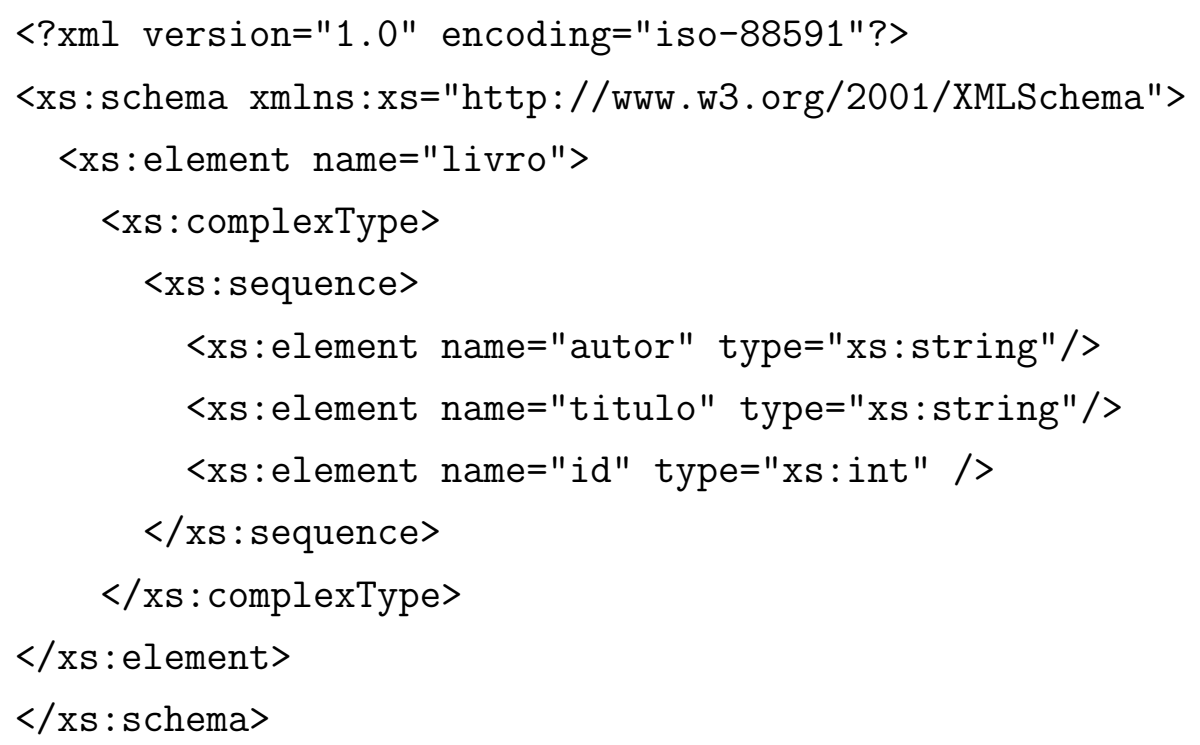

${ }^{2}$ http://www.w3.org/TR/2008/REC-xml-20081126/

${ }^{3}$ http://www.w3.org/TR/xmlschema-0/ 
- $\mathrm{JSON}^{4}$ (JavaScript Object Notation) é um conjunto de chaves e valores, que podem ser interpretados por qualquer linguagem. Além de ser um formato de troca de dados $l_{e v e}^{5}$, é fácil de ser entendido e escrito pelos programadores. Estas propriedades fazem do JSON uma linguagem ideal para o intercâmbio de dados como XML (Jun et al., 2008). Exemplo de um Livro em JSON:

\{

"autor": "George Orwell",

"titulo": "1984",

"id": 42

\}

- $\operatorname{SOAP}^{6}$ (Simple Object Access Protocol): é um protocolo padrão de troca de mensagens estruturado em XML que possibilita à comunicação entre serviços. Ele define os componentes essenciais e opcionais das mensagens transmitidas entre os serviços através do protocolo HTTP. Exemplo de um envelope SOAP:

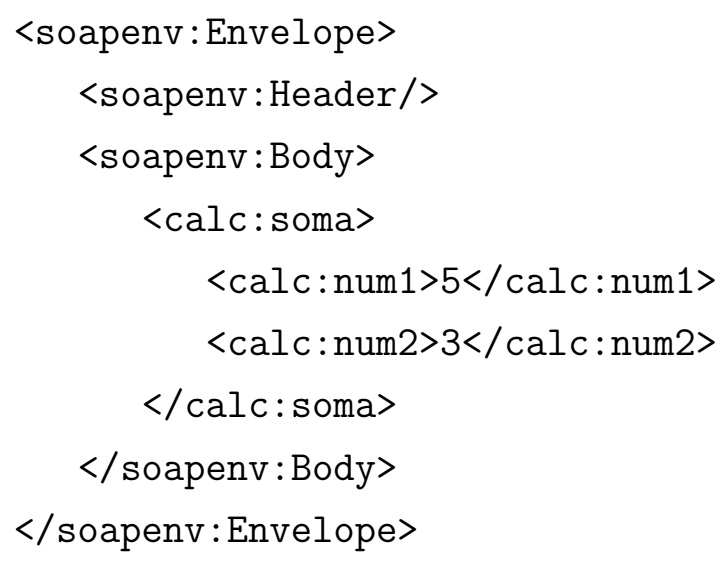

- $\mathrm{WSDL}^{7}$ (web services Description Language): é um modelo e um formato XML para descrever web services, possibilitando a separação entre a funcionalidade oferecida de sua descrição abstrata. A descrição do web service define a sua interface, ou seja, o conjunto de operações possíveis entre o provedor e cliente do serviço, bem como as mensagens que serão trocadas entre eles. Exemplo de um arquivo WSDL:

\footnotetext{
${ }^{4}$ http://www.json.orgljson-en.html

${ }^{5}$ Em Tecnologia da Informação (TI), a expressão leve é às vezes aplicada a um programa, protocolo, ou qualquer outro dispositivo com um menor número de componentes e que seja relativamente mais simples ou mais rápido.

${ }^{6} \mathrm{http}: / /$ www.w3c.org/TR/soap12-part1/

${ }^{7}$ http://www.w3c.org/TR/2003/WD-wsdl12-20030611/
} 


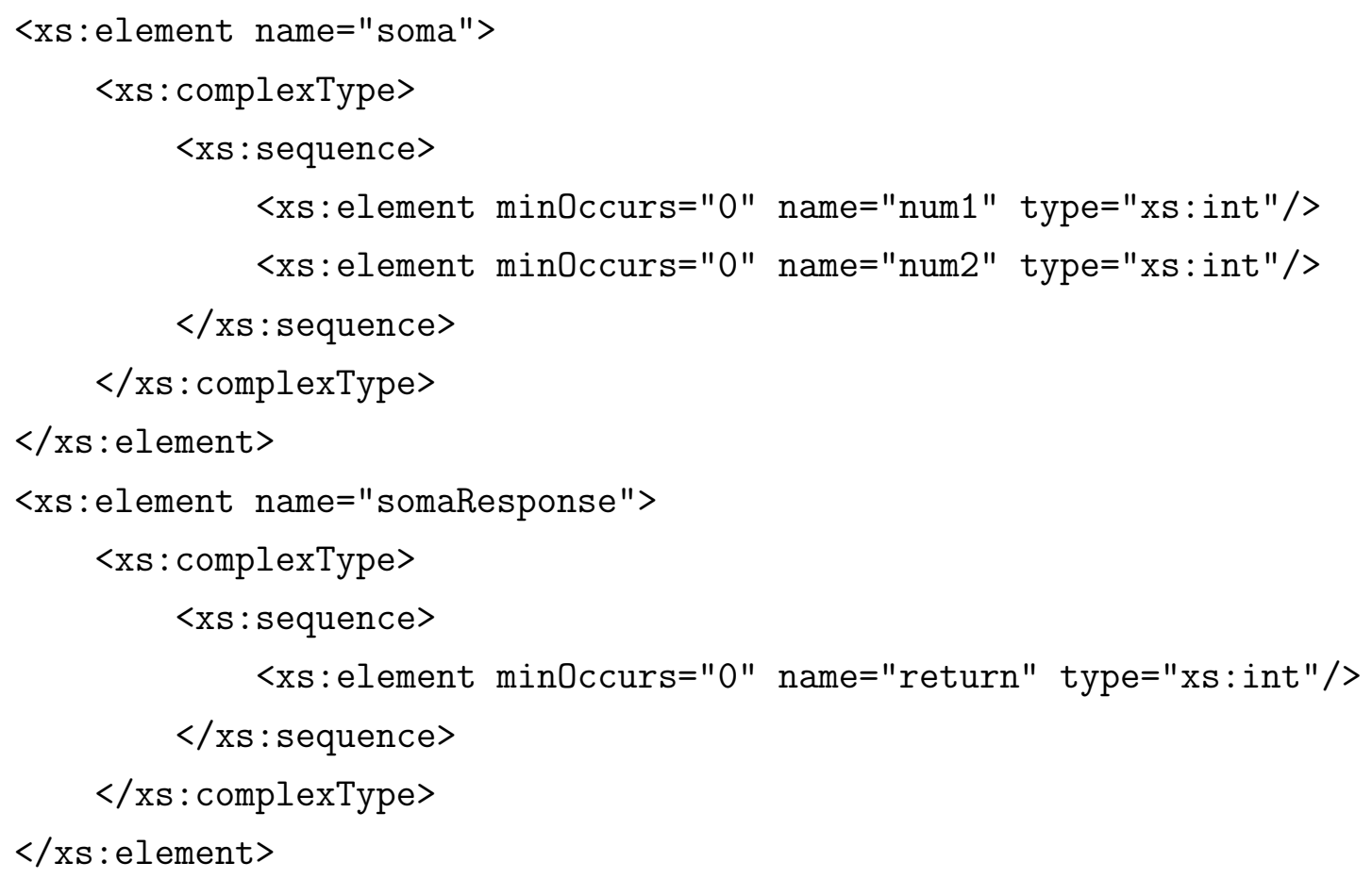

- $\mathrm{UDDI}^{8}$ (Universal Description, Discovery, and Integration): oferece um mecanismo para que os clientes possam encontrar um determinado web service. O UDDI pode ser considerado o DNS para os web services, contendo informações sobre o provedor do serviço, sua localização, além das descrições do serviço (WSDL) (Wang et al., 2004). Os repositórios de serviços podem ser públicos ou privados, sendo que tanto o registro quanto a consulta de serviço são realizadas por meio de arquivos XML. Exemplo do UDDI:

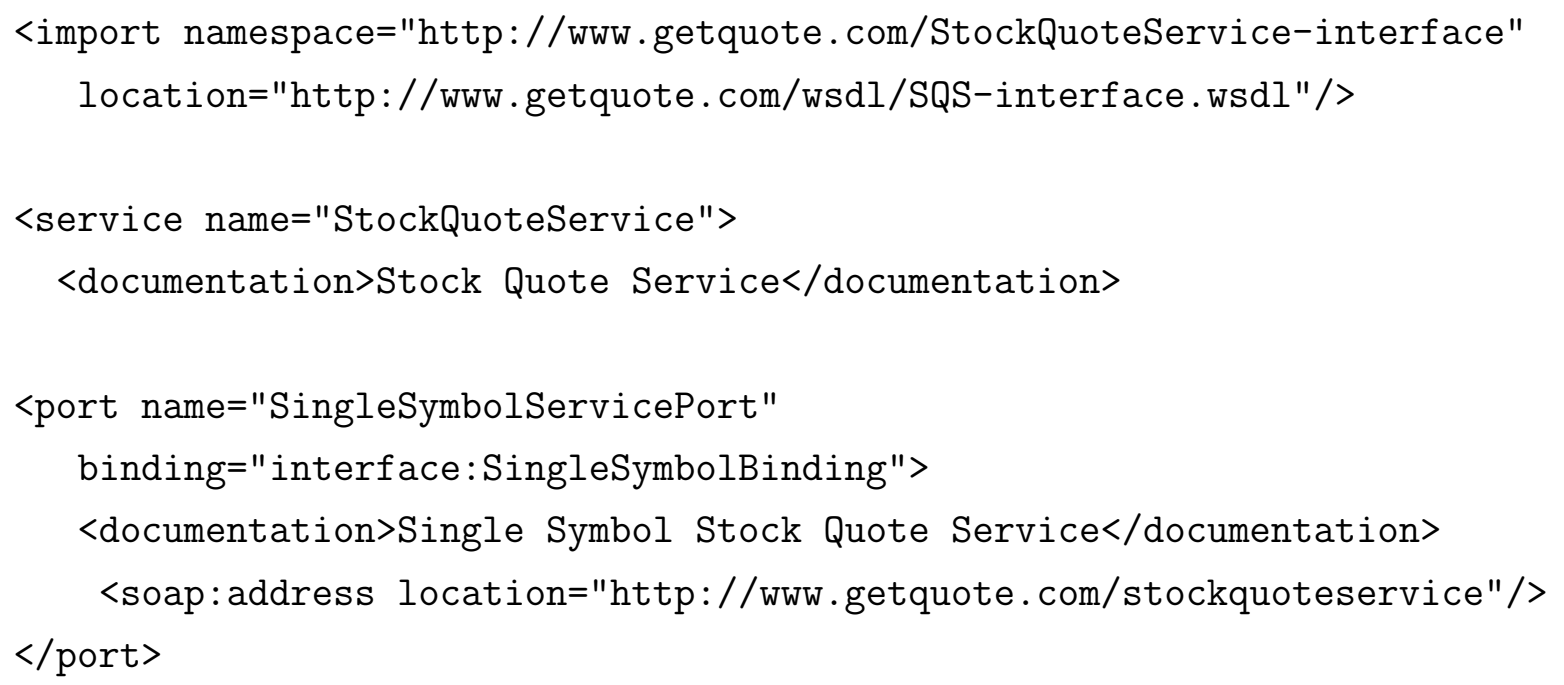

Os padrões descritos nesta seção fazem parte da primeira geração de web services. A segunda geração também conhecida como "WS-*" representa um complemento fornecendo

\footnotetext{
${ }^{8}$ http://uddi.org/pubs/uddi-v3.00-published-20070719.htm
} 
novos recursos e funcionalidades para suprir as limitações da geração anterior. Entre essas especificações e padrões destacam-se o WS-security, WS-Addressing e WS-Reliable ${ }^{9}$ considerados fundamentais para o desenvolvimento de aplicações distribuídas utilizando web services (Erl, 2004).

A pilha de protocolos associados aos web services é formada por protocolos de rede responsáveis pela definição, localização, implementação e troca de mensagens (Cerami, 2002). Podemos dividi-la também em quatro camadas: busca, descrição, comunicação e transporte conforme mostra a Figura ??. No topo da pilha encontra-se a descoberta dos serviços, com o protocolo UDDI. Na segunda camada está situada a descrição dos serviços com o protocolo WSDL. A terceira camada refere-se à troca de mensagens XML, com os protocolos XML-RPC, SOAP e XML. Na última camada está situado o transporte, com os protocolos HTTP, SMTP, FTP e BEEP.

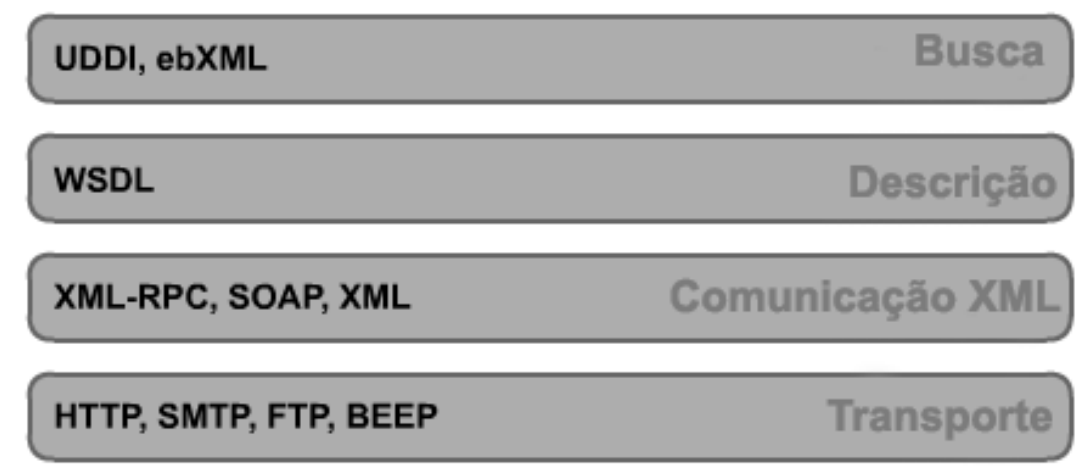

Figura 2.3: Pilha conceitual de web services (Cerami, 2002)

Para este projeto, a pilha conceitual proposta pela IBM foi adotada por apresentar os conceitos de forma genérica e completa, englobando os padrões básicos e as principais especificações emergentes (IBM, 2009). Conforme a Figura 2.4.

\subsubsection{Arquitetura de Web Services}

Com base nos padrões descritos da seção anterior e nos conceitos de Arquitetura Orientada a Serviços (SOA), a comunicação entre clientes e provedores utiliza o protocolo de mensagens SOAP, através da interface definida pelo documento WSDL do serviço. As operações de publicação e descoberta de serviços são definidas pela especificação UDDI, na forma de um repositório de descrições de serviços. Os provedores de serviço publicam seus documentos WSDL, enquanto o cliente realiza a busca pela WSDL do serviço requisitado em um registro UDDI.

\footnotetext{
${ }^{9}$ http://www.oasis-open.org/specs/
} 


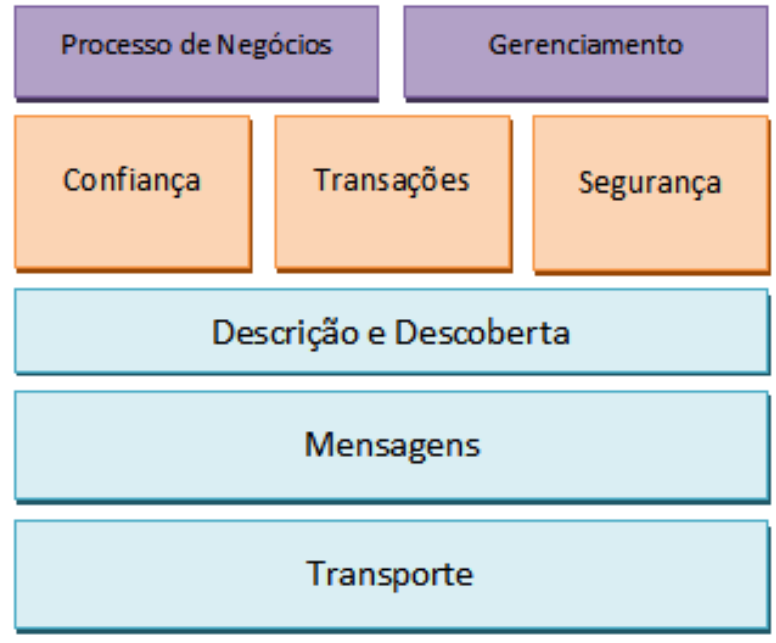

Figura 2.4: Pilha conceitual de web services (IBM, 2009)

Conforme Figura 2.5, o provedor de serviços responsável por manter o serviço executa os seguintes passos:

1. cria a descrição do web service (WSDL)

2. publica o arquivo WSDL no repositório UDDI

3. o cliente faz uma busca no repositório

4. obtém o WSDL do serviço a partir do qual cria um cliente e

5. finalmente comunica-se com o serviço

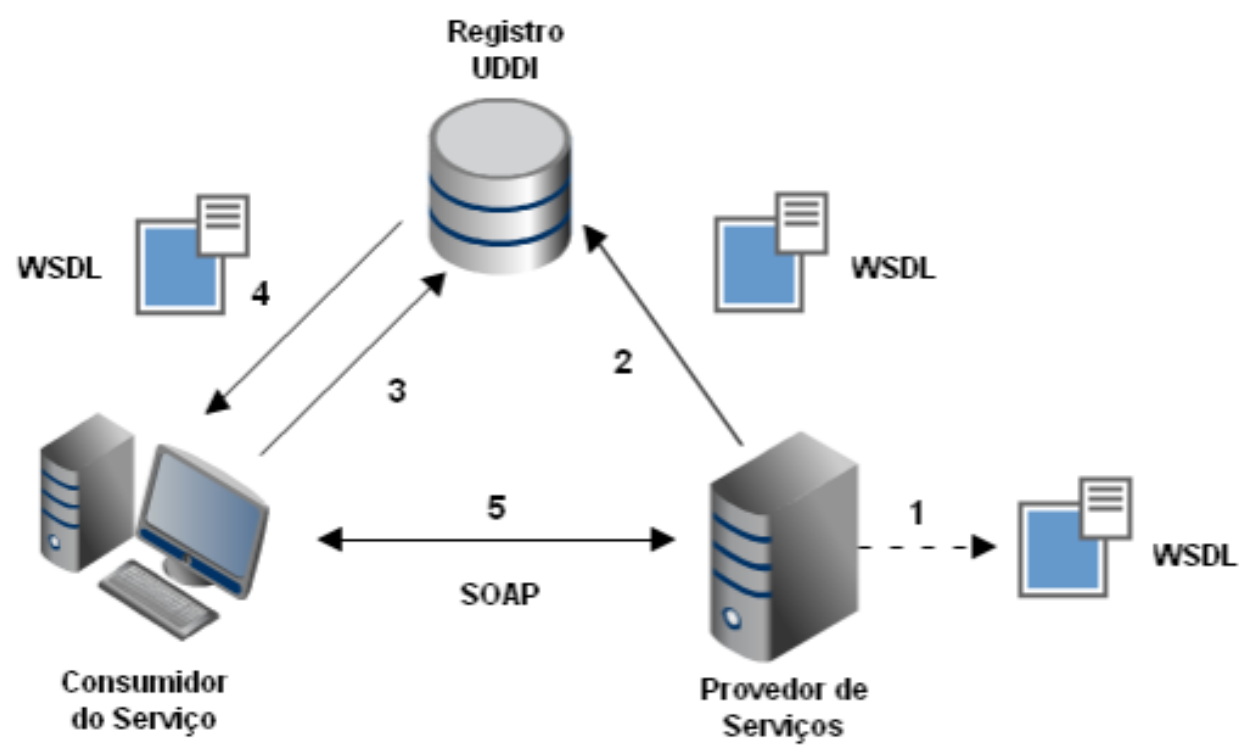

Figura 2.5: Arquitetura de web services 


\subsubsection{Arquitetura RESTful}

Os web services RESTful (Representational State Transfer) surgiram como uma forma de simplificar o desenvolvimento de serviços web, portanto, não é um padrão e sim um estilo arquitetural para construção de sistemas distribuídos definido por Roy Thomas Fielding (Fielding, 2000). Os padrões já existentes e amplamente usados na web como HTTP, XML, URI, entre outros, foram empregados para o desenvolvimento dos serviços RESTful, evitando assim o excesso de padronização presente nos serviços web SOAP. Sendo assim, tornando mais fácil a publicação e utilização desses serviços (Pautasso et al., 2008).

O elemento fundamental da arquitetura RESTful é o recurso. Um recurso pode ser uma página web, figura, imagem ou vídeo. Para localizar os recursos envolvidos em uma interação entre os componentes da arquitetura RESTful é utilizado o chamado Identificador de Recurso. Sendo assim, um recurso pode ser representado através de diferentes formatos, como por exemplo, HTML, XML, JSON, entre outros.

Segundo (Pautasso et al., 2008) o estilo de arquitetura RESTful é baseado em quatro princípios:

Recurso de identificação através de URI. Um serviço web RESTful expõe um conjunto de recursos que permitam identificar os alvos da interação com seus clientes. Os recursos são identificados por URIs, que proporcionam um espaço de endereçamento global para a descoberta de recursos e serviços.

Interface Uniforme. Os recursos são manipulados através de um conjunto fixo de quatro operações: PUT, GET, POST e DELETE. O método PUT cria um novo recurso, que pode então ser apagado usando o método DELETE. O método GET recupera o estado atual de um recurso em alguma representação. O método POST transfere um novo estado para um recurso.

Mensagens auto-descritivas. Como explicado anteriormente os recursos são dissociados de sua representação, para que seu conteúdo possa ser acessado em uma variedade de formatos. Os metadados sobre o recurso são utilizados, por exemplo, para controlar o cache, detectar erros de transmissão, negociar o formato de uma representação adequada e realizar controle de autenticação ou acesso.

Interações Stateful através de hiperlinks. Entre cada interação com um recurso as mensagens de solicitação são auto-suficientes. Interações stateful são baseadas nos conceitos de transferência de estado explícito. Existem várias técnicas para trocar de estado, por exemplo, URI reescrita, cookies e campos de formulário ocultos. O estado 
pode ser incorporado em mensagens de resposta para apontar para os futuros estados válidos da interação.

\subsection{Os principais Padrões de Web Services}

Os web services, como explicado anteriormente, são essencialmente baseados em três padrões fundamentais: SOAP, WSDL e UDDI. Inicialmente, o protocolo SOAP permite que aplicações se comuniquem entre si de forma interoperável por meio da troca de mensagem. A WSDL oferece uma interface comum para descrever os serviços, e o UDDI oferece os mecanismos para publicação e localização dos serviços em um repositório. Cada protocolo será descrito nas subseções a seguir.

\subsubsection{XML-RPC}

O XML-RPC é um protocolo que utiliza o formato XML para realizar chamadas remotas. As requisições são codificadas e enviadas via HTTP utilizando o método POST. As respostas XML são embutidas no corpo da resposta HTTP. Pelo fato do XML-RPC ser independente de plataforma, é possível que diversas aplicações, em diferentes plataformas, se comuniquem. Por exemplo, um cliente Java pode se comunicar via XML-RPC, com um servidor C++ ou Python (Laurent et al., 2001).

O XML-RPC não utiliza o método HTTP GET, somente o método HTTP POST. Pois, o XML-RPC é um protocolo para fazer chamadas remotas de procedimento utilizando XML, além de ser o antecessor do protocolo SOAP.

Conforme exibido na Figura ?? dois protocolos podem ser utilizados pela troca de mensagens XML, XML-RPC e SOAP. Em muitos casos, XML-RPC é mais simples e, por isso, mais fácil de ser adotado. Entretanto, ao contrário do SOAP, XML-RPC não possui uma interface de descrição do serviço. Isso impede a invocação automática de serviços XML-RPC, uma característica crucial para a integração de aplicações just-in-time(Laurent et al., 2001).

\subsubsection{JSON}

O JSON (JavaScript Object Notation) ${ }^{10}$ é um mecanismo de codificação/decodificação de valores para intercâmbio de dados. Possui uma sintaxe de alto nível, fácil de ser entendida, facilitando o trabalho dos programadores e dos computadores. Ele é nativo da linguagem JavaScript. O JSON é também um formato de texto que é completamente independente

\footnotetext{
${ }^{10}$ http://www.json.org/
} 
da linguagem de programação, mas usa convenções que são familiares para programadores Java, PHP, C/C++ e muitas outras. Estas propriedades fazem do JSON um formato ideal para transmissão de dados orientada a objetos através da rede.

O formato JSON é um modelo de formato para intercâmbio de dados, não é um documento. É uma linguagem textual, e um subconjunto de JavaScript, leve e muito fácil de analisar. Sendo assim, o JSON tem sido amplamente adotado no meio acadêmico e por diversas empresas, principalmente devido ao fato de ser altamente produtivo em aplicações distribuídas e no desenvolvimento de serviços web.

Além de possuir a capacidade de representar as estruturas de dados gerais como: registros, listas e árvores, a sintaxe JSON é significativamente mais simples, então o processamento é mais eficiente em comparação com o XML. Portanto, esta é a diferença mais significativa entre os dois formatos no intercâmbio de dados ${ }^{11}$.

\subsubsection{Simple Object Access Protocol (SOAP)}

O protocolo SOAP é um dos principais componentes da tecnologia web services. Além de definir a sintaxe, a semântica e a ordem das mensagens que serão trocadas entre aplicações e servidores, o SOAP é um protocolo de comunicação de dados extensível para troca de informações em ambientes descentralizados e distribuídos. Para permitir a comunicação entre duas aplicações de forma interoperável, este protocolo estabelece um formato de mensagem padrão baseado em XML (SOAP, 2007).

Outras linguagens proveem funcionalidades similares ao SOAP, como CORBA, Java RMI e DCOM, mas é importante destacar que o protocolo SOAP é escrito completamente em XML e independente de plataforma e linguagem.

A especificação SOAP define duas partes principais, que podem ser visualizadas na Figura 2.6.

\section{Envelope SOAP}

Define as regras para encapsulamento de dados que serão transferidos entre dois computadores. Isso inclui dados específicos das aplicações, como nome de métodos, parâmetros ou valores de retorno, podendo incluir informações sobre quem deverá processar o seu conteúdo e, em caso de falha, como codificar mensagens de erro.

\section{Regras de codificação}

Para a troca de dados, os computadores devem estabelecer algumas regras específicas de codificação. Por exemplo, dois computadores que processam preços de ações precisam

\footnotetext{
${ }^{11} \mathrm{http}$ ://www.json.org/fatfree.html
} 


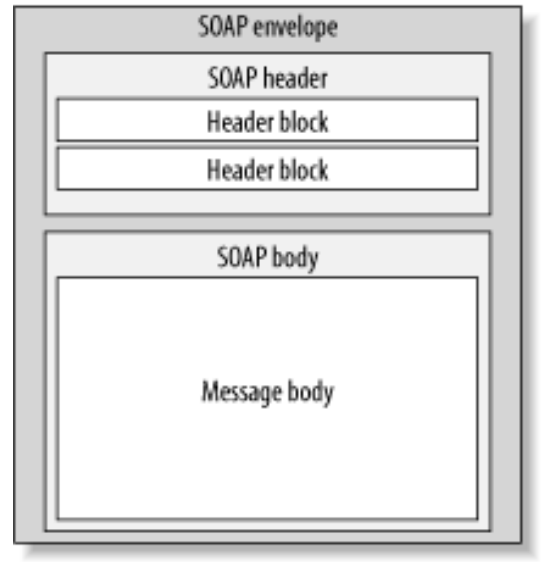

Figura 2.6: Estrutura de uma mensagem SOAP (Snell et al., 2002)

de uma regra para codificar tipos de dados flutuantes. O protocolo SOAP inclui seu próprio conjunto de convenções para codificação de tipos de dados, a maioria baseada em recomendações da especificação W3C XML Schema (W3C, 2004b).

\section{Convenções SOAP}

O protocolo SOAP pode ser utilizado em diversos sistemas de troca de mensagens, incluindo unidirecionais ou bidirecionais. Para troca bidirecional, SOAP define uma convenção simples para representação de chamadas e respostas de procedimentos remotos (RPC). Isso permite que uma aplicação cliente especifique o nome do método remoto, inclua alguns parâmetros caso necessário, o servidor ao receber a requisição através da rede, processa a resposta e retorna para o cliente através da rede.

As mensagens SOAP possuem também uma estrutura que contém o elemento envelope como elemento principal de dois elementos internos: header e body. O conteúdo desses elementos é definido pela aplicação, não fazendo parte do protocolo em si. O cabeçalho (header) é opcional, define apenas informações, como rota de transmissão e informações relativas ao processamento de mensagens. Esse elemento possibilita a extensão da mensagem através de cada aplicação. O elemento body é obrigatório, define o conteúdo e a informação que será transmitida na mensagem.

\subsubsection{Web Service Description Language (WSDL)}

A especificação SOAP não aborda a descrição. Com isso a W3C criou o padrão WSDL, uma especificação que provê recursos para descrever web services utilizando o formato XML. Esta especificação permite estabelecer a comunicação entre os web services provendo descrições para as localizações e descoberta de serviços (endpoints) padronizados, fornecendo as informações necessárias para estabelecer a integração com outros serviços e aplicações (Erl, 2004). 
A especificação WSDL define uma linguagem que permite que os web services possam publicar uma interface dos seus serviços com informações baseada no formato das mensagens de requisição e resposta. Sendo assim, a WSDL descreve um web service basicamente em duas partes: uma abstrata e outra concreta. Cada estágio contém um conjunto de componentes que definem a descrição de forma organizada no sentido de separar os diferentes propósitos e promover reusabilidade das descrições (W3C, 2007).

A parte abstrata descreve a interface do serviço propriamente dita, ou seja, descreve como o serviço pode ser invocado por seus clientes. Assim como, quais são as operações disponíveis, quais são os parâmetros de entrada e saída que uma determinada operação utiliza para enviar e receber mensagens, e como as mensagens envolvidas são descritas.

A parte concreta define os protocolos, formatos de dados e o endereço onde o serviço estará disponibilizado. A descrição das informações concretas pode ser definida através dos seguintes componentes:

- Service - representa uma coleção de localizações de serviços;

- Endpoint - contém informações sobre uma localização de serviço individual;

- Binding - referencia os vínculos entre os endpoints e as operações.

Existem também componentes complementares para fornecer informações adicionais e novas funcionalidades:

- Types - permite construir tipos de dados para dar suporte às definições de web services

- Documentation - permite incluir anotações adicionais ao documento WSDL.

Lembrando que todos esses componentes citados anteriormente devem ser incluídos dentro de um componente denominado definitions, que representa as definições dos web services em um documento WSDL. A Figura 2.7 ilustra a estrutura de um documento WSDL.

\subsubsection{Universal Description, Discovery, and Integration (UDDI)}

O protocolo UDDI é uma especificação técnica para descrever, descobrir e integrar os web services. Em seu núcleo, UDDI consiste de duas partes. Primeiro, UDDI é uma especificação técnica para a construção de um diretório distribuído de negócios e serviços web. Os dados são armazenados em um formato XML específicos, e a especificação UDDI inclui detalhes da API para pesquisa de dados existentes e publicação de novos dados. Segundo, o UDDI Business Registry (também frequentemente referido como o UDDI 


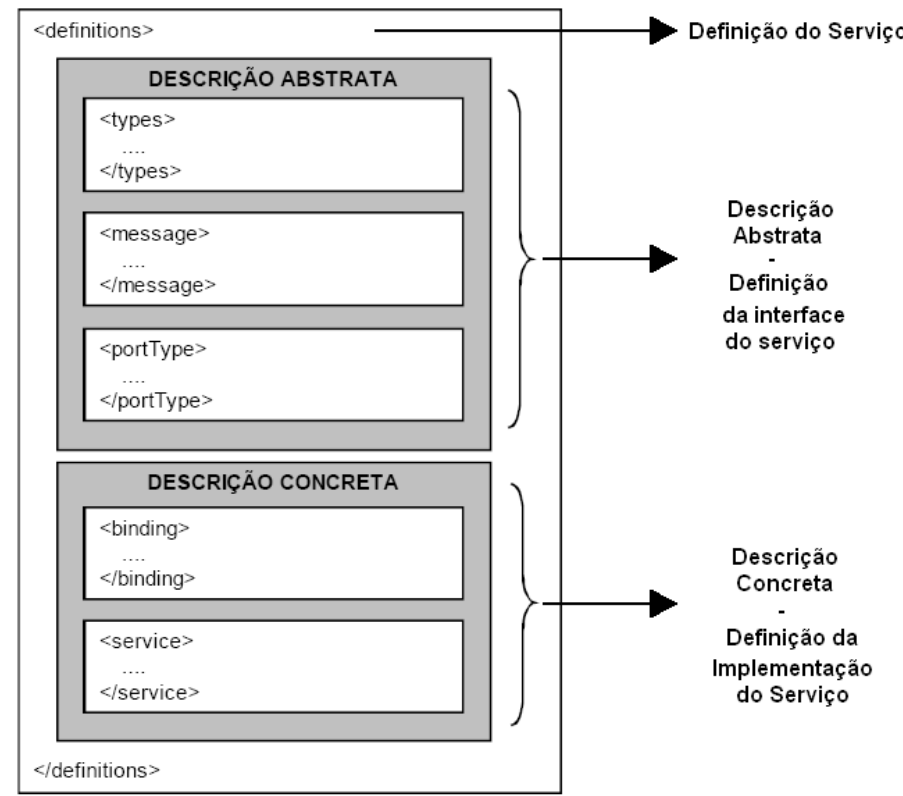

Figura 2.7: Estrutura de um documento WSDL (Weerawarana et al., 2005)

"serviços em nuvem") é uma implementação operacional completa da especificação UDDI. Lançada em maio de 2001 pela Microsoft e IBM, o registro UDDI agora permite que qualquer pessoa pesquise os dados existentes. Ele também permite que qualquer empresa possa registrar os seus serviços (Cerami, 2002).

Os dados capturados dentro do UDDI são divididos em três categorias principais:

\section{Páginas Brancas}

Inclui informações gerais sobre uma empresa específica. Por exemplo, nome da empresa, descrição do negócio, informações de contato, endereço e números de telefone. Pode também incluir identificadores de negócio único.

\section{Páginas Amarelas}

Inclui os dados de classificação geral da empresa ou do serviço oferecido. Por exemplo, esses dados podem incluir a indústria, produto, ou códigos geográficos com base em taxonomias padrão.

\section{Páginas Verdes}

Esta categoria contém informações técnicas sobre um serviço web. Geralmente, isso inclui um ponteiro para uma especificação externa e um endereço para invocar o serviço web. O UDDI não é restrito para descrever serviços web baseados em SOAP. Pelo contrário, UDDI pode ser usado para descrever qualquer serviço, a partir de uma única página da web, e-mail ou todo o caminho até o SOAP, CORBA e Java RMI. 
O UDDI cria uma plataforma padrão que permite que companhias e aplicações busquem e descubram web services de forma rápida, fácil e dinâmica. Além disso, UDDI também permite que registros operacionais sejam mantidos por diferentes propósitos em diferentes contextos (Oasis, 2005).

\subsection{Vantagens e Desvantagens das Diferentes Aborda- gens de Web Services}

Proporcionar interoperabilidade entre tecnologias heterogêneas e promover o acoplamento fraco entre o consumidor do serviço (cliente) e o prestador de serviços são os principais objetivos da arquitetura SOA com base nos conceitos e tecnologia de web services. Porém, muitos estilos diferentes de web services podem ser usados para integrar aplicações empresariais (Pautasso et al., 2008). A escolha é uma decisão importante de arquitetura, que influencia os requisitos e as propriedades do sistema integrado. A tecnologia de web services SOAP oferece a interoperabilidade, assim como o Remote Procedure Call (RPC) e estilos de integração de mensagens. Cada uma das seguintes abordagens de web services: SOAP-WSDL, REStful XML, REstful JSON e XML-RPC serão detalhadas à seguir.

\subsubsection{Web Services SOAP-WSDL}

Apesar da sua complexidade, devido a grande quantidade de padronização, o formato de mensagem SOAP e a linguagem de definição de interface (WSDL) ganharam ampla adoção de tecnologias como o gateway ${ }^{12}$ capaz de oferecer interoperabilidade entre os sistemas de middleware heterogêneos. Uma das vantagens do WS-* são a transparência e independência de protocolo. Usando SOAP, a mesma mensagem no mesmo formato pode ser transportada através de uma variedade de sistemas middleware ${ }^{13}$, que dependa do HTTP (Pautasso et al., 2008).

Os problemas de interoperabilidade podem ocorrer quando, por exemplo, tipos de dados nativos e construções de linguagem da execução de serviços estão presentes em sua interface. Esse problema pode ser atenuado por afirmar e fazer cumprir determinadas diretrizes de codificação, tais como o desenvolvimento contract-first ${ }^{14}$.

\footnotetext{
${ }^{12}$ Gateway, ou porta de ligação, é uma máquina intermediária geralmente destinada a interligar redes, ou mesmo traduzir protocolos.

${ }^{13} \mathrm{O}$ middleware é uma camada que provê acesso comum para diversas fontes heterogêneas de informação e serviço, isto é, um protocolo de interoperabilidade (Adam et al., 2000)

${ }^{14}$ Ao criar web services, existem dois estilos de desenvolvimento: Contract Last e Contract First. Ao utilizar uma abordagem contract-last, você começa com o código Java, e deixa que o contrato do web service (WSDL) seja gerado automaticamente. Ao usar o contract-first,
} 
Além disso, a utilização de WSDL para descrever uma interface de serviço ajuda a abstrair o protocolo de comunicação e os dados de serialização, bem como a plataforma de implementação do serviço (sistema operacional e linguagem de programação). Contratos WSDL fornecem uma descrição de processamento da sintaxe e da estrutura do pedido correspondente e mensagens de resposta para as máquinas, além de definir um caminho evolutivo e flexível para o serviço. Assim como os negócios e os requisitos tecnológicos mudam, a interface abstrata do mesmo serviço pode ser vinculada a diferentes protocolos de transporte e endpoints de mensagens. Em particular, WSDL pode modelar interfaces de serviços para sistemas baseados em padrões de interação síncronos e assíncronos. Este tipo de flexibilidade torna-se fundamental quando gateways de construção de sistemas legados já existentes, ou que nem sempre usam protocolos web amigáveis (Pautasso et al., 2008).

\subsubsection{Web Services RESTFul XML}

Os web services RESTful são conhecidos pela sua simplicidade, pois o estilo REST aproveita as normas existentes e conhecidas da W3C/IETF (HTTP, XML, URI, MIME) baseada em uma infra-estrutura generalizada. Os clientes e servidores HTTP já estão disponíveis para todas as linguagens de programação e principais plataformas de sistema operacional/hardware, e a porta HTTP padrão 80 é comumente deixada em aberto por padrão na maioria das configurações de firewall $^{15}$ (Pautasso et al., 2008).

Essa infra-estrutura leve, em que os serviços podem ser construídos com ferramentas mínimas, é de baixo custo para a aquisição e, portanto, tem pouca resistência para a sua adoção. O esforço necessário para construir um cliente para um serviço RESTful é muito pequeno, os desenvolvedores podem começar a testar esses serviços a partir de um navegador da web comum, sem ter que desenvolver o software de cliente personalizado. Implantar um serviço web RESTful é muito similar à construção de um site dinâmico (Pautasso et al., 2008).

Além disso, graças aos URIs e hiperlinks, o REST demonstrou que é possível descobrir os recursos da web sem uma abordagem baseada em registro obrigatório para um repositório centralizado. Do ponto de vista operacional, os web services RESTFul oferecem suporte para cache, clustering e balanceamento de carga. O REST possibilita também maior liberdade para otimizar o desempenho de um web service com um formato de mensagem mais leve, por exemplo, o JavaScript Object Notation (JSON) que será abordado na próxima seção (Pautasso et al., 2008).

você começa com o contrato WSDL, e utiliza o código Java para implementar o contrato. http://static.springsource.org/spring-ws/sites/1.5/reference/html/why-contract-first.html

${ }^{15}$ Firewall (muro corta-fogo) é o nome dado ao dispositivo de uma rede de computadores que tem por objetivo aplicar uma política de segurança a um determinado ponto de controle da rede. 
Os web services REST costumam ser implementados de duas formas diferentes: Hi-REST e Lo-REST. Hi-REST é a implementação conforme descrito por Fielding (Fielding, 2000), também chamada de RESTful. A implementação Lo-REST, por outro lado, utiliza apenas os métodos HTTP GET e POST. Existem algumas confusões sobre as melhores práticas comumente aceitas para a construção de web services RESTful. As recomendações Hi-REST foram estabelecidas de maneira informal, mas nem sempre são totalmente seguidas (Pautasso et al., 2008).

Assim, apenas dois métodos, (GET para pedidos idempotentes ${ }^{16}$ e $^{P_{\text {OST }}}{ }^{17}$ para tudo o mais), são usados. Isto é devido ao fato de que proxies e firewalls nem sempre permitem conexões HTTP que usam qualquer outro método. Como a maioria das soluções não-padrão, eles não podem ser entendidos por todos os servidores web, e exigem desenvolvimento adicional e esforço de teste (Pautasso et al., 2008).

Outra limitação torna impossível seguir estritamente o método GET para pedidos idempotentes que tenham grandes quantidades de dados de entrada (mais de $4 \mathrm{~KB}$ na maioria das implementações atuais). Não é possível codificar esses dados no recurso URI, pois o servidor irá rejeitar como "mal formados" URIs - ou, no pior caso, será acidental, expondo o serviço a ataques de buffer overflow. O tamanho do pedido, não obstante, também pode ser um desafio para codificar estruturas complexas de dados em um URI como não há nenhum mecanismo que aceite o marshalling ${ }^{18}$. Essencialmente, o método POST não sofre tais limitações (Pautasso et al., 2008).

\subsubsection{Web Services RESTFul JSON}

Quando se trata de gerenciar a evolução de um web service, o acoplamento fraco implica a capacidade de fazer modificações no serviço sem afetar seus clientes. No caso de web services RESTful, é evidente que os quatros métodos HTTP GET, POST, PUT, DELETE são uniformes e os mesmos para todos os serviços e nunca mudam. O congelamento do protocolo básico permite a dissociação total de clientes e servidores, como qualquer alteração no servidor nunca vai quebrar um cliente, tal mudança simplesmente não acontece.

Para os web services de WS-*, existe um formato de mensagem simples e padronizada: SOAP. Por outro lado, os web services RESTful atualmente não usam um único formato para representar recursos. Em vez disso, contam com a flexibilidade proporcionada pelas características e conteúdo do REST para escolher entre uma variedade de MIME types

\footnotetext{
${ }^{16} \mathrm{O}$ método GET é idempotente, ou seja, os efeitos causados por várias solicitações GET idênticas são os mesmos que para uma única solicitação GET, ou seja, quando pode-se efetuar uma ação repetidamente, sem efeitos colaterais. Além disso, os métodos HTTP PUT, HEAD e GET são considerados idempotentes.

${ }^{17} \mathrm{O}$ método HTTP POST não é idempotente, pois os dados submetidos em seu corpo podem ser destinados a uma transação que não pode ser desfeita.

${ }^{18}$ Semelhante à serialização, é o processo de transformar a representação da memória de um objeto para um formato de dados adequados para o armazenamento ou transmissão.
} 
do documento que pode também incluir SOAP. Tal situação pode complicar e dificultar a interoperabilidade de serviços web RESTful, como por exemplo, os clientes esperando os dados JSON não serão capazes de analisar um arquivo XML. Além disso, um web service RESTful é capaz de prover os recursos em formatos de representação múltipla, o que requer mais esforço de manutenção. No entanto, o formato JSON sobre o XML pode compensar o esforço extra e a falta de interoperabilidade com uma redução significativa da sobrecarga (Pautasso et al., 2008).

\subsubsection{Web Services XML - RPC}

O XML-RPC é um protocolo que utiliza chamadas de procedimento remoto que funciona sobre a internet. Além disso, uma mensagem XML-RPC é uma solicitação HTTP POST. O corpo do pedido está em XML. Um procedimento é executado no servidor e o valor que ele retorna também é formatado em XML. Parâmetros de procedimento podem ser escalares, números, strings, datas, etc, e também pode ser recorde complexo e estruturas da lista ${ }^{19}$.

O RPC é a sigla para Remote Procedure Calls. Essa técnica é usada na construção de aplicações distribuídas. Baseia-se no conceito convencional de funções e procedimentos locais de um programa, estendendo-o. Utilizando RPC é possível chamar um procedimento que não esteja implementado localmente, tampouco escrito na mesma linguagem.

A abordagem RPC facilita o trabalho do programador, pois poupa o trabalho de ter que aprender sobre protocolos subjacentes, redes e vários detalhes de implementação. As bibliotecas RPC são geralmente projetadas para serem relativamente transparentes e muitas vezes são operadas com uma única função de chamada em vez de uma API complexa. Programas escritos em mainframes, minicomputadores, workstations e computadores pessoais, até mesmo de diferentes fornecedores, podem se comunicar, se estiverem em uma rede comum (Laurent et al., 2001).

Efetivamente, RPC fornece aos desenvolvedores um mecanismo para definição de interfaces que pode ser chamado através de uma rede. Essas interfaces podem ser tão simples como uma única chamada de função ou tão complexas e extensas como uma API grande. O RPC é um mecanismo que permite ao desenvolvedor, usufruir o máximo dela, limitado apenas pelos custos de sobrecarga da rede e preocupações arquitetônicas (Laurent et al., 2001).

A seguir um exemplo de uma requisição e de uma resposta em XML-RPC:

\footnotetext{
${ }^{19} \mathrm{http}: / /$ xmlrpc.scripting.com/spec.html
} 


\section{Requisição em XML-RPC}

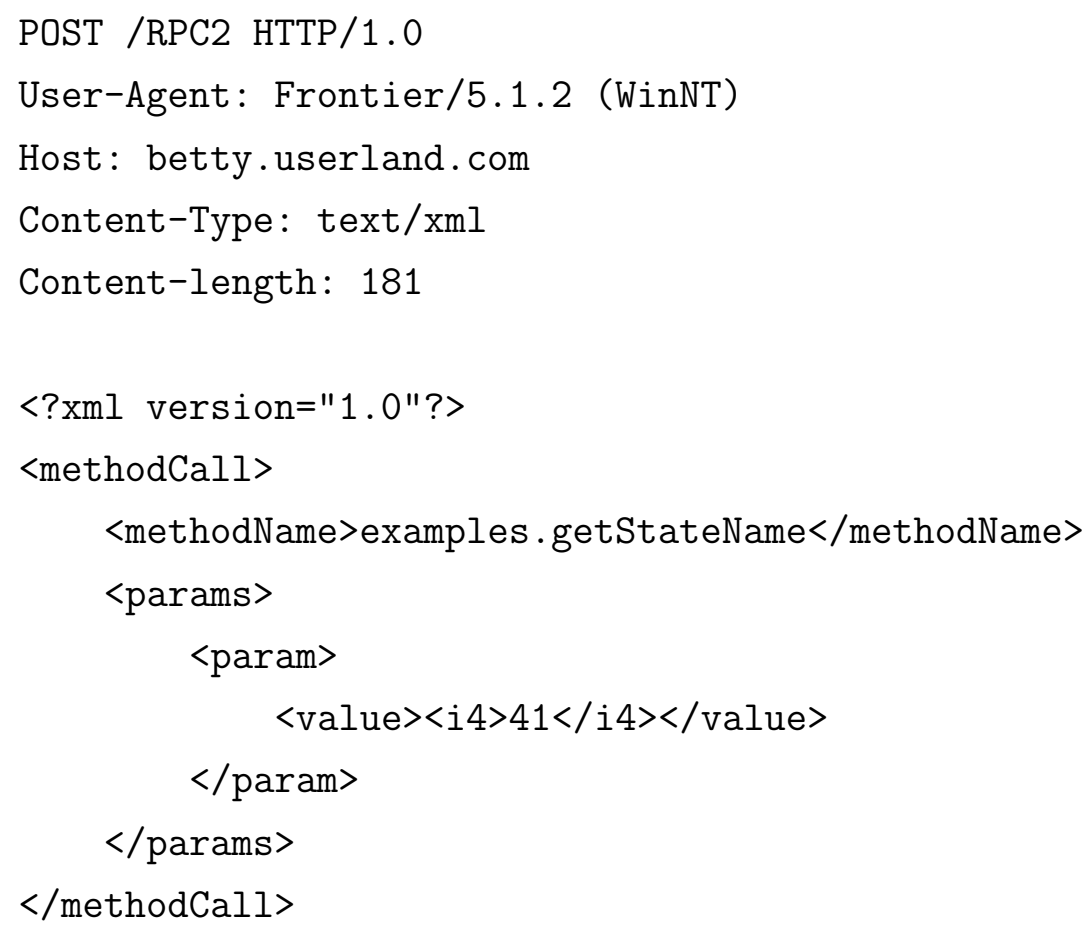

\section{Resposta em XML-RPC}

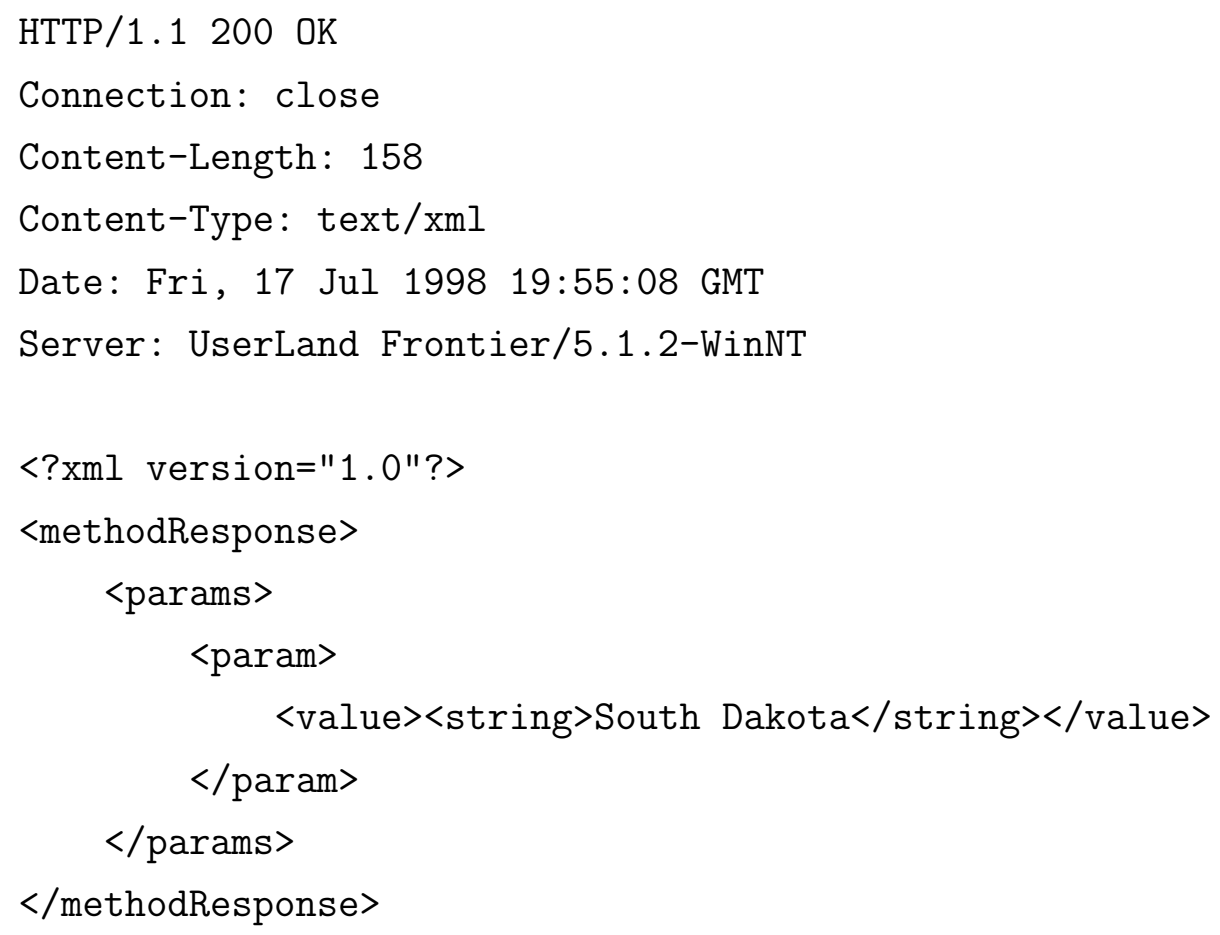




\subsection{A escolha dos Web Services RESTful e SOAP-WSDL}

Os web services RESTful e SOAP-WSDL foram escolhidos para a avaliação comparativa da manutenibilidade, pois as tendências tecnológicas recentes no domínio dos web services (WS) indicam que são os mais utilizados no meio empresarial. Além disso, o web service RESTful é mais adequado para cenários básicos de integração do tipo ad hoc, enquanto o SOAP-WSDL é uma tecnologia mais flexível, além de abordar os requisitos de qualidade do serviço web comumente utilizados na computação empresarial (Pautasso et al., 2008). Além disso, a linguagem de programação Java foi escolhida pelo aluno de mestrado por ter maior facilidade, domínio, tempo de experiência e inclusive possuir a certificação Java Sun Certified Java Programmer SE 6 (SCJP6).

\subsection{Manutenibilidade de Web Services}

A manutenibilidade é o conjunto de atributos que evidenciam o esforço necessário para se fazer modificações especificadas (ISO2000, 2000). Sendo assim, a avaliação de manutenibilidade é fundamental para garantir a qualidade e a evolução do serviço em um sistema computacional. No decorrer desta seção serão abordadas também as questões de custo e a grande demanda pelo processo de manutenção de software. Serão descritas também as principais atividades que contribuem para os elevados custos de manutenção como o entendimento do código existente, fator importante para permitir o sucesso da manutenção na redução de custos (Canfora et al., 1996). A legibilidade do código fonte e a qualidade da documentação devem ser levadas em conta ao medir a capacidade de manutenção de software (Aggarwal et al., 2002).

Além disso, a manutenção faz parte da qualidade do software (ISO9126, 2003) e da evolução. Refere-se também às modificações que são feitas no sistema depois da entrega inicial (Carlo Ghezzi, 1991). As mudanças são implementadas por meio de modificações de componentes de sistema existentes e, quando necessário, por meio da adição de novos componentes ao sistema (Sommerville, 2007). Sendo assim, é importante destacar que a manutenção de um sistema em operação pode ser responsável por mais de $60 \%$ de todo o esforço despendido por uma organização de desenvolvimento, e a porcentagem continua a aumentar com mais softwares sendo produzidos (Manna, 1993). Para analisar os fatores que afetam esses custos, é comum dividir a manutenção de software em três categorias:

1. Manutenção Corretiva: refere-se à manutenção de reparo de defeitos. 
2. Manutenção Adaptativa: refere-se à adaptação a um novo ambiente, podendo significar também a adaptação do software aos novos requisitos.

3. Manutenção Evolutiva: refere-se ao aperfeiçoamento do sistema de software por meio da implementação de novas funcionalidades, mas em outras situações pode significar manter a funcionalidade do sistema, melhorando, porém sua estrutura e seu desempenho.

Grandes sistemas de software exibem grande complexidade e são difíceis de manter. Segundo a pesquisa de Erlikh (Erlikh, 2000) o custo de software dedicado à manutenção e evolução do sistema já responde por mais de $90 \%$ dos custos totais de software. Os pesquisadores demonstraram que os mantenedores de software gastam aproximadamente $50 \%$ do seu tempo no processo de compreensão do código. Para facilitar as tarefas de manutenção, gerentes de projetos e desenvolvedores recorrem frequentemente ao histórico da evolução do sistema de software para recuperar vários tipos de informações úteis, como fenômenos anômalos e decisões de design perdidos. Além disso, a mineração da informação a partir do histórico da evolução é custoso e consome muito tempo, devido à presença de dados abundantes.

Uma razão importante dos custos de manutenção ser altos é que é mais oneroso adicionar uma nova funcionalidade depois que o sistema já está em funcionamento do que a implementação da mesma funcionalidade durante o desenvolvimento. Os fatores fundamentais que distinguem o desenvolvimento e a manutenção e que levam a maiores custos de manutenção são (Sommerville, 2007), (Pressman e Pressman, 2004):

1. Estabilidade da equipe. Depois que um sistema foi entregue a equipe é desfeita e as pessoas são alocadas para novos projetos. A nova equipe ou as pessoas responsáveis pela manutenção dos sistemas não entendem a arquitetura e nem os padrões de projeto aplicados ao sistema, o que demanda muito esforço e tempo para compreender o sistema existente antes de implementar as mudanças.

2. Responsabilidade contratual. O contrato para manter um sistema geralmente é separado do contrato de desenvolvimento. Outro ponto importante é que o contrato de manutenção pode ser concedido a uma empresa diferente da que desenvolveu o sistema. Esse fator aliado com a falta de estabilidade da equipe não incentiva para que os desenvolvedores escrevam um código fácil de ser entendível e modificado. Se puderem ser feitas simplificações com o intuito de poupar esforços mesmo que acarrete aumento nos custos, a equipe fará isso.

3. Habilidade do pessoal. O pessoal de manutenção geralmente é inexperiente e sem familiaridade com o domínio da aplicação. Além disso, sistemas antigos podem ter 
sido escritos em linguagens de programação obsoletas. Os mantenedores podem não ter tanta experiência em desenvolvimento nessas linguagens e devem aprendê-las para executar a manutenção do sistema.

4. Idade e estrutura do programa. À medida que o tempo passa, a estrutura de um programa tende a se degradar pelas mudanças tornando-se, assim, cada vez mais difícil de ser compreendida e modificada. Alguns sistemas foram desenvolvidos sem as modernas técnicas de Engenharia de Software ou nunca terem sido bem estruturados levando-se em conta a eficiência ao invés da facilidade de compreensão. Além disso, a documentação pode estar inconsistente e o desperdício de tempo é muito maior para encontrar as versões corretas dos componentes do sistema a serem modificados.

Os três primeiros problemas decorrem do fato de que muitas organizações ainda consideram o desenvolvimento e a manutenção como atividades separadas. No entanto, o quarto problema retrata o problema da estrutura degradada, de certa maneira é o problema mais fácil de resolver do sistema.

A Figura 2.8 mostra como os custos de todo o ciclo de vida, que podem diminuir quanto maior for o esforço e o orçamento despendido durante a fase do desenvolvimento para produzir um sistema fácil de manter. Devido ao potencial de redução de custos na compreensão, análise e teste, existe um efeito multiplicador significativo quando o sistema é desenvolvido considerando-se a sua facilidade de manutenção. Para o sistema 1 da Figura 2.8, o custo de desenvolvimento de 25 mil dólares é investido para tornar o sistema mais fácil de manter. Isso resulta em uma economia de 100 mil dólares em custos de manutenção durante todo o ciclo de vida do software. Supõe-se que o percentual de aumento nos custos de desenvolvimento resulta em um decréscimo percentual comparável em custos globais do sistema.

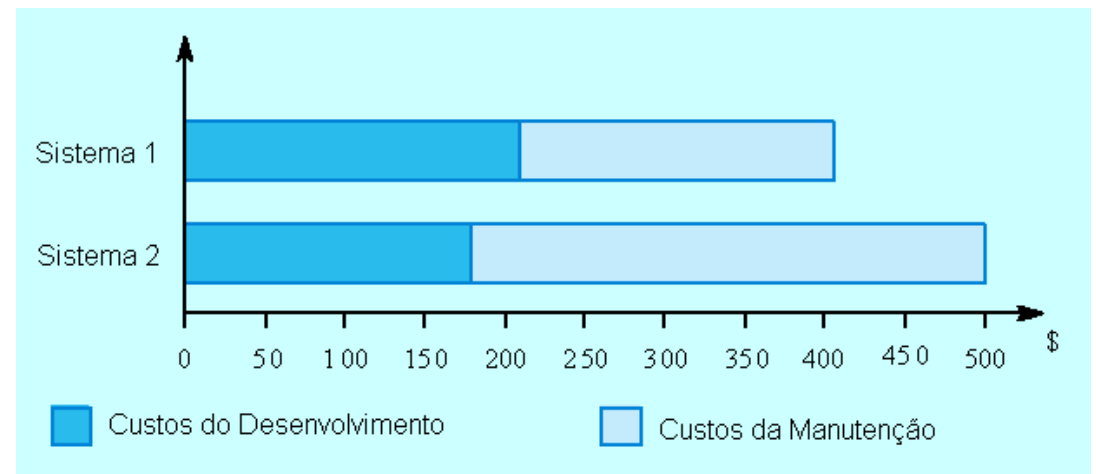

Figura 2.8: Custos de desenvolvimento e de manutenção (Sommerville, 2007)

Podemos concluir segundo Sommerville (Sommerville, 2007) que é mais benéfico investir esforços no projeto e na implementação de um sistema para reduzir os custos de 
manutenção, pois adicionar novas funcionalidades depois do sistema implantado é oneroso, devido ao esforço empregado para compreender o sistema e analisar o impacto das mudanças propostas.

Há uma grande inconsistência e imprecisão no tratamento das terminologias envolvidas com a manutenção do software. Esta situação é agravada pelo fato de que existem diferentes dimensões da manutenibilidade, cada um requerendo tratamento específico. Em (Mari e Eila, 2003) é apresentado um framework de manutenção e as técnicas que promovem a manutenibilidade em três níveis de abstração: sistema, arquitetura e componentes. Na dimensão do sistema, a exigência de manutenção é considerada uma questão de negócio relacionado com os aspectos do sistema. Na arquitetura, manutenibilidade, é um conjunto de atributos de qualidade, por exemplo, extensibilidade e flexibilidade. No nível dos componentes, manutenção, centra-se na integrabilidade, modificabilidade e testabilidade. Portanto, este trabalho de mestrado está envolvido no nível dos componentes.

Com base nas informações anteriormente mencionadas a manutenibilidade de web services oferece um novo desafio para Engenharia de Software. O sucesso da nova geração de sistemas de negócios não depende apenas de como implementar a nova tecnologia, mas também sobre como evoluí-la e mantê-la ao longo do tempo. A partir da perspectiva de evolução e manutenção, há muitas questões que devem ser examinadas. Entre elas incluem questões de evolução e manutenção de web services para cada uma das abordagens proposta por este projeto de mestrado.

Atualmente a maioria das empresas de software está em processo de desenvolvimento de serviços web. Porém, as organizações não possuem conhecimento necessário para a evolução e manutenção de sistemas baseados em web services, acarretando um enorme custo de manutenção, e insatisfação do cliente/contratante. No cenário atual da web as empresas desenvolvem sistemas dinâmicos de e-business que são por natureza extremamente ágil às demandas de novos negócios. A empresa que fornecer uma resposta mais rápida às novas mudanças em requisitos de negócios, além de ajudar a prestar serviços de alta qualidade, obtém vantagens competitivas e oportunidades, adaptando e sobrevivendo melhor no mercado. No entanto a maioria dessas organizações é incapaz de reagir rapidamente às novas demandas de negócio (Kajko-Mattsson, 2005).

Os sistemas web service como explicado anteriormente são distribuídos, estão em rápida evolução, compostos por vários módulos de diferentes organizações. Um exemplo de um web service pode ser um serviço que oferece um preço de um produto ou permite que um usuário envie uma fatura. Devido as suas propriedades, os web services não possui fronteiras bem definidas. Em vez de ter sistemas ou subsistemas distintos, temos um conjunto de serviços provenientes e/ou fornecidos por diversas outras instituições, onde cada uma contribui com funcionalidades necessárias para o aplicativo final. Como mostrado 
na Figura 2.9, isso pode resultar em hierarquias de serviços em que serviços de alto nível podem ser compostos por serviços de baixo nível, e assim por diante, permitindo assim a construção recursiva de cadeias de fornecimento de serviços (Kajko-Mattsson, 2005).

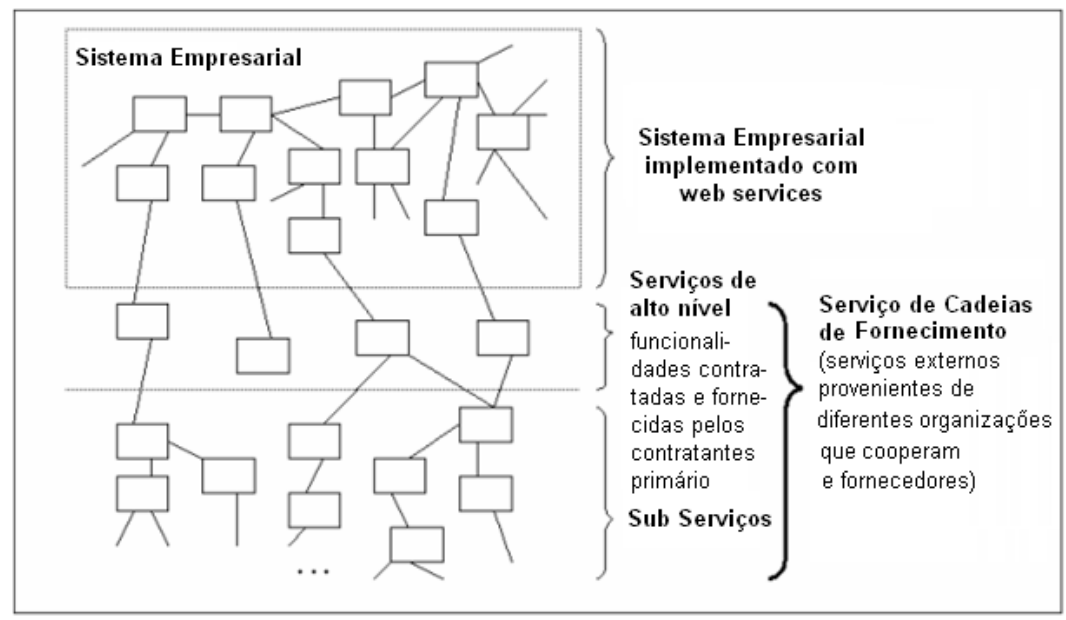

Figura 2.9: Redes de Fornecimento de Serviço (Kajko-Mattsson, 2005)

Assim como em um desenvolvimento baseado em componentes, ao adicionar novas funcionalidades nas aplicações de web services, os engenheiros de software vão procurar por web services adequados no mercado de serviços web na internet, ao invés de desenvolvê-los por conta própria. Após ter encontrado os serviços apropriados, os engenheiros vão usá-los como estão ou terão de fazer algumas adaptações a eles e, eventualmente, alterar as especificações de requisitos ou fazer alguma outra medida adequada. Eles também terão de considerar o fato de que os web services oferecidos no mercado de serviços de hoje pode ser mudado amanhã.

Segundo o trabalho de Kajko-Mattsson (Kajko-Mattsson, 2005) foram identificadas questões que são únicas em evolução e manutenção do sistema de serviços web. Os resultados mostraram que existem diferenças entre a gestão dos sistemas de softwares convencionais e sistemas web services, devido ao baixo acoplamento, maior flexibilidade e reutilização dos serviços. Sendo assim, é preciso encontrar novas metodologias de Engenharia de Software para desenvolvimento, evolução e manutenção. Portanto, devemos rever as nossas metodologias de Engenharia de Software atual e identificar as mudanças a serem feitas.

\subsection{Considerações Finais}

Este capítulo apresentou uma visão geral sobre os principais conceitos que envolvem a tecnologia dos web services, desde a descrição de cada entidade pertencente à esta tecnologia, até a interação entre eles, apresentando uma infra-estrutura fornecida pelos fundamen- 
tos da Arquitetura Orientada a Serviços. Também foi visto que os web services é uma abordagem que admite a heterogeneidade de sistemas, permitindo sua integração e interoperabilidade. No entanto, a aquisição de tais propriedades pode implicar em problemas de manutenibilidade, tornando-se um dos principais fatores que pode afetar o custo do serviço oferecido, visto que o custo é importante para a adoção e aceitação de um serviço.

Considerando ainda que os web services sejam aplicações disponibilizadas em uma rede heterogênea como a internet, garantir a evolução é desafiador, tornando-se necessária a adoção de técnicas e abordagens específicas. Para comprovar se os serviços atendem as necessidades dos requisitantes em termos de manutenibilidade de forma adequada, a adoção de técnicas adequadas para a avaliação de manutenibilidade é uma etapa fundamental. Sendo assim, conceitos relacionados com a evolução e manutenção de web services serão abordados no Capítulo 3. 


할

\section{Engenharia de Software Experimental}

\subsection{Considerações Iniciais}

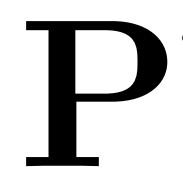
ara atender a demanda e as necessidades da indústria e da academia, diferentes métodos, técnicas, processos e ferramentas são propostos regularmente. No entanto, muitas vezes não são apresentadas evidências sobre as soluções propostas, ou seja, não há resultados práticos de sua aplicação ou do avanço em relação às tecnologias já estudadas. A Engenharia de Software Experimental propõe que os estudos tecnológicos da área sejam realizados a partir de experimentos como uma forma de validar e compartilhar eficientemente as soluções elaboradas pelos pesquisadores (Travassos, 2002).

Neste capítulo são apresentados os principais conceitos relacionados à Engenharia de Software Experimental. Esses conceitos foram parcialmente extraídos de (Travassos, 2002), (Wohlin et al., 2000) e (Juristo e Moreno, 2010).

\subsection{Engenharia de Software Experimental}

A Engenharia de Software Experimental estabeleceu-se como uma área de pesquisa dentro da Engenharia de Software durante as últimas duas décadas. Em 1986 Basili et al. (Basili et al., 1986) publicou um documento sobre a metodologia de experimentação em Engenharia de Software. Alguns estudos empíricos foram publicados, mas o número de 
estudos era limitado e muito pouco se discutiu sobre a realização de estudos empíricos em Engenharia de Software. Desde então, o uso de trabalho empírico em Engenharia de Software tem crescido consideravelmente, embora ainda reste muito trabalho.

Uma revista dedicada à Engenharia de Software Experimental foi lançada em 1996 e conferências com foco sobre o tema também foram iniciadas. Hoje, as avaliações e validações empíricas muitas vezes são esperadas em trabalhos de pesquisa. No entanto, o avanço na pesquisa deve refletir sobre a educação. Isto significa, que se tornou muito importante incluí-la também nos estudos empíricos sistematicamente nos currículos em ciência da computação e Engenharia de Software (Wohlin, 2007). Os cientistas da computação e Engenheiros de Softwares capazes de executar estudos empíricos e compreender como estudos empíricos podem ser utilizados como uma ferramenta de avaliação, a validação de predição, e assim por diante.

A literatura sobre educação em Engenharia de Software empírica é limitada. A literatura descreve experiências específicas de um curso, como Host (Höst, 2002), ou deve-se realizar uma pesquisa com os alunos como sujeitos (Thelin et al., 2003). A maioria dos estudos empíricos realizados em um ambiente educacional é experimentos controlados, embora alguns artigos estejam mais relacionados aos estudos de projetos de estudantes e, portanto, poderia ser classificada como estudos de caso (Berander, 2004; Höst, 2002). Algumas exceções existem, onde os autores discutem o uso dos alunos em estudos empíricos para diferentes fins (Carver et al., 2003).

A Engenharia de Software está principalmente preocupada com o desenvolvimento em grande escala de software e, portanto, a utilização de experimentos controlados em ambiente de laboratório não é uma tarefa simples.

Quando a experimentação foi introduzida na Engenharia de Software, o foco principal era sobre a execução de experimentos. À medida que o trabalho progredia, mais foco tem sido dado aos métodos atuais utilizados. Os dois livros sobre a experimentação (Juristo e Moreno, 2010; Wohlin et al., 2000) são bons exemplos. Os pesquisadores também começaram a abordar como os resultados de diferentes estudos empíricos devem ser combinados através de meta-análise (Hayes, 1999; Miller, 1999) ou usando uma abordagem mais fundamentada em evidências (Kitchenham et al., 2004). Outros pesquisadores têm abordado o desafio de construir famílias de experimentos (Basili et al., 1999) e, portanto, planos para combinar experiências ao invés de tentar combinar estudos existentes. Essa proposta também está intimamente relacionada com a questão da replicação (Shull et al., 2002).

Alguns experimentos reais realizados são apresentados em (Sj”berg et al., 2002), em especial, o artigo defende o financiamento para execução e contratação de profissionais para participar dos experimentos, para viabilizar sua realização. No entanto, precisamos 
entender melhor como a transferência dos resultados de experimentos de laboratório com os alunos para complementar a condução dos experimentos maiores, portanto, os experimentos tornam-se muito mais caros com a contratação dos profissionais. Em particular, é um desafio executar métodos empíricos de uma forma eficaz e simultaneamente executar estudos que sejam valiosos a partir de uma perspectiva de pesquisa ou a partir de uma perspectiva de transferência de tecnologia.

Quando se trata de realmente tentar entender o papel dos alunos como sujeitos em experimentos controlados em Engenharia de Software, o primeiro artigo a abordar o tema explicitamente foi publicado em 2000 (Höst et al., 2000). O artigo apresenta um estudo empírico em que ambos os estudantes e profissionais da área participaram de um experimento controlado, e em seguida, o artigo compara os dois grupos de indivíduos. Neste caso, não houve diferenças identificadas no desempenho. Com base apenas na observação visual dos estudantes versus profissionais, um esquema foi desenvolvido para incluir a experiência e a motivação (Höst et al., 2005). Em outro estudo, uma observação interessante foi feita quando uma situação foi encontrada em que os resultados obtidos com as experiências realizadas com os estudantes tornaram-se possível generalizar. Mas logo em seguida surgiram novos métodos melhores para serem utilizados (Staron et al., 2006). Quando se trata de trabalhar em objetos para uso em experimentos, a pesquisa é muito limitada.

\subsection{Experimentação na Engenharia de Software}

$\mathrm{Na}$ Engenharia de Software os objetivos da condução de experimentos são a caracterização, avaliação, previsão, controle e melhoria em relação aos produtos, processos, recursos, modelos e outros resultados e atividades do processo de desenvolvimento de software (Travassos, 2002). Além de avaliar técnicas e atividades da Engenharia de Software, a experimentação permite contribuir com a evolução, previsão, compreensão, controle e aperfeiçoar o processo de desenvolvimento de software e produtos (Basili et al., 1986). Os experimentos em Engenharia de Software são quasi-experimentos, ou seja, um conjunto representativo de sujeitos do mundo real, pois nem sempre é possível fornecer aleatorização, dentre outras dificuldades existentes nesse contexto.

A literatura define três principais tipos de experimentos, diferenciando-os em relação ao controle de execução, o controle de medição, o custo de investigação e a facilidade de repetição. São eles: pesquisa de opinião, estudo de caso e experimento controlado (Travassos, 2002). Para decidir qual o tipo de experimento a ser executado, o pesquisador deve identificar o rigor necessário para o experimento e os recursos disponíveis para sua execução. 
A pesquisa de opinião, também conhecida como Survey, é utilizada como uma forma de avaliação de uma técnica proposta, ou seja, é uma investigação executada em retrospectiva. Esse tipo de pesquisa pode ser realizado para a determinação de atributos e características dos itens estudados. A pesquisa de opinião auxilia os pesquisadores a compreender as razões que levaram um grupo de pessoas a utilizar determinada técnica em relação à outra.

A principal forma de coleta de dados para esse tipo de experimento é por meio de questionários ou entrevistas. Por ser um método com baixo custo de aplicação a quantidade de participantes pode ser grande, aumentando assim a validade dos resultados estatísticos. Por outro lado, o Survey não oferece nenhum controle sobre a execução ou medição dos dados, por isso é considerado o método menos rigoroso para a realização de experimentos.

O estudo de caso é comumente utilizado na monitoração de técnicas e ferramentas. Nessa estratégia as observações são concentradas em um atributo e no seu relacionamento com atributos diferentes (Travassos, 2002). Uma aplicação muito comum para os estudos de caso é na validação de uma nova tecnologia, em que a tecnologia proposta é comparada com a tecnologia atual em relação aos aspectos de interesse e suas vantagens são detalhadas.

Assim como o survey o estudo de caso não tem controle sobre a execução do experimento. No entanto, esse método é mais rigoroso do que a pesquisa de opinião, pois a medição das variáveis é controlada. Um ponto importante a ser observado no estudo de caso é a ocorrência de fatores de conflito (confounding factors). Esses fatores estão presentes em experimentos em que mais de um fator pode ocasionar um mesmo efeito e devido à falta de controle sobre a execução do experimento não é possível determinar qual a origem do efeito obtido. Estudos de casos devem ser planejados com cuidado a fim de evitar a ocorrência de fatores de confusão, pois esses podem prejudicar as conclusões obtidas pelo experimento.

A estratégia mais rigorosa a ser aplicada é o experimento controlado. Geralmente esse tipo de experimento é realizado em laboratório, podendo ser in-vitro ${ }^{1}$, onde todas as variáveis são controladas, ou in-vivo ${ }^{2}$, sob condições naturais. O objetivo do experimento controlado é manipular uma ou algumas variáveis e manter as outras fixas, medindo o efeito do resultado (Travassos, 2002).

- Experimentos in-vitro são feitos em laboratórios simulando a forma que eles aconteceriam no mundo real;

- Experimentos in-vivo são feitos no mundo real e monitorados à medida em que o uso do objeto de estudo realmente ocorre;

\footnotetext{
${ }^{1}$ Realizado em condições controladas tais como em um laboratório ou um grupo fechado.

${ }^{2}$ Envolve pessoas no seu próprio ambiente de trabalho em condições realistas de trabalho.
} 
- Em Engenharia de Software, normalmente experimento controlados são feitos in-vitro e estudos de caso são feitos in-vivo.

Os experimentos controlados permitem controlar a execução, medição e investigação da proposta. Para obter tal nível de rigor, todos os fatores para a execução do experimento devem ser isolados. O custo para a realização do experimento controlado é maior do que o estudo de caso, porém, devido à maior rigorosidade, ele é mais fácil de ser repetido. A validade do experimento e a confiança agregada são também maiores no experimento controlado do que nas outras estratégias.

\subsection{Terminologia e Conceitos Básicos}

A condução de experimentos não é uma tarefa simples, pois é preciso lidar com uma grande quantidade de informações. É importante também que os pesquisadores responsáveis pelo experimento tenham conhecimento sobre o vocabulário utilizado. A seguir são apresentados os principais termos da Engenharia de Software Experimental de acordo com (Travassos, 2002).

As variáveis em um experimento são as informações que são manipuladas pelos pesquisadores e podem ser classificadas em dois grupos dependendo da forma como são obtidas. Variáveis independentes são aquelas referentes à entrada do processo de experimentação, ou seja, são as variáveis que podem ser manipuladas ou controladas no processo de experimentação. Elas correspondem às causas que podem afetar o resultado do experimento. Essas variáveis também são chamadas de fatores e seu valor é denominado tratamento.

As variáveis que apresentam o efeito causado pelos fatores do experimento são denominadas variáveis dependentes, ou seja, são variáveis referentes à saída. Além disso, podemos dizer que as variáveis dependentes são aquelas nas quais são observados os resultados da manipulação das variáveis independentes e que expressam o efeito na relação causa-efeito definida no experimento. O valor das variáveis dependentes é chamado resultado e é obtido após a execução do experimento.

O relacionamento entre as variáveis é ilustrado na Figura 3.1. Na parte superior as hipóteses são formuladas tentando prever os diversos comportamentos do experimento, construindo assim, um relacionamento causa-efeito. Durante a execução do experimento os valores das variáveis independentes produzem os resultados das variáveis dependentes, resultados esses que devem ser comparados com os efeitos previstos na preparação do experimento.

Os objetos são todos os artefatos que podem ser manipulados durante o processo de experimentação. O sistema de medição e as diretrizes de execução são responsáveis 


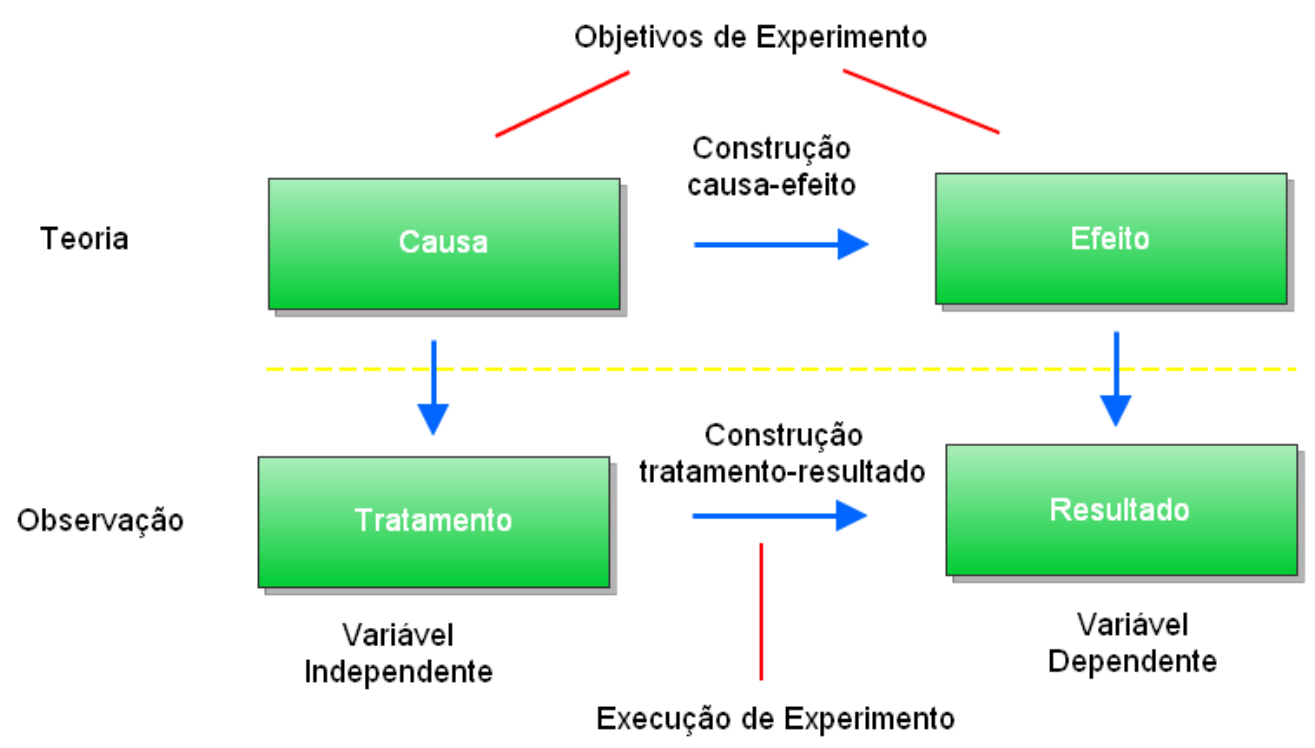

Figura 3.1: Apresentação dos conceitos de um experimento (Wohlin et al., 2000).

por definir como os objetos serão manipulados possibilitando a instrumentação do experimento.

Os participantes são os indivíduos selecionados dentre a população para conduzir o experimento (Travassos, 2002). A escolha dos participantes deve ser feita de forma cuidadosa para que seja selecionada uma amostra representativa da população a ser estudada. Para atingir essa representatividade alguns aspectos devem ser considerados, como por exemplo, o método de escolha e a quantidade de participantes. Aspectos esses que devem ser sempre proporcionais à variedade da população.

O contexto do experimento refere-se às condições de execução do experimento, por exemplo, se o experimento será executado sob condições controladas dentro de um laboratório ou se será executado em condições naturais. No contexto também são definidos quem serão os responsáveis pela condução do experimento, qual a natureza do problema tratado e se o experimento é válido apenas em um contexto particular ou se pode ser generalizado para outros domínios.

O objetivo do experimento é de avaliar a proposta do autor, geralmente expressa como uma relação de causa e efeito. Para tal avaliação o experimento é formulado por meio de hipóteses. A hipótese principal se chama hipótese nula e declara que não há nenhum relacionamento estatisticamente significante entre a causa e o efeito (Travassos, 2002). O experimento é realizado com o objetivo de, baseando-se nos resultados obtidos, chegar à conclusão de que a hipótese nula possa ser rejeitada. Para chegar a essa conclusão é importante que alguns princípios sejam seguidos. 


\subsection{Princípios e Validade}

Para garantir a confiabilidade e a validade dos resultados do experimento, um conjunto de princípios deve ser considerado. Os princípios definidos na Engenharia de Software Experimental devem ser seguidos durante todo o ciclo de vida do experimento desde o processo de organização, de execução até a fase de apresentação e empacotamento dos resultados. Wohlin (Wohlin et al., 2000) descreve os três princípios básicos da Engenharia de Software Experimental:

Aleatoriedade: todos os métodos estatísticos usados para analisar os dados exigem que a observação seja feita a partir das variáveis independentes e aleatórias (de Barros Neto et al., 2003). A aleatoriedade é aplicada na alocação dos objetos, dos participantes e na ordem em que os testes são executados. Ela é utilizada para minimizar alguns efeitos indesejados que podem ocorrer devido à ordenação proposital dos artefatos.

Agrupamento: se existe uma variável independente que tenha um efeito sobre o resultado, mas esse efeito não é interessante para os pesquisadores o agrupamento deve ser utilizado. Agrupar variáveis em blocos é uma possível solução para "diluir" efeitos indesejados causados por essas variáveis (Travassos, 2002).

Balanceamento: princípio que procura garantir que todos os tratamentos possuem o mesmo número de participantes com mesmo nível de conhecimento. Essa característica é importante para simplificar a análise estatística e garantir a uniformidade entre os grupos de participantes (de Barros Neto et al., 2003).

Além dos princípios básicos apresentados, outros princípios também devem ser considerados, como por exemplo, o impacto da investigação nos objetos. Se a investigação de um objeto no experimento pode afetar o seu comportamento, esse impacto deve ser considerado e os valores obtidos devem estar calibrados para contornar o impacto causado.

A garantia de validade do experimento deve ser uma preocupação constante para os organizadores. A validade de um experimento pode ser ameaçada por diversos fatores e são classificados de acordo com a origem e o impacto causado (Travassos, 2002):

Validade de conclusão: preocupa-se em garantir que o relacionamento entre o tratamento e os resultados do experimento foi construído de maneira correta. Para tal avaliação é preciso analisar como ocorreu o processo desde a coleta das medidas até as conclusões obtidas. Para a validade de conclusão, conceitos como a escolha do teste estatístico, a escolha do tamanho do conjunto de participantes e a confiabilidade das medidas devem ser consideradas.

Validade interna: verifica se os resultados obtidos são realmente consequência do tratamento que foi aplicado. Essa validação é importante, pois os resultados podem ser influenciados por fatores que não foram medidos ou controlados durante o experimento. $\mathrm{O}$ 
foco da verificação da validade interna está nos participantes envolvidos no experimento. Deve ser levado em consideração o aprendizado do participante ao realizar o experimento, o nível de cansaço apresentado no decorrer das atividades, as habilidades individuais e a representatividade em relação à população estudada.

Validade de construção: tem como objetivo garantir que a construção do experimento foi feita de forma correta, ou seja, que tanto o tratamento dado quanto os resultados obtidos refletem bem a causa e o efeito definidos no experimento. Fatores que podem ameaçar a validade de construção podem ser causados tanto pelos participantes quanto pelos pesquisadores.

Os participantes podem ser influenciados pelas hipóteses levantadas no experimento, ou ainda, devido à situação do experimento, eles podem se sentirem avaliados e se comportarem de maneira diferente de situações normais (Travassos, 2002). Os pesquisadores podem ser tendenciosos projetando os resultados para aqueles esperados para o experimento.

Validade externa: define as condições que limitam a generalização do experimento para a prática industrial. Os motivos dessas limitações devem ser explicitados, como por exemplo, a pouca representatividade dos participantes ou condições específicas do experimento que não podem ser encontradas na indústria.

\subsection{Processo de Experimentação}

O experimento controlado é um dos estudos principais, assim como estudos de caso, surveys e pesquisa ação (Sjoberg et al., 2005). Além disso, a experimentação pode ser vista como um processo sistemático composto por fases, subprocessos e produtos gerados ao final de cada fase. Caracteriza-se por um processo que se inicia na definição do experimento passando pelo planejamento, operação, análise e interpretação até a apresentação e empacotamento (Wohlin et al., 2000). Essas fases compõem o processo experimental ilustrado na Figura 3.2.

O processo experimental tem início na definição do experimento que será detalhada na Subseção 5.2.1. Nessa fase, são definidos aspectos gerais e específicos do experimento, relacionados ao problema que será tratado, objetivos e metas do estudo. Devem ser respondidas questões como: qual o objeto do estudo? (o que será estudado); qual o propósito do experimento? (intenção do estudo); qual será o foco de qualidade? (principal aspecto de qualidade que será estudado); qual perspectiva usar? (ponto de vista em que os resultados serão interpretados) e qual o contexto? (ambiente no qual o experimento será executado). Com base nas respostas a essas questões define-se o planejamento do experimento que será detalhado na Subseção 5.2.3. 


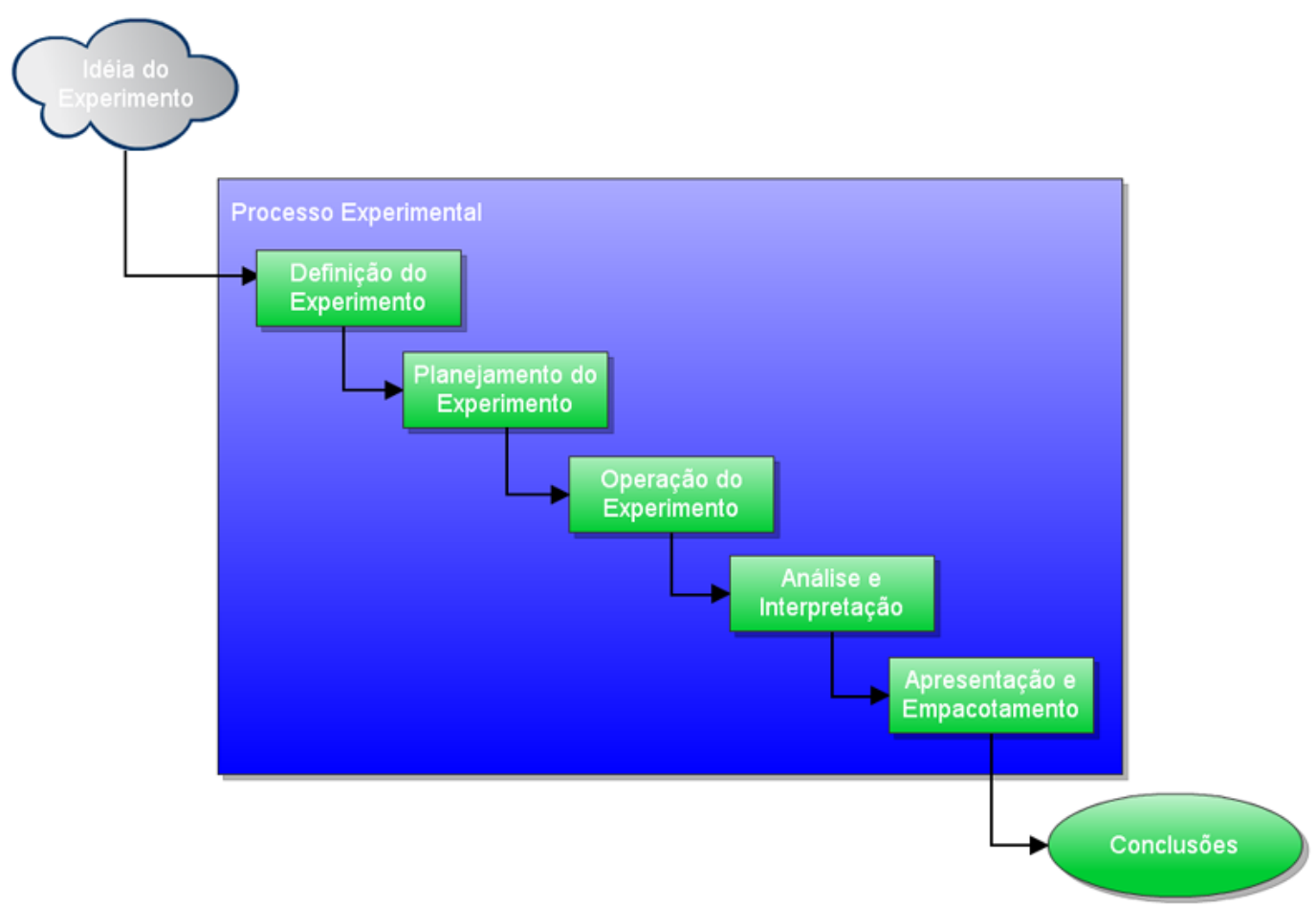

Figura 3.2: O processo de experimentação e suas fases (Wohlin et al., 2000)

No planejamento o projeto do experimento é mais detalhado, incluindo também a avaliação dos riscos. São definidos o contexto, as hipóteses, as variáveis, os participantes, o projeto experimental, a instrumentação e a avaliação de validade do projeto experimental.

Três atividades compõem a fase de operação do experimento: preparação, execução e validação de dados. Durante a preparação o material que será utilizado no experimento é organizado, os participantes são informados a respeito do objetivo da realização do experimento e o consentimento de participação é preenchido pelos participantes. Durante a execução ocorre a condução do experimento. As tarefas previstas no planejamento são executadas e os dados são coletados. A validação dos dados é necessária para checar se estes foram coletados corretamente. A operação do experimento será melhor detalhada na Subseção 5.2.4.

A fase de análise e interpretação será descrita no Capítulo 7, nesta fase, recebe como entrada os dados coletados para que estes possam ser analisados e interpretados usando uma análise estatística. Pode ocorrer uma redução do conjunto de dados para remover informações (dados) que possam prejudicar a análise, ou a fim de reduzir o conjunto inicial para que a análise seja facilitada. Os resultados gerados pela análise e interpretação são usados pelo experimentador na tentativa de rejeitar a hipótese nula (teste de hipóteses) e confirmar a hipótese alternativa. Nas fases de apresentação e empacotamento os resultados obtidos no experimento são apresentados e empacotados, por meio de documentação (artigos de pesquisa), pacotes de laboratório ou ainda formando 
uma base de conhecimento. A fase de apresentação e empacotamento será detalhada na Subseção 8.2.1.

A Engenharia de Software Experimental possibilitou utilizar uma abordagem científica para o desenvolvimento, evolução e manutenção dos web services: RESTful e SOAP-WSDL. Além disso, a Engenharia de Software Experimental possibilitou entender a natureza dos processos e produtos de software e a relação entre as abordagens de web services no desenvolvimento, manutenção e evolução de sistemas de Softwares Orientados a Serviços.

É importante destacar também que a Engenharia de Software Experimental é intensivamente humana e podemos destacar as características de experimentos em ciências sociais:

- Difícil de controlar.

- Difícil de coletar dados.

- Envolvem dados subjetivos e qualitativos.

\subsection{Considerações Finais}

Neste capítulo foi apresentada uma visão geral sobre um dos principais conceitos envolvidos neste projeto. Inicialmente foram descritos os conceitos básicos da Engenharia de Software Experimental, abordando os diferentes tipos de experimentos (pesquisa de opinião, estudo de caso e experimento controlado). Em seguida foram apresentados os conceitos sobre princípios e validade, para garantir a confiabilidade e a validade dos resultados do experimento. Por fim, foram abordados conceitos sobre o processo experimental, enfatizando as principais etapas de um experimento controlado.

Os estudos experimentais aqui apresentados tiveram como objetivo explanar o que tem sido feito de experimentação em web services, pois nesta proposta de trabalho está incluída a realização de um estudo experimental. No Capítulo 4 será apresentada uma visão sobre a aplicação de web services no contexto de manutenibilidade de software. 


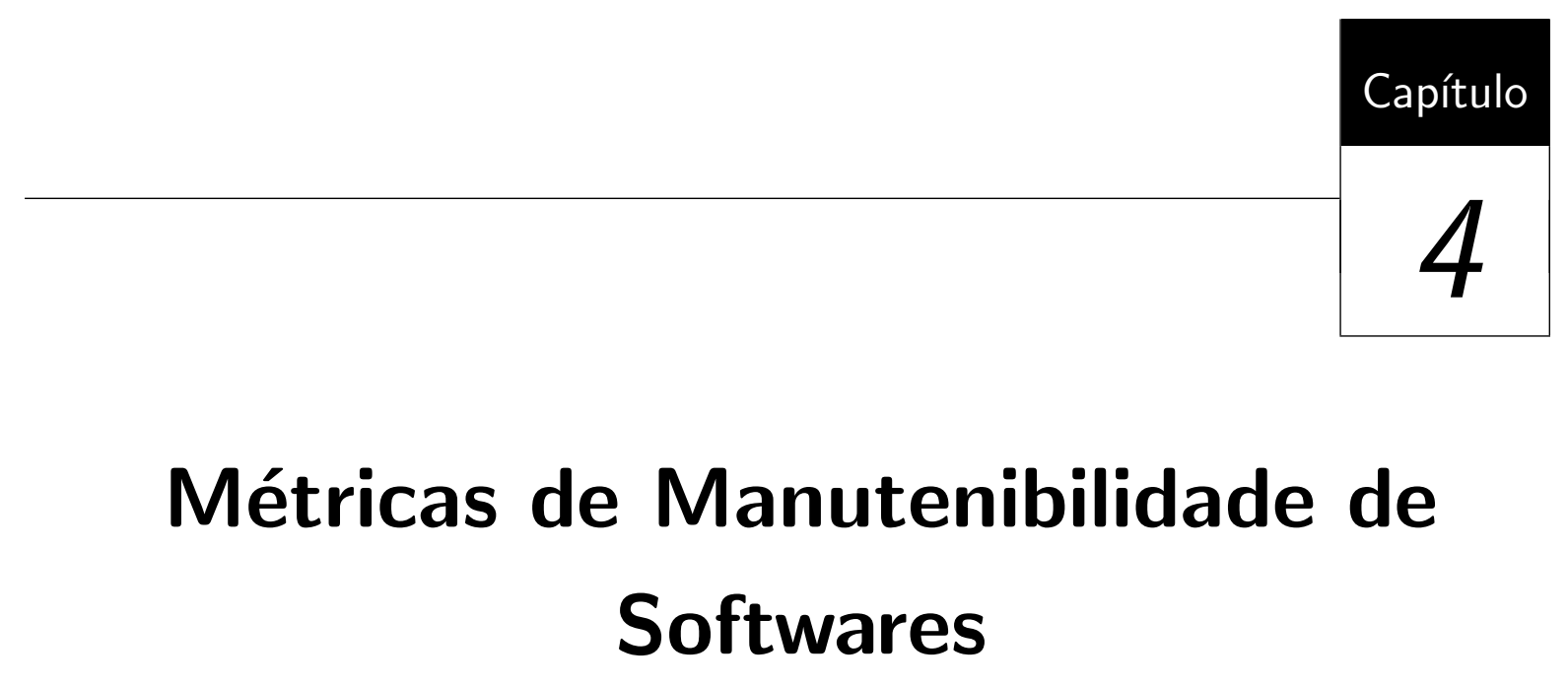

\subsection{Considerações Iniciais}

garantia da qualidade é uma das principais preocupações da indústria de desen-
volvimento de software, pois atualmente a maior parte das empresas atuantes
no mercado utiliza esse tipo de aplicação para gerir seus negócios, produtos e relacionamentos com clientes, necessitando maior confiabilidade e qualidade. Existem diversas medidas de garantia de qualidade fundamentais para o sucesso de qualquer tipo de aplicação de software, dentre elas, a medição de software. Nesse sentido, a medição de software auxilia a tomada de decisão, pois através de dados quantitativos, é capaz de informar que aspectos do produto atendem ou não ao padrão de qualidade especificado, além de permitir a avaliação dos benefícios de novos métodos e ferramentas de Engenharia de Software, o entendimento e aperfeiçoamento do processo de produção, a avaliação do retorno do investimento e tornar o gerenciamento de projetos em conformidade com a realidade da empresa. 


\subsection{Métricas de Manutenibilidade de Softwares}

Para medir software, são utilizadas diversas métricas que são como tipos de medições aplicadas a um sistema de software, documentação ou processo relacionado. Através dessas métricas é possível determinar o esforço ou tempo para realização de uma tarefa ou o tamanho do produto, por exemplo. Além disso, as métricas de software são facilmente calculadas, entendidas e testadas e independem do observador que as aplica, sendo também uma boa fonte para estudos estatísticos acerca do ciclo de vida do software.

Dentro desse contexto, esta seção tem por objetivo apresentar algumas métricas de software e sua importância no processo de desenvolvimento. Para isso, algumas métricas serão mostradas, permitindo ao leitor compreender e analisar seus benefícios imediatos.

\subsubsection{Utilização de Métricas na Engenharia de Software}

Existem dois tipos de métricas no contexto de desenvolvimento de produtos de software: as métricas diretas, que são realizadas em termos de atributos observáveis, como por exemplo, esforço, tamanho e custo, e as métricas indiretas ou derivadas, que podem ser obtidas através de outras métricas, como por exemplo, complexidade, confiabilidade, e facilidade de manutenção. As métricas diretas e indiretas podem ser visualizadas conforme a Tabela 4.1.

Tabela 4.1: Categoria das Métricas

\begin{tabular}{|c|c|}
\hline MEDIDAS DIRETAS & MEDIDAS INDIRETAS \\
\hline Custo & Funcionalidade \\
\hline Esforço & Qualidade \\
\hline Linhas de Código & Complexidade \\
\hline Velocidade de Execução & Eficiência \\
\hline Memória & Confiabilidade \\
\hline $\mathrm{N}^{\circ}$ de Erros & Manutenibilidade \\
\hline
\end{tabular}

Em relação ao contexto, as métricas podem ser aplicadas em produtos ou em processos. Quando as métricas incidem diretamente no produto de software, são chamadas de métricas de predição, quando em processos de software, são comumente chamadas de métricas de controle e sua aplicação normalmente é realizada em processos já maduro e controlado.

Para obter resultados significativos, as métricas devem ser aplicadas em um ciclo constante, que envolve as etapas de planejamento, medição, análise de resultados, tomada de decisão e implementação das decisões. Desta maneira, pode-se construir uma base histórica do artefato medido que permitirá ao engenheiro de software analisar que processos, 
ferramentas e métodos melhor se aplicam àquele tipo de produto. Alguns cuidados também devem ser tomados no processo de medição, como o momento e a escolha do conjunto de métricas mais relevantes a serem aplicadas, e a comparação entre produtos através da aplicação de métricas (pois nenhum produto é igual a outro). O escopo, os desenvolvedores e o ambiente são fatores que podem influenciar o processo de desenvolvimento. Assim, comparações devem ser cuidadosamente analisadas.

As métricas podem e deve ser aplicado durante as fases de desenvolvimento do software, o que garante ainda mais seu impacto positivo no produto final.

\subsubsection{O Modelo GQM (Goal/Question/Metric)}

Segundo alguns especialistas, para medir artefatos de software através de métricas significativas, as medições devem ser definidas de acordo com objetivos específicos. Nesse sentido, o GQM (Goal/Question/Metric), desenvolvido por Basili em 1988, é uma abordagem para aplicação de métricas a fim de aprimorar o processo de desenvolvimento de software (e, consequentemente, os produtos de software gerados) enquanto mantém os objetivos de negócio e objetivos técnicos da organização nivelados. É uma abordagem top-down que estabelece uma medição sistemática para objetivos relacionados ao processo de desenvolvimento, estabelecendo os objetivos organizacionais, definindo as metas e inserindo questões com o propósito de abordar os objetivos especificados e identifica as métricas que fornecem respostas para as questões definidas.

A abordagem GQM é composta de quatro fases:

1. A fase do planejamento, quando o projeto da medição está selecionado, definido, caracterizado, e planejado, resultando em o plano do projeto;

2. A fase da definição, quando o programa da medição conceitualmente preparado, ou seja, os objetivos, as questões, as métricas e as hipóteses são estabelecidas;

3. A fase da coleta de dados, quando a coleta de dados experimentais é efetivamente feita resultando em conjunto de dados prontos para a interpretação;

4. A fase da interpretação, quando os dados são processados a respeito das métricas, questões, e objetivos definidos.

A Figura 4.1 apresenta o processo principal da abordagem GQM. 


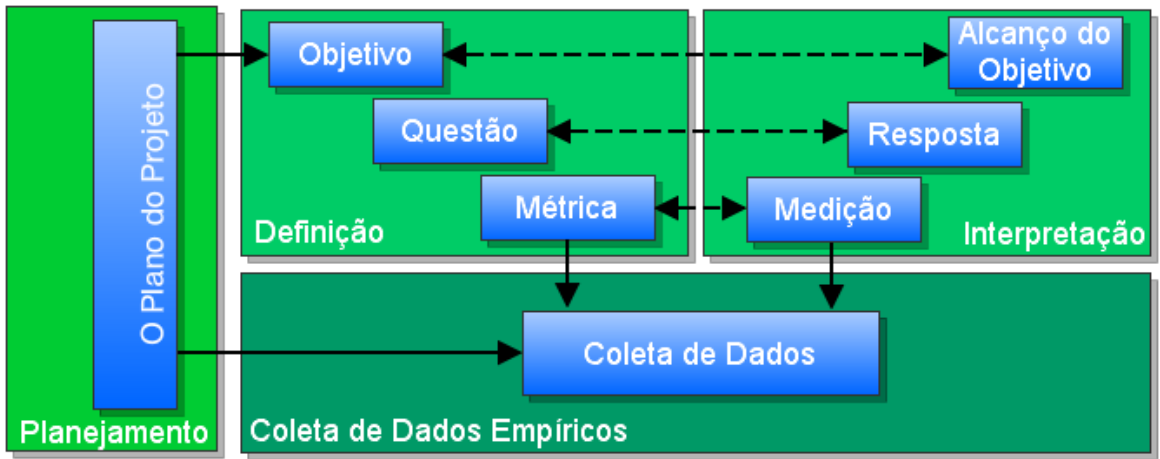

Figura 4.1: O processo principal da abordagem GQM (Solingen, 1999)

A Figura 4.2 apresenta um exemplo com os princípios da abordagem GQM utilizados no experimento controlado.

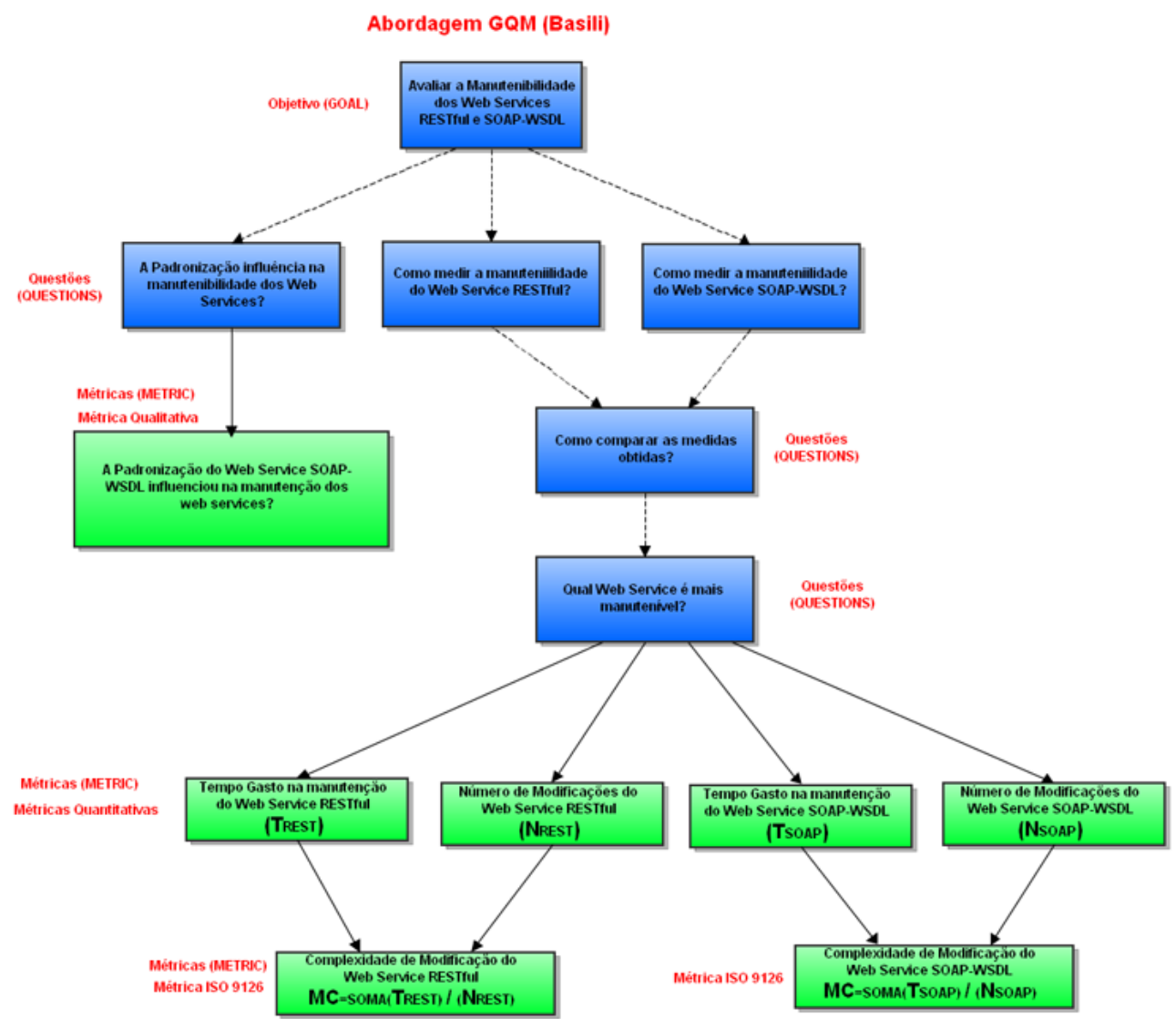

Figura 4.2: Abordagem GQM utilizada no experimento controlado (Basili et al., 1994)

Além disso, o GQM define um modelo de três níveis, ilustrado na Figura 4.3. 


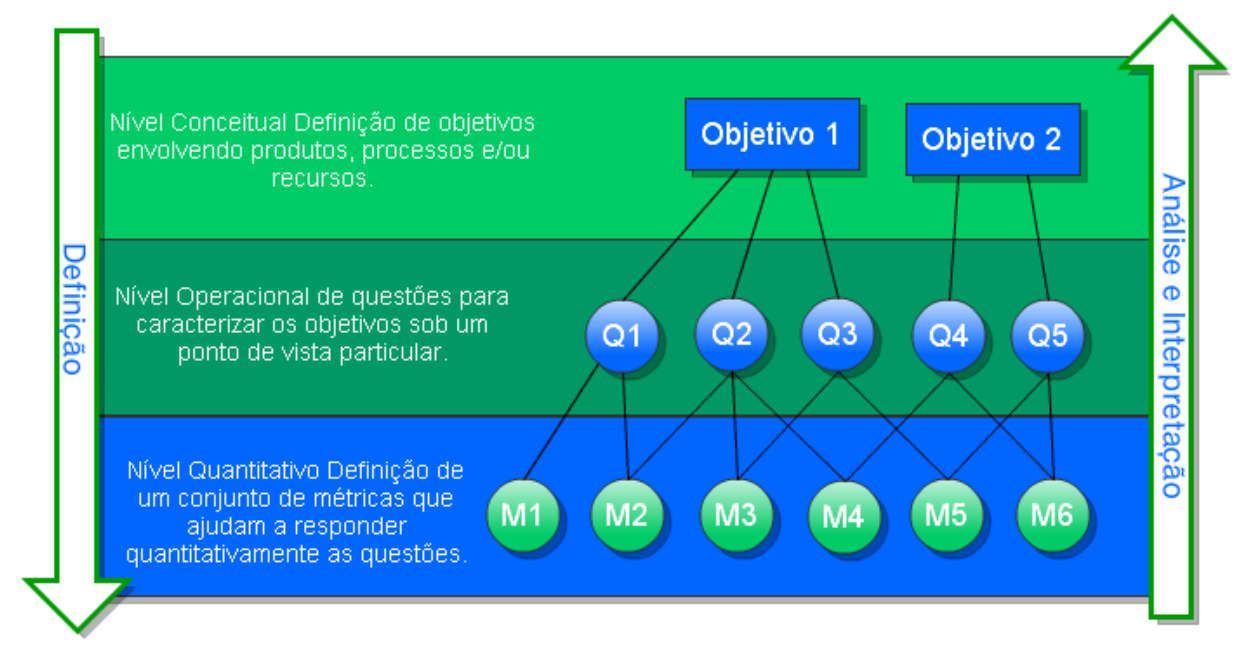

Figura 4.3: Níveis do modelo GQM

O GQM pode ser muito útil na definição de quais métricas são necessárias de serem coletadas e analisadas para responder questões sobre um determinado objetivo. Isso é importante para evitar que esforço seja gasto com coleta desnecessária de métricas, que provavelmente nunca serão utilizadas.

\subsubsection{Os Tipos de Métricas de Manutenibilidade}

Existem muitas métricas de manutenibilidade. Dentre elas podemos destacar as seguintes:

- Métricas de Complexidade de Halstead

- Métricas de Manutenibilidade em Nível de Design

- Métricas Híbridas

- Norma ISO 9126

\section{MÉTRICAS DE COMPLEXIDADE DE HALSTEAD}

Halstead (Halstead, 1977) desenvolveu métricas de complexidade que ainda hoje são utilizadas para a manutenibilidade de software. As métricas de Halstead são baseadas em quatro números escalares derivados diretamente de um programa fonte (SEI, 2003):

1. $n 1=$ numero - de - operadores - distintos

2. $n 2=$ numero - de - operandos - distintos

3. $N 1=$ numero - total - de - operadores

4. $N 2=$ numero - total - de - operandos

A partir destes números, cinco métricas são derivadas, como consta da Tabela 4.2. 
Tabela 4.2: Métricas de Halstead (Halstead, 1977)

\begin{tabular}{|c|c|l|}
\hline Métrica & Símbolo & Fórmula \\
\hline Tamanho do Programa & $N$ & $N=N 1+N 2$ \\
\hline Vocabulário do Programa & $n$ & $n=n 1+n 2$ \\
\hline Volume & $V$ & $V=N *\left(\log _{2} n\right)$ \\
\hline Dificuldade & $\mathrm{D}$ & $D=\left(\frac{n 1}{2}\right) *\left(\frac{N 2}{n 2}\right)$ \\
\hline Esforço & $\mathrm{E}$ & $E=D * V$ \\
\hline
\end{tabular}

\section{MÉTRICAS DE MANUTENIBILIDADE EM NÍVEL DE DESIGN}

As métricas de código ignoram as interdependências entre módulos, assumindo que cada componente é uma entidade separada. As métricas de design de arquitetura tentam quantificar o nível de interação entre módulos, partindo do pressuposto que as interdependências contribuem para a complexidade geral do software (Henry e Selig, 1990).

H. Dieter Rombach, faz uma distinção entre design da arquitetura, que é de alto nível, e design algorítmico, de baixo nível. O design da arquitetura impacta mais na manutenibilidade do que design do algoritmo (Rombach, 1990), e sua experiência demonstra que não vale a pena medir o código: maior ganho é obtido ao investir na arquitetura, e o fator mais importante é a experiência e conhecimento do designer.

As métricas de complexidade no nível de design que afetam a manutenibilidade mais citadas na literatura são:

\section{a) Complexidade Ciclomática}

Desenvolvida por McCabe (McCabe, 1982) para indicar a testabilidade e manutenibilidade de software, medindo o número de caminhos linearmente independentes do programa (ou método). Para determinar os caminhos, representa-se o método como um grafo fortemente conectado com uma única entrada e uma única saída. Os nodos são blocos sequenciais de código, e as arestas são decisões que causam uma ramificação. A complexidade é dada por:

$$
C C=E-N+2
$$

onde:

$E=$ numero - de - arestas $\mathrm{e}$

$N=$ numero - de - nodos

\section{b) Fluxo de Informação}

Definido por Sallie Henry e Denis Kafura (Henry e Selig, 1990), o valor da métrica é dado pelo quadrado da multiplicação do fan-in de um módulo pelo seu fan-out.

$$
C c=(f a n-i n * f a n-o u t)^{2}
$$


O fan-in é a quantidade de fluxos de informações que entram no programa; fan-out é a quantidade de fluxos que saem do programa. No cálculo também devem ser consideradas as variáveis globais utilizadas e modificadas pelo programa ou método.

\section{MÉTRICAS HÍBRIDAS}

O Software Engineering Institute (SEI, 2003) adotou uma técnica específica: o Maintainability Index (MI), que foi desenvolvido por Paul Oman (Coleman et al., 1994). Artigo de Don Coleman (Coleman et al., 1995), cita e explica como os elementos do MI foram calibrados, validando a sua utilização para a indústria de software.

Neste índice, a manutenibilidade é calculada utilizando uma combinação de métricas. O MI de um conjunto de programas é dado pelo seguinte polinômio:

$M I=171-3.42 * \ln ($ mediaV $)-0.23 *$ mediaV $\left(g^{\prime}\right)-16.2 * \ln ($ mediaLDC $)+(50 *$ $\sin (\sqrt{2.46 * \operatorname{per} C M}))$

Onde:

mediaV $=$ Media - do - Volume - de - Halstead - por - modulo

mediaV $\left(g^{\prime}\right)=$ Media - estendida $-d a-$ complexidade - ciclomatica - por - modulo

mediaLDC $=$ Media - de - linhas - de - cdigo $-(L D C)-$ por - modulo $\operatorname{per} C M=$ Media-percentual-de-linhas - de-comentarios-por-modulo(opcional)

A manutenibilidade é diretamente proporcional ao MI, ou seja, quanto maior o índice, mais manutenível é o programa. Um índice de 6, por exemplo, é de manutenção quase impossível. Já um índice de 70 é muito bom.

\section{Norma ISO/IEC 9126}

A Norma ISO/IEC 9126 define seis características de qualidade de software listadas a seguir:

1. Funcionalidade: finalidade do produto.

2. Usabilidade: esforço para utilizar, aprender o produto.

3. Confiabilidade: frequência de falhas, recuperabilidade.

4. Eficiência: desempenho.

5. Manutenibilidade: esforço necessário para modificar.

6. Portabilidade: capacidade de transferir o produto para outros ambientes. 
Além disso, a Norma ISO/IEC 9126 é baseada em 3 níveis: características, subcaracterísticas e métricas. Cada característica é refinada em um conjunto de subcaracterísticas e cada subcaracterística é avaliada por um conjunto de métricas.

\section{Manutenibilidade - É fácil de modificar?}

Tabela 4.3: Subcaracterísticas da Norma ISO/IEC 9126 (ISO9126, 2003)

\begin{tabular}{|c|c|}
\hline SUBCARACTERÍSTICA & PERGUNTA CHAVE \\
\hline Analisabilidade & É fácil de encontrar uma falha, quando ocorre? \\
\hline Modificabilidade & É fácil modificar e adaptar? \\
\hline Estabilidade & Existe risco de efeitos inesperados quando se faz alterações? \\
\hline Testabilidade & É fácil validar o software modificado? \\
\hline
\end{tabular}

A métrica utilizada para avaliar a manutenibilidade entre as abordagens dos web services RESTful e SOAP-WSDL foi a norma ISO 9126 que define a manutenibilidade como a capacidade do produto de software ser modificado. As modificações podem incluir correções, melhorias ou adaptação do software às mudanças no ambiente e nos requisitos e especificações funcional ISO (ISO9126, 2003).

As métricas utilizadas foram retiradas do ISO / IEC TR 9126-1:2001 conjunto de métricas de manutenção. Note-se que todas as métricas ISO / IEC são definidas em uma escala de razão, sendo assim adequado para a análise paramétrica estatística utilizada neste estudo.

\section{Métrica de Modificabilidade}

A Complexidade de Modificação é representada por: $(\mathrm{MC})=\operatorname{Sum}(\mathrm{T}) / \mathrm{N}$, onde $\mathrm{T}=$ tempo de trabalho gasto em cada mudança e $\mathrm{N}=$ número de alterações. A interpretação dos valores possíveis: $0<$ MC, o mais próximo de 0, melhor (Perepletchikov e Ryan, 2011).

\subsection{Considerações Finais}

Neste capítulo foram apresentados os principais conceitos relacionados as métricas de manutenibilidade de softwares, abordando às métricas mais utilizadas. Foram apresentados os fundamentos e conceitos básicos entre as principais métricas mais utilizadas na manutenção de softwares. Além disso, as principais diferenças entre as métricas diretas e indiretas foram detalhados. Também foi apresentada a norma ISO 9126 que possibilitou posteriormente a análise estatística realizada nesta pesquisa. Com todos os conceitos e fundamentos apresentados é possível compreender melhor o contexto do experimento e todos os passos necessários para sua execução. A partir das informações apresentadas neste capítulo o experimento pode ser planejado e definido. 


5

\section{Definição e Planejamento do Estudo}

\subsection{Considerações Iniciais}

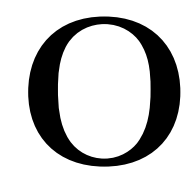

s conceitos apresentados neste capítulo foram construídos com base no processo experimental definido em Wohlin et al. (2000). Um estudo experimental tem início com a definição, em que o objetivo do experimento é determinado e outras questões são definidas, como o objeto de estudo, o foco de qualidade e o contexto em que o estudo será realizado. Após essa fase, o experimento é planejado com o objetivo de preparar a fase de operação.

Além disso, é importante destacar que a experiência obtida no projeto Quality Platform for Open Source Software(Qualipso) com manutenção de software e com o desenvolvimento de web services para integração de aplicações web, mostrou-se importante para a etapa de planejamento dos experimentos.

Por fim, neste capítulo são apresentados a definição e o planejamento do estudo experimental realizado. Na Seção 5.2 são apresentados os principais elementos da fase de definição do experimento. Na Seção 5.3 é apresentada a seleção dos indivíduos, assim como, as variáveis dependentes e independentes do experimento controlado e, na Seção 5.4 são apresentadas as considerações finais deste capítulo. 


\subsection{Experimento Realizado: Definição e Planejamento}

Na etapa de definição, o experimento é expresso em termos dos problemas e objetivos. Nessa fase, são descritas as principais questões que deram origem ao experimento. A partir dessas questões, são formuladas as hipóteses, o escopo do experimento é definido e planejado (Travassos, 2002).

\subsubsection{Objetivos}

Avaliação da manutenibilidade dos web services: RESTful e SOAP-WSDL. Os critérios são: tempo gasto na manutenção e a modificabilidade dos serviços web. A avaliação foi realizada para responder às seguintes questões (hipóteses):

- Qual o tipo de web service é mais manutenível do lado do cliente?

- Qual o tipo de web service é mais manutenível do lado do servidor?

- Quais dos web services avaliados, RESTful e SOAP-WSDL proporcionam o menor custo com gastos de manutenção e evolução para as empresas de softwares que desenvolvem serviços web?

\subsubsection{Metas}

- Objeto de estudo: servidor ou fornecedor do serviço web RESTful, cliente ou consumidor do serviço web RESTful, servidor ou fornecedor do serviço web SOAP-WSDL e cliente ou consumidor do serviço web SOAP-WSDL.

- Propósito: avaliar o custo e a manutenibilidade dos web services RESTful e SOAP-WSDL.

- Foco da qualidade: custo e manutenibilidade.

- Perspectiva: ponto de vista das empresas.

- Contexto: este experimento controlado assim como todo o conjunto de programas referentes ao domínio do sistema de gerenciamento educacional Sistema de Informação de Ambiente Universitário (SInAU) foram desenvolvidos pelo aluno de mestrado utilizando as ferramentas computacionais do repositório SVN Server ${ }^{1}$ assim como o plugin do Netbeans Simple Code Metrics ${ }^{2}$ para auxiliar na avaliação dos critérios de manutenibilidade e condução do experimento controlado.

\footnotetext{
${ }^{1}$ http://subversion.apache.org/

${ }^{2}$ http://plugins.netbeans.org/plugin/9494/simple-code-metrics
} 
É importante destacar que o sistema gerenciamento educacional (SInAU) foi desenvolvido pelo aluno de mestrado, porém a manutenção do sistema foi realizada pelos alunos do ICMC-USP por meio das tarefas de cada grupo, para não comprometer a validade dos resultados e as conclusões obtidas no experimento controlado.

\subsubsection{Planejamento}

Nesta fase, o projeto do experimento foi mais detalhado, incluindo também a avaliação dos riscos e ameaças à validade. Foram definidos o contexto, hipóteses, variáveis, participantes, o projeto experimental, a instrumentação e a avaliação de validade do estudo. Após o planejamento o estudo experimental estava totalmente elaborado e pronto para execução.

\subsubsection{Seleção do Contexto}

O estudo foi realizado pelo próprio pesquisador que o definiu. Foi utilizado um conjunto de serviços web fornecedor e consumidor RESTful e SOAP-WSDL desenvolvidos utilizando a linguagem de programação Java. Inicialmente pretendia-se utilizar um conjunto de programas representativos dos programas que utilizavam web services RESTful e SOAP-WSDL, neste caso, a solução seria usar aplicações reais para análise dos critérios de manutenibilidade. Porém, ao iniciar a busca por programas com código-fonte disponível que pudessem ser utilizados no experimento foi constatado que nem todas as aplicações encontradas poderiam ser utilizadas em razão da dificuldade em encontrar aplicações RESTful e SOAP-WSDL com baixo acoplamento em Java que usam o padrão de projeto MVC com código fonte disponível e adequado ao experimento pretendido.

Dessa forma, optou-se por desenvolver uma arquitetura adequada para o experimento realizado. A arquitetura desenvolvida contribuiu de forma significativa para a coleta dos dados e será detalhada melhor na Seção 6.3.

\subsubsection{Hipóteses}

A hipótese deste estudo é que os sistemas concebidos e implementados utilizando a tecnologia de web services RESTful são mais fáceis de manter do que os que foram concebidos e implementados usando a tecnologia SOAP-WSDL. "Mais fácil de manter", neste contexto, significa que os programadores levam menos tempo para executar uma tarefa de manutenção, ou que a tarefa exigida requer poucas mudanças no código. Isso também significa que os programadores perceberam a mudança como conceitualmente mais fácil 
ou que se depararam com menos erros durante a tarefa de manutenção. A manutenção é definida em termos das variáveis usadas para medir o desempenho dos sujeitos.

O estudo executado busca identificar características pouco exploradas no domínio da manutenibilidade de softwares orientados a serviço. Desse modo as hipóteses propostas não pretendem ser definitivas, mas sim fornecer evidências sobre as questões estudadas e que posteriormente possam ser utilizadas como referência para novos estudos na área.

Portanto, a metodologia assim como as formulações das hipóteses realizadas nesta pesquisa estão de acordo com os estudos de Perepletchikov (Perepletchikov e Ryan, 2011) no seu experimento controlado para avaliar o impacto do acoplamento na manutenção de Software Orientado a Serviço.

Com base nessas informações foi definida a seguinte pergunta que pretende ser respondida com este trabalho, considerando para isso uma hipótese nula e uma hipótese alternativa:

Os web services RESTful são mais manuteníveis do que os web services SOAP-WSDL no lado do servidor ou fornecedor de serviço web?

Para avaliar a manutenibilidade dos web services RESTful e SOAP-WSDL foram definidas as seguintes hipóteses:

\section{Hipótese 1}

Hipótese $\operatorname{Nula}\left(H_{0}\right)$ : Não existe diferença de manutenibilidade entre as abordagens de web services RESTful e SOAP-WSDL do lado do servidor ou provedor de serviços web.

$$
\left.H_{0}: \text { Manutenibilidade(RESTful }\right)=\text { Manutenibilidade(SOAP-WSDL) }
$$

Hipótese Alternativa $\left(H_{1}\right)$ : Existe diferença de manutenibilidade entre as abordagens de web services RESTful e SOAP-WSDL do lado do servidor ou provedor de serviços web.

$H_{1}$ : Manutenibilidade(RESTful) $\neq$ Manutenibilidade(SOAP-WSDL)

Do mesmo modo, admitindo-se que a manutenibilidade dos web services RESTful é maior do lado do servidor ou provedor de serviços web quanto do lado do cliente ou consumidor de serviços desenvolvidos com a tecnologia SOAP-WSDL.

Com isso, a pergunta 2 foi definida:

Os web services RESTful são mais manuteníveis do que os web services SOAP-WSDL no lado do cliente ou consumidor de serviço web?

\section{Hipótese 2}


Hipótese $\operatorname{Nula}\left(H_{0}\right)$ : Não existe diferença de manutenibilidade entre as abordagens de web services RESTful e SOAP-WSDL do lado do cliente ou consumidor de serviços web.

$H_{0}:$ Manutenibilidade(RESTful $)=$ Manutenibilidade(SOAP-WSDL)

Hipótese Alternativa $\left(H_{1}\right)$ : Existe diferença de manutenibilidade entre as abordagens de web services RESTful e SOAP-WSDL do lado do cliente ou consumidor de serviços web.

$H_{1}$ : Manutenibilidade(RESTful) $\neq$ Manutenibilidade(SOAP-WSDL)

\subsection{Seleção dos Indivíduos}

Como o estudo em questão exige o conhecimento das diferentes tecnologias de desenvolvimento de web services e bastante tempo de dedicação, o experimento foi realizado pelo próprio pesquisador que o definiu. Após preparar o ambiente do experimento, a descrição e especificação e o desenvolvimento dos serviços web RESTful e SOAP-WSDL foi oferecido um curso de web services Java para a execução do experimento com os alunos da disciplina de Padrões de Projeto no Desenvolvimento Web que possui os pré-requisitos para as disciplinas de Engenharia de Software e Técnicas de Programação Web na Universidade de São Paulo.

Para participar do curso foi estabelecido o critério rigoroso, sendo necessário ter os conhecimentos básicos de Java para web, XML e arquitetura cliente-servidor. No processo seletivo foram selecionados 10 alunos. Os sujeitos foram divididos aleatoriamente em dois grupos: Grupo A e Grupo B.

O curso serviu para introduzir alguns conceitos básicos sobre Introdução aos conceitos e definições de web services, desenvolvimento de web services SOAP-WSDL utilizando a API JAX-WS ${ }^{3}$ e desenvolvimento de web services RESTful utilizando a API JAX-RS ${ }^{4}$.

A primeira fase envolveu ensinar os conceitos gerais dos web services utilizados no estudo para os alunos. Não há dados experimentais coletados durante o primeiro dia do curso. A segunda fase foi à experiência real, em que os alunos do curso executaram tarefas de manutenção; eles realizaram as tarefas e os dados foram coletados. Todos os alunos estavam matriculados no curso (para os três dias de curso).

O curso teve carga horária total de 12 horas e foi realizado nos dias:

$1^{\text {o }}$ Dia - 23/11/2011 Horário: 19:00hs até 23:00hs

\footnotetext{
${ }^{3}$ http://jax-ws.java.net/

${ }^{4}$ http://jcp.org/about Java/communityprocess/final/jsr311/index.html
} 
$2^{\circ}$ Dia - 30/11/2011 Horário: 19:00hs até 23:00hs

$3^{\circ}$ Dia - 07/12/2011 Horário: 19:00hs até 23:00hs

Carga horária diária: 4hs

Carga Horária Total: 12 hs

Horário do Curso: 19:00hs às 23:00hs

Seria conveniente utilizar no estudo, um número maior de indivíduos para que possíveis diferenças relacionadas à manutenção dos web services RESTful e SOAP-WSDL pudessem ser identificadas. Espera-se que a documentação gerada neste estudo possa servir como base para que o experimento possa ser replicado com um número maior de participantes.

\subsubsection{Variáveis}

Variáveis Independentes: Foram identificadas neste experimento as seguintes variáveis:

1 - A Linguagem de Programação Java

2 - Servidor ou fornecedor do web service RESTful

3 - Cliente ou consumidor do web service RESTful

4 - Servidor ou fornecedor do web service SOAP-WSDL

5 - Cliente ou consumidor do web service SOAP-WSDL

6 - Informações sobre os sujeitos: Experiência e Treinamento

7 - Tarefas de Manutenção descritas no próximo capítulo.

Variáveis Dependentes: As variáveis dependentes identificadas neste estudo são:

1 - Tempo gasto na manutenção do servidor ou fornecedor do web service RESTful $T S_{R E S T}$

2 - Tempo gasto na manutenção do cliente ou consumidor do web service RESTful $T C_{R E S T}$

3 - Tempo gasto na manutenção do servidor ou fornecedor do web service SOAP-WSDL $-T S_{S O A P}$

4 - Tempo gasto na manutenção do cliente ou consumidor do web service SOAP-WSDL $-T C_{S O A P}$ 
5 - Número de modificações do servidor ou fornecedor do web service RESTful $N S_{R E S T}$

6 - Número de modificações do cliente ou consumidor do web service RESTful $N C_{R E S T}$

7 - Número de modificações do servidor ou fornecedor do web service SOAP-WSDL $N S_{S O A P}$

8 - Número de modificações do cliente ou consumidor do web service SOAP-WSDL $N C_{S O A P}$

9 - Complexidade de modificação do servidor ou fornecedor do web services RESTful - MCS $R E S T$

10 - Complexidade de modificação do cliente ou consumidor do web services RESTful - $M C C_{R E S T}$

11 - Complexidade de modificação do servidor ou fornecedor do web services SOAP-WSDL - $M C S_{S O A P}$

12 - Complexidade de modificação do cliente ou consumidor do web services SOAP-WSDL - $M C C_{S O A P}$

\subsubsection{Descrição da Instrumentação do Experimento}

Conforme apresentado anteriormente o objetivo principal do experimento é avaliar a manutenibilidade entre as abordagens de web services RESTful e SOAP-WSDL. Para a avaliação da manutenibilidade foi necessário elaborar uma arquitetura adequada. Desse modo, o experimento teve início com o desenvolvimento dos fornecedores e consumidores dos web services RESTful e SOAP-WSDL na linguagem de programação Java. Durante a atividade de desenvolvimento foi instalada uma wiki open source, a mediawiki ${ }^{5}$, no servidor GARAPA do laboratório Intermídia na Universidade de São Paulo (USP), para auxiliar na documentação dos web services RESTful e SOAP-WSDL. Observou-se que, para o contexto do experimento, o uso da ferramenta colaborativa da wiki no servidor "GARAPA" foi suficiente para atender às necessidades da documentação dos web services.

Após o termino do desenvolvimento e da instalação da wiki foram elaboradas quatro tarefas que os alunos participantes do curso deveriam executar, sendo elas, duas no lado do fornecedor e duas do lado do consumidor dos web services RESTful e SOAP-WSDL.

\footnotetext{
${ }^{5}$ http://www.mediawiki.org/wiki/MediaWiki
} 
Por último, para a avaliar a manutenibilidade dos web services RESTful e SOAPWSDL, estabeleceu-se quais os parâmetros e as métricas deveriam ser utilizadas no experimento, após avaliar a manutenibilidade, foi realizada uma comparação estatística para posterior análise.

\subsubsection{Validade}

Um fator que pode comprometer a validade interna deste experimento é o grau de experiência do pesquisador para o desenvolvimento dos fornecedores e consumidores dos web services RESTful e SOAP-WSDL. Outro fator que pode afetar a validade interna é o domínio e a complexidade dos programas utilizados. Para mitigar esse fator foram utilizados programas de domínios e complexidades de um sistema de gerenciamento educacional, facilmente compreensível pelos participantes, para não haver risco de que os programas fossem desenvolvidos para favorecer os resultados sobre os critérios de manutenibilidade.

O Software Orientado a Serviços foi desenvolvido especificamente para este estudo, destinado a apoiar a investigação das hipóteses experimentais apresentados na Seção 5.2.5. O sistema foi baseado em uma aplicação web para apoio ao Sistema de Informação de Ambiente Universitário (SInAU), que foi vagamente inspirado nas regras e procedimentos comuns de uma gestão acadêmica. A versão experimental do SInAU foi composta por web services distintos implementados usando plataforma Java EE 6. O sistema original foi projetado para fornecer suporte para as avaliações práticas utilizadas no curso de web services RESTful e SOAP-WSDL. Note que o domínio de aplicação escolhido (gerenciamento educacional) teve a vantagem de ser facilmente compreensível pelos participantes, garantindo assim que os requisitos do sistema podem ser facilmente interpretados.

Durante avaliação de validade do experimento são considerados os riscos que podem comprometer os resultados e conclusões obtidas no experimento.

A validade do experimento corresponde à habilidade de chegar a uma conclusão correta sobre os relacionamentos entre o tratamento e os resultados obtidos no experimento. Uma das ameaças a validade de conclusão é a confiabilidade das métricas. Neste estudo, as métricas avaliadas foram extraídas automaticamente pelas ferramentas do Netbeans ${ }^{6}$ e pela norma ISO 9126 por meio da aplicação desenvolvida, com isso acredita-se que a repetição do experimento por diferentes pesquisadores produzirá resultados semelhantes aos obtidos neste estudo. Além disso, a avaliação estatística foi feita por métodos adequados, verificando sempre a normalidade do conjunto de dados. Foi aplicado o teste t de student para conjuntos com distribuição de dados normal por meio do plugin do excel ${ }^{7}$ com nível de significância $(\alpha)=0.05$.

\footnotetext{
${ }^{6}$ http://plugins . netbeans.org/plugin/9494/simple-code-metrics

${ }^{7}$ http://www. portalaction.com.br/
} 
A validade interna depende da existência de uma relação causal entre tratamento e resultado. Logo, para garantir que este princípio não seja violado, os responsáveis pelo experimento devem garantir que não há interferência de algum fator que não tenha sido medido ou controlado, na relação causa-efeito.

Para garantir a validade de construção o pesquisador deve assegurar que o tratamento reflete a construção da causa, e o resultado a construção do efeito. Para isso foram selecionadas ferramentas para auxiliar a avaliação.

A repetição do experimento com um número maior de participantes é interessante para avaliar as possíveis diferenças nos resultados, a partir das tarefas executadas por diferentes pessoas. A validade externa do experimento refere-se à capacidade de generalização dos resultados obtidos. Como o escopo do estudo se restringiu a programas do domínio de estrutura de dados e o conjunto de programas dentro desse domínio é bastante abrangente, o conjunto de programas não ameaça a validade do estudo para esse domínio.

\subsection{Considerações Finais}

Neste capítulo foram apresentadas a definição e o planejamento do estudo experimental conduzido com base nos conceitos apresentados por Wohlin et al. (2000) e descritos no Capítulo 3. A definição e planejamento do experimento representam os passos que devem ser seguidos para execução e análise dos resultados. No Capítulo 6 são detalhadas as fases de preparação e execução do experimento. 



뭉

\section{Preparação do Ambiente e Execução do Experimento}

\subsection{Considerações Iniciais}

pós a definição e o planejamento do estudo a próxima etapa no processo de ex-
perimentação é a execução. Esta é uma etapa muito delicada no experimento,
pois envolve o fator humano. A coleta dos dados deve ser realizada de maneira que não cause efeito significativo no processo sendo estudado. Nesta etapa também é realizada a validação preliminar dos dados experimentais.

Na preparação são definidos os indivíduos que participarão do experimento e os recursos para a execução do estudo. Na execução os participantes desempenham as tarefas definidas de acordo com os diferentes tratamentos, finalizando com a coleta de dados.

Neste capítulo são descritos como ocorreram à preparação e a execução do experimento conduzido. Na Seção 6.2 são apresentados os principais conceitos sobre a fase de preparação do ambiente do experimento e descrição dos web services RESTful e SOAP-WSDL desenvolvidos para o experimento controlado. Na Seção 6.3 são apresentados conceitos sobre a fase de execução e na Seção 6.4 são apresentadas as considerações finais deste capítulo. 


\subsection{Preparação do Experimento}

Antes que o experimento fosse executado algumas tarefas foram realizadas, como a preparação do material e o desenvolvimento dos web services RESTful e SOAP-WSDL a serem utilizados.

\subsubsection{O Ambiente de Manutenção}

O ambiente de manutenção para realização do experimento foi construído usando os seguintes artefatos:

- Máquina Virtual devidamente instalada e configurada no laboratório;

- A documentação e especificação de cada web services analisado e

- Código fonte dos fornecedores e consumidores RESTful e SOAP-WSDL.

Dentre os benefícios encontrados com a adoção da máquina virtual pode-se citar: a portabilidade, não só das ferramentas e do sistema operacional, mas de toda a configuração de sistema, a possibilidade de replicação e geração de backup de forma prática e relativamente rápida, a viabilidade de evolução de configurações de ferramentas sem o comprometimento de uma configuração já estável, a possibilidade de interrupção e continuação de uma tarefa em datas diferentes mantendo-se o mesmo estado do sistema operacional e dos programas utilizados e a persistência direta dos resultados gerados internamente pela cópia em uso (Prado, 2009). Além disso, podemos citar outro fator muito importante e fundamental para o sucesso do experimento que a máquina virtual possibilitou aos alunos utilizar o container web com privilégios de administrador.

O ambiente construído para a avaliação da manutenibilidade entre as abordagens de web services RESTful e SOAP-WSDL possui as seguintes características:

- Sistema operacional Linux, distribuição Ubuntu - versão 11.10, com um servidor de gerenciador de versões por meio de um repositório SVN Server versão 1.6.12 (Servidor GARAPA no laboratório do Intermídia)

- Sistema Operacional Windows XP utilizado nas máquinas virtuais e no curso de web services para realização das tarefas de manutenção.

- Container Web Apache Tomcat $7^{2}$

\footnotetext{
${ }^{1}$ http://subversion.apache.org/

${ }^{2}$ http://tomcat.apache.org/download-70.cgi
} 
- IDE $^{3}$ de desenvolvimento do Netbeans versão 7.0.1

- MySQL Driver JDBC versão 5.1.13 ${ }^{4}$

- Especificações JAX-RS ${ }^{5}$, JAX-WS ${ }^{6}$ e JPA $2.0^{7}$

- Implementação de Referência Jersey ${ }^{8}, \mathrm{METRO}^{9}$ e Eclipse $\operatorname{Link}^{10}$

- Java SE Development Kit - JDK $7^{11}$

- Plugin da ferramenta Netbeans Simple Code Metrics ${ }^{12}$ para obtenção das métricas diretas a partir do código fonte

\subsubsection{Descrição dos Web Services RESTful e SOAP-WSDL}

Os programas desenvolvidos para o experimento estão implementados na linguagem de programação Java. A Figura 6.1 corresponde aos dez web services desenvolvidos no sistema web para apoio ao Sistema de Informação de Ambiente Universitário (SInAU). Sendo eles, um serviço web para cada entidade do sistema (SInAU). Além disso, cada web service desenvolvido RESTful e SOAP-WSDL são responsáveis por fornecer os serviços de CRUD (Create, Read, Update e Delete) correspondente a sua entidade. Além das operações básicas de CRUD, foram implementadas operações específicas para cada entidade referentes ao sistema de gerenciamento educacional SInAU, como por exemplo, a entidade "Curso" possui o método getNumeroDeBolsistas() que retorna o número de bolsista de um determinado curso. Portanto, para cada um dos dez web services RESTful e SOAP-WSDL existem os seus respectivos clientes correspondentes que consomem os serviço web por meio das quatros operações básicas e específicas de cada entidade do sistema de informação SInAU.

É importante destacar que todos os gráficos desta seção foram gerados à partir dos dados referentes aos resultados obtidos pelo plugin Simple Code Metrics do Netbeans que calculou automaticamente todas as métricas diretas como: o número de linhas de código (LOC), o número de classes, o número de métodos e a complexidade ciclomática, por meio do código fonte de cada projeto cliente e servidor RESTful e SOAP-WSDL.

\footnotetext{
${ }^{3}$ Integrated Development Environment

${ }^{4}$ http://dev.mysql.com/doc/refman/5.1/en/connector-j-reference-configuration-properties . html

${ }^{5}$ http://java.sun.com/developer/technicalArticles/WebServices/jax-rs/index.html

${ }^{6}$ http://jax-ws.java.net/

${ }^{7}$ http://jcp.org/aboutJava/communityprocess/final/jsr317/index.html

${ }^{8}$ http: //jersey.java.net/

${ }^{9}$ http://metro.java.net/

${ }^{10}$ http://www.eclipse.org/org/press-release/20080317_Eclipselink.php

${ }^{11}$ http://www . oracle.com/technetwork/java/javase/downloads/index.html

12 http://plugins.netbeans.org/plugin/9494/simple-code-metrics
} 


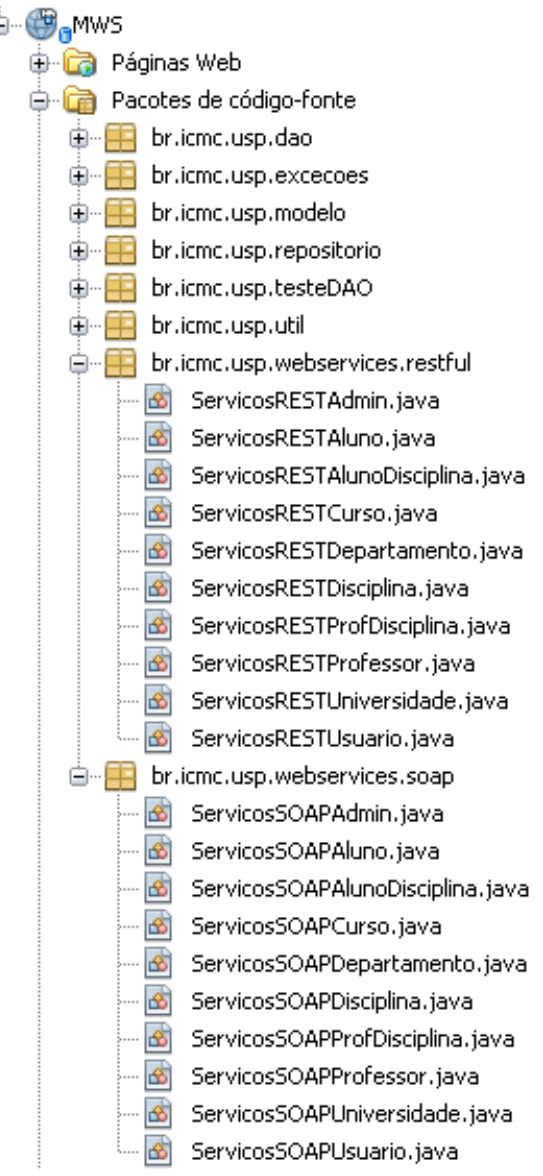

Figura 6.1: Projeto Netbeans dos web services RESTful e SOAP-WSDL

A Figura 6.2 apresenta a quantidade em linhas de código (LOC) existentes em cada programa cliente e servidor RESTful e SOAP-WSDL. Essas informações fornecem uma idéia do grau de complexidade dos programas.

A Figura 6.3 mostra o número de classes de cada cliente e servidor dos web services RESTful e SOAP-WSDL desenvolvido para o experimento.

A Figura 6.4 mostra o número de métodos de cada cliente e servidor dos web services RESTful e SOAP-WSDL desenvolvido para o experimento.

A média da complexidade ciclomática de cada cliente e servidor dos web services RESTful e SOAP-WSDL está representada na Figura 6.5, além disso, podemos visualizar tanto os provedores quanto os clientes RESTful e SOAP-WSDL foram desenvolvidos com a mesma complexidade ciclomática tanto do lado servidor quanto do lado do cliente.

A arquitetura utilizada para avaliar a manutenibilidade entre as abordagens de web services RESTful e SOAP-WSDL será descrita na Seção 6.3, além disso, para não dificultar as tarefas de manutenibilidade do experimento controlado não houve também a necessidade de implementar um repositório UDDI para os web services SOAP-WSDL, pois o interesse da pesquisa é a manutenção dos web services. 


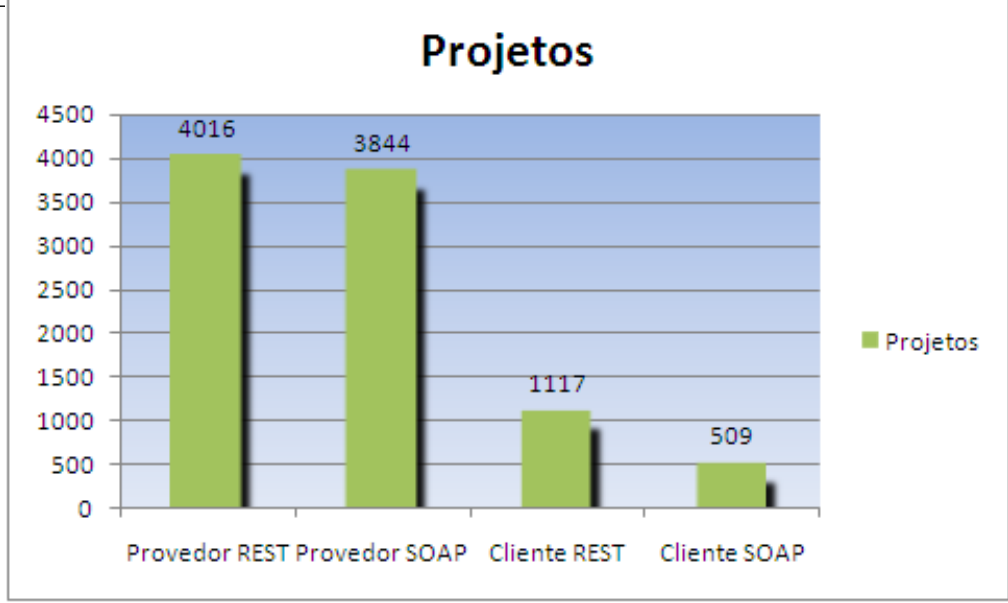

Figura 6.2: Linhas de Código de cada Projeto Provedor e Cliente RESTful e SOAP-WSDL utilizados no experimento

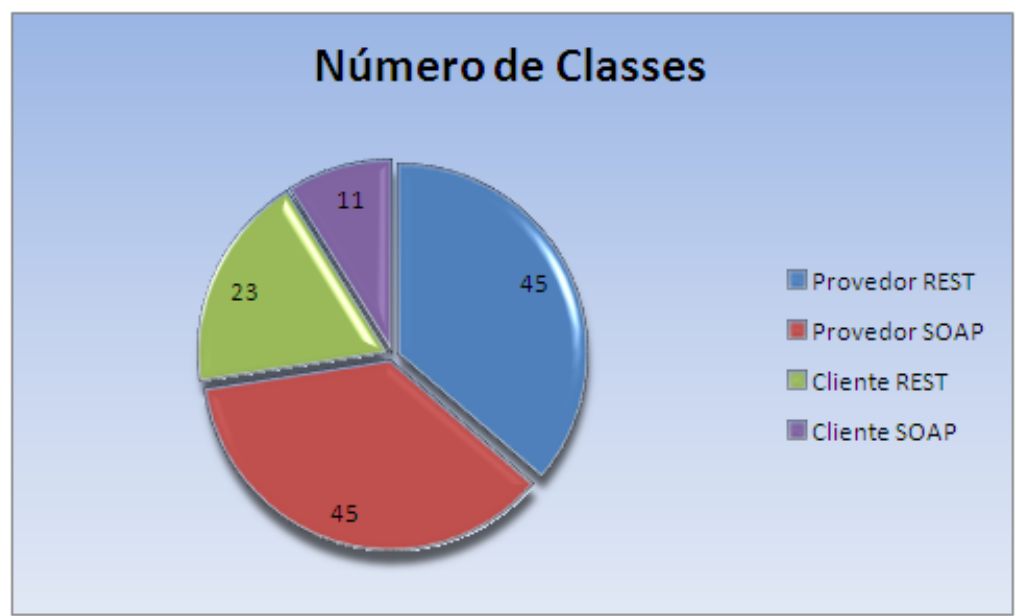

Figura 6.3: Número de Classes de cada projeto Provedor e Cliente RESTful e SOAP-WSDL utilizados no experimento

\subsection{Execução do Experimento}

Esta experiência foi um "within subjects" por meio dos sujeitos participantes do experimento. De acordo com as variáveis independentes descritas na Seção 3.4, os participantes do experimento cursaram as disciplinas de Padrões de Projeto no Desenvolvimento Web (SCC0266) que tem como pré-requisito as disciplinas Programação Orientada a Objetos (SCC0204), Técnicas de Programação para Web (SCC0263) e Engenharia de Software I (SCC0121) ${ }^{13}$. Além da disciplina os melhores alunos selecionados tinham conhecimentos da linguagem Java para web, XML e arquitetura cliente-servidor que foram exigidos como pré-requisito para o curso de web services.

\section{Arquitetura dos web services RESTful e SOAP-WSDL}

\footnotetext{
${ }^{13}$ https://sistemas . usp.br/jupiterweb/listarCursosRequisitos?coddis=SCC0266
} 


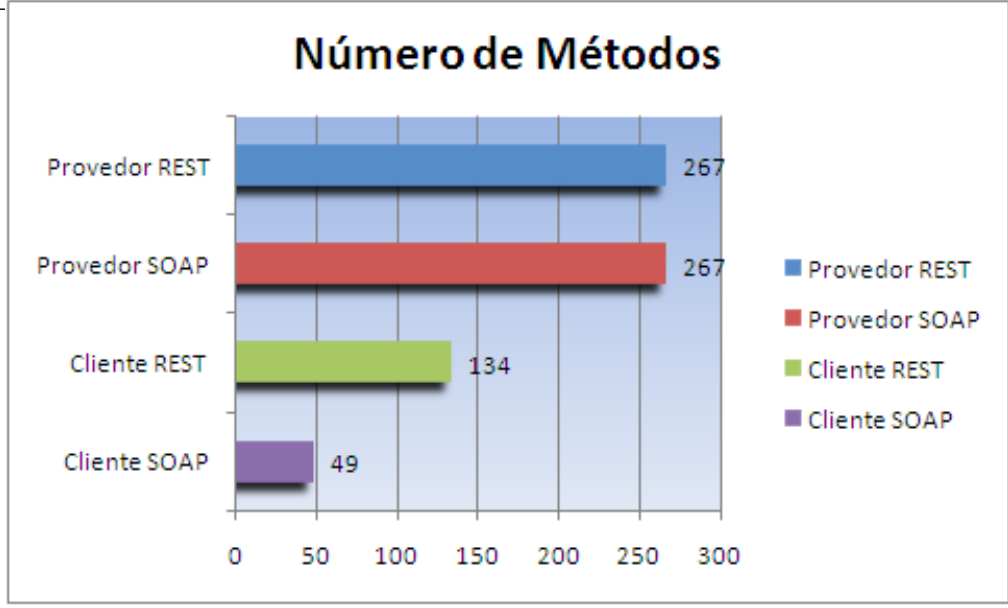

Figura 6.4: Número de Métodos de cada projeto Provedor e Cliente RESTful e SOAP-WSDL utilizados no experimento

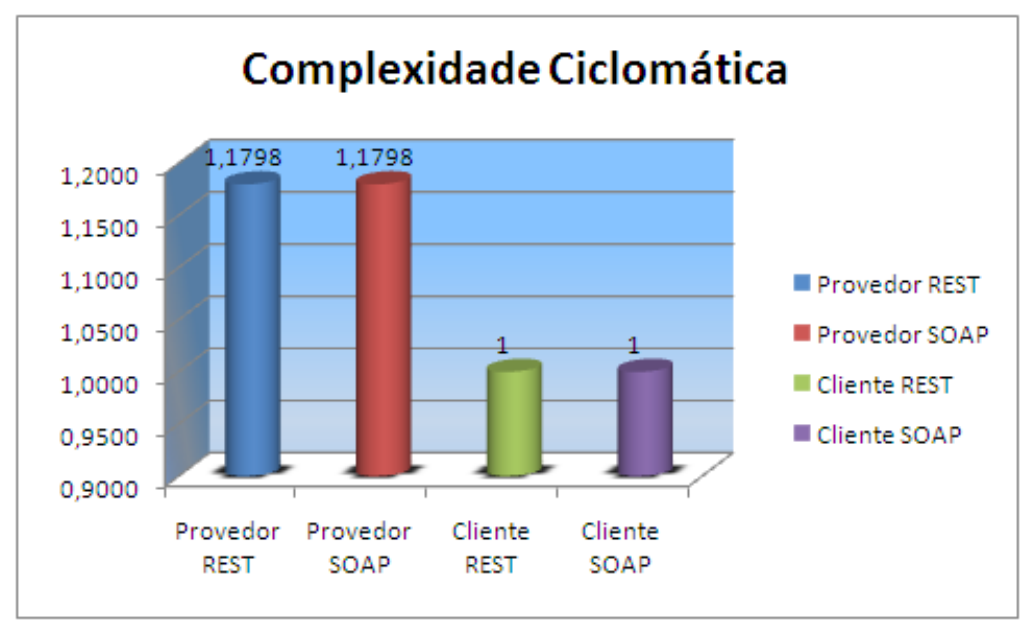

Figura 6.5: Média da Complexidade Ciclomática de cada Provedor e Cliente RESTful e SOAP-WSDL utilizados no experimento

A arquitetura desenvolvida para o experimento utilizou os padrões de projeto: Data Access Object (DAO) e o padrão de projeto ModelView-Controller (MVC) no lado da aplicação cliente e uma arquitetura de duas camadas ${ }^{14}$ no lado da aplicação servidor, para obter o menor acoplamento possível e facilitar a tarefa de manutenção para os alunos, pois o interesse da pesquisa é a manutenção dos web services. A Figura 6.6 mostra a arquitetura dos servidores e clientes dos web services RESTful e SOAP-WSDL, por meio da figura é possível visualizar que as camadas: View e Controller são idênticas para ambos os consumidores RESTful e SOAP-WSDL, diferenciando apenas na camada Model com os serviços web RESTful e SOAP-WSDL. Portanto, a arquitetura é constituída por aplicações independentes.

\footnotetext{
${ }^{14}$ Camada de negócio e de persistência ou armazenamento de dados.
} 
CAPÍTULO 6. PREPARAÇÃO DO AMBIENTE E EXECUÇÃO DO EXPERIMENTO

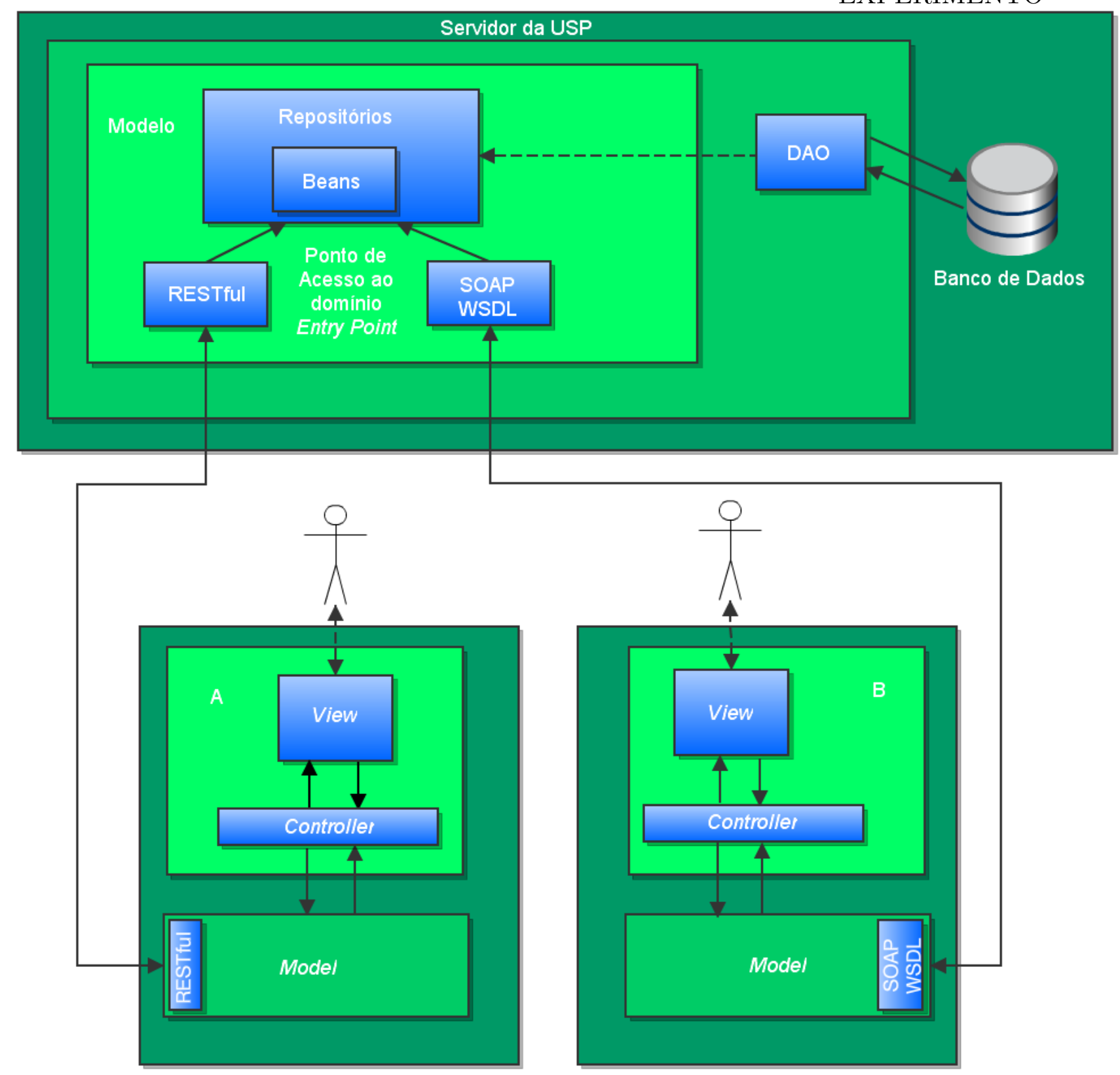

Figura 6.6: Arquitetura utilizada no experimento

No lado do servidor existe apenas uma aplicação que fornece tanto o serviço RESTful quanto o seu complemento e equivalente em SOAP-WSDL. No entanto, o componente de negócio que depende do DAO usa a interface mais simples exposta pelo DAO para seus clientes do repositório. O DAO oculta completamente os detalhes de implementação da persistência ${ }^{15}$ dos dados de seus clientes. A interface exposta pelo DAO para clientes não se altera quando a implementação do código é modificada, este padrão permite que o DAO se adapte a diferentes regimes de armazenamento, sem afetar seus clientes ou os

\footnotetext{
${ }^{15} \mathrm{O}$ processo de armazenagem e captura de dados em um banco de dados é chamado de persistência.
} 
componentes de negócio. Essencialmente, o DAO funciona como um adaptador entre o componente e a fonte de dados.

Além disso, o DAO permite implementar o Repositório dentro do domínio da aplicação servidor, lembrando que ao utilizar o domínio, será referenciado pelas interfaces ou contratos, e o DAO ficará totalmente encapsulado e plugável, completamente substituível, pois a injeção de dependência diminui o acoplamento entre modelo de negócio e a base de dados.

É importante mencionar que a arquitetura descrita nesta seção foi utilizada apenas no $3^{\circ}$ dia de curso, pois os dois servidores de cada web services fazem parte da mesma aplicação como mostrado na Figura 6.1 para não replicar o código referente a camada View e a camada Controller, pois a única camada diferente é a camada do Model. A arquitetura utilizada possibilitou que uma única aplicação servidor pudesse atender ambos os clientes RESTful e SOAP-WSDL em tempo real. Sendo assim, no $2^{\circ}$ dia do curso de web services cada grupo recebeu uma cópia com projetos independentes dos servidores RESTful e SOAP-WSDL.

\section{Coleta de Dados}

Este experimento coletou dois conjuntos de dados. O primeiro conjunto de dados foi descritivo e foi usado para mostrar a homogeneidade entre os indivíduos e entre os grupos. Estes dados foram gerados pelos questionários dos indivíduos que completaram as tarefas que realizavam. Os dados dos estudantes foram usados para mostrar que o experimento foi livre de distorções em relação aos sujeitos. Os dados das tarefas foram usados para apoiar afirmações sobre as habilidades da arquitetura cliente-servidor e da linguagem de programação Java.

Para organizar melhor o experimento foram estabelecidos os seguintes identificadores:

1. Identificador dos alunos (1 a 5$)^{16}$ para cada grupo dos sujeitos;

2. Identificador dos grupos (Grupo A ou Grupo B) e

3. Identificador das tarefas (1 ou 2).

No primeiro dia do curso de web services foram coletados os dados referentes ao perfil de cada aluno por meio de questionário com o auxílio da ferramenta de questionários do Google ${ }^{17}$ como apresentado na Figura 6.7.

O primeiro dia do curso foi apenas introdutório, o experimento foi realizado no segundo e no terceiro dia de curso. No segundo dia do curso de web services cada sujeito ou

\footnotetext{
${ }^{16}$ Grupo A: REST01, REST02, REST03, REST04 e REST05

Grupo B: SOAP01, SOAP02, SOAP03, SOAP04 e SOAP05

${ }^{17}$ http: //docs.google.com/?utm_source=en-et-asblog\&utm_medium=et\&utm_campaign=pt
} 


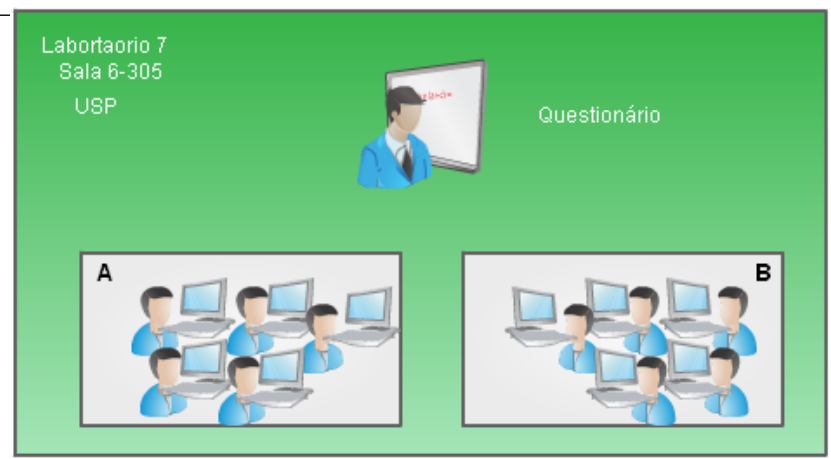

Figura 6.7: Questionário aplicado aos alunos no $1^{\circ}$ dia do curso de web services

aluno era obrigado a executar duas tarefas de modificação para os web services RESTful e SOAP-WSDL. O Grupo A modificou o servidor do web services RESTful enquanto os alunos do grupo B fizeram o inverso: eles modificaram o servidor do web services SOAP-WSDL.

Todos os indivíduos realizaram duas tarefas. Cada tarefa foi executada uma vez em cada um dos dois web services. Todos os participantes realizaram as tarefas na mesma ordem. As tarefas eram de natureza muito semelhante e não foram selecionadas para expor qualquer atributo particular. Ao final da primeira tarefa todos os participantes preencheram um formulário com o tempo de início da tarefa e o tempo final de cada tarefa antes de iniciar a execução da próxima tarefa.

As tarefas do $\mathbf{2}^{\mathbf{o}}$ dia do curso de $\boldsymbol{w e} \boldsymbol{b}$ services para cada grupo são descritas a seguir:

\section{Grupo A}

Tarefa 1 - Implementar o serviço web getMelhorAluno() como recurso da cópia do servidor RESTful (Manutenção Evolutiva):

/* Método que retorna o melhor aluno da disciplina */ public Aluno getMelhorAluno(Integer idDisciplina) throws ExcecaoDAO \{ /* Implementação do Método */ \}

Tarefa 2 - Implementar todos os dez web services da cópia do servidor RESTful para SOAP-WSDL (complementar os serviços RESTful) (Manutenção Adaptativa).

\section{Grupo B}




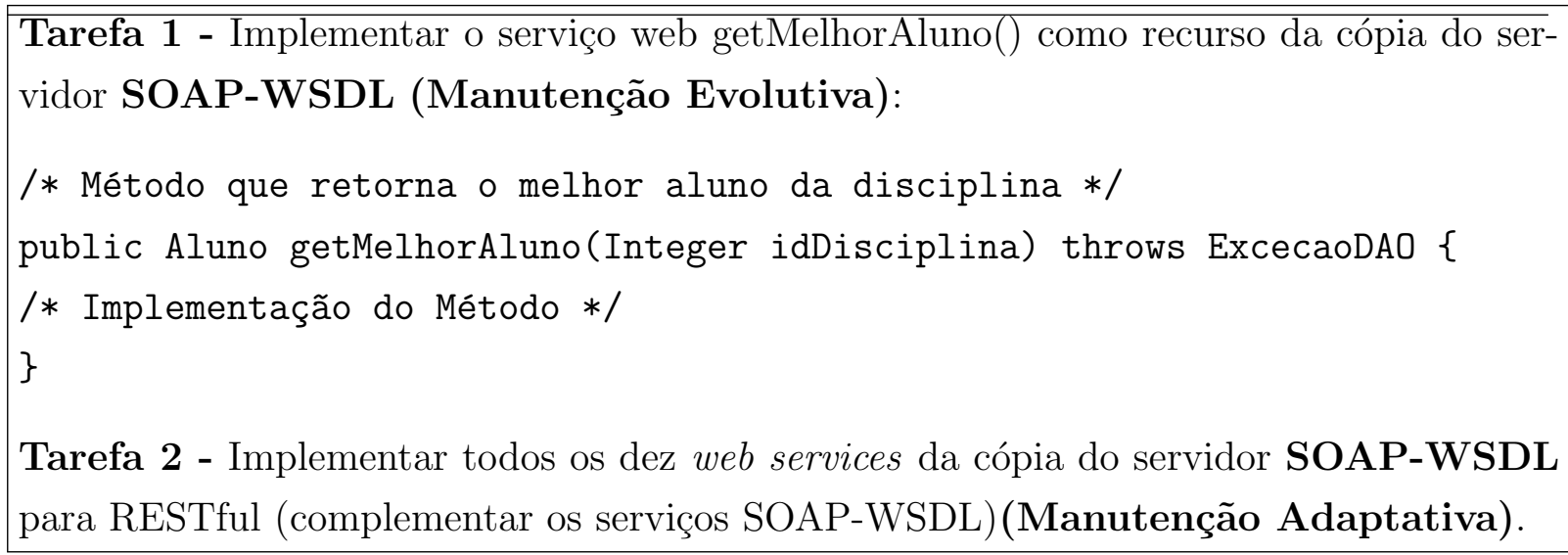

Tarefa 2 - Implementar todos os dez web services da cópia do servidor SOAP-WSDL para RESTful (complementar os serviços SOAP-WSDL)(Manutenção Adaptativa).

As tarefas do segundo dia foram executadas localmente na máquina virtual com uma cópia do servidor RESTful (identificadores SR1, SR2, SR3, SR4 e SR5) para os integrantes do Grupo A e uma cópia do servidor SOAP-WSDL (identificadores SS1, SS2, SS3, SS4 e SS5) para cada integrante do Grupo B. As atividades referentes as tarefas do segundo dia do curso de web services foram executadas localmente e estão ilustradas na Figura 6.8.

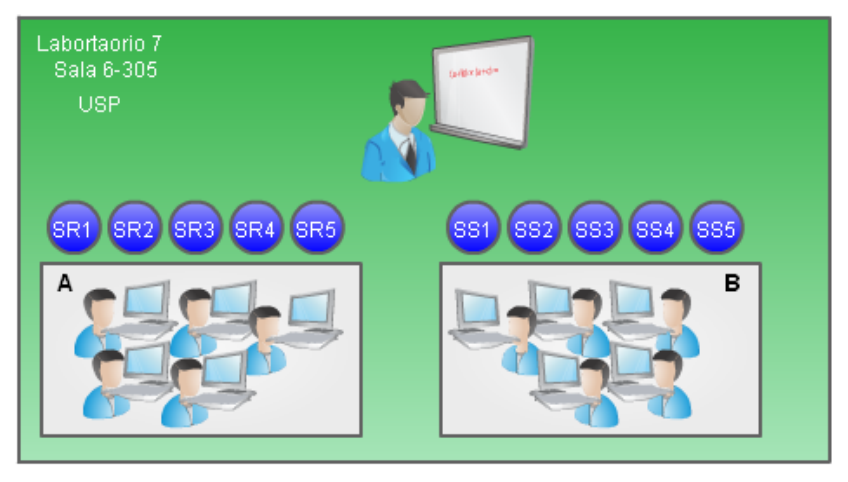

Figura 6.8: $2^{\circ}$ dia do curso de web services

Além disso, foi criado um repositório SVN para cada cópia dos servidores RESTful e SOAP-WSDL, após o término de cada tarefa, os alunos eram obrigados a fazer o commit das modificações realizadas para posterior análise do código-fonte, conforme mostra a Figura 6.9.

Após terminar todas as tarefas do lado do servidor, para o terceiro dia de curso foi estabelecido apenas uma tarefa, pois a idéia era reproduzir em laboratório um cenário real com uma aplicação servidor RESTful comunicando com um cliente RESTful em tempo real, da mesma forma o cenário foi replicado para clientes dos web services que consumiam o serviço web SOAP-WSDL.

A tarefa do $3^{\mathbf{o}}$ dia do curso de $\boldsymbol{w e b}$ services para cada grupo são descritas a seguir:

\section{Grupo A}




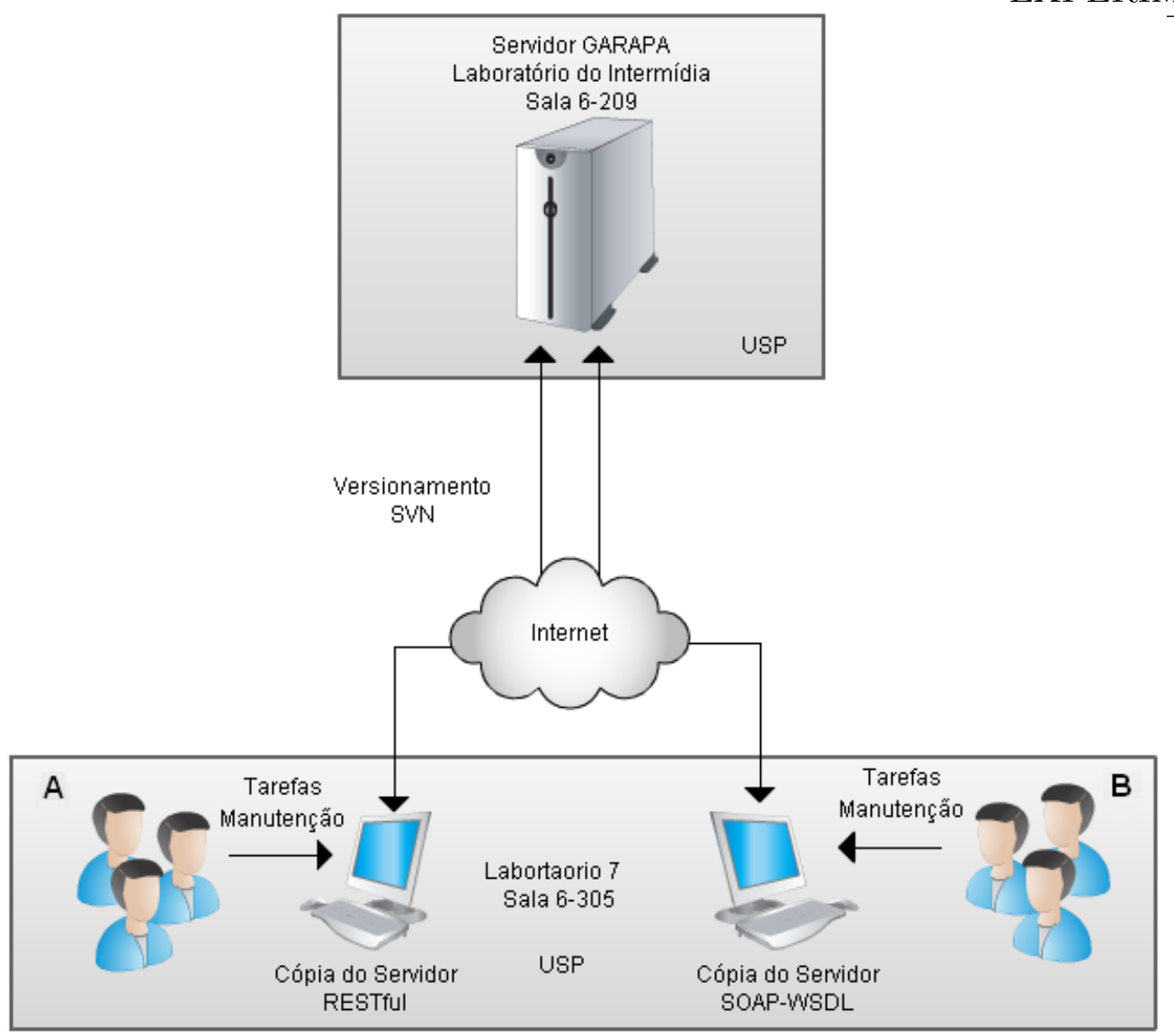

Figura 6.9: Organização do Experimento no $2^{\circ}$ dia de curso

Tarefa 1 - Desenvolver um cliente SOAP-WSDL a partir da cópia do cliente RESTful (Manutenção Adaptativa).

\section{Grupo B}

Tarefa 1 - Desenvolver um cliente RESTful a partir da cópia do cliente SOAP-WSDL (Manutenção Adaptativa).

Conforme mostra a Figura 6.10 a arquitetura elaborada para o experimento possibilitou que uma única aplicação servidor (identificadores SR (Servidor RESTful) e SS (Servidor SOAP-WSDL)) atendesse de forma distribuída tanto os clientes ou consumidores RESTful (identificadores CR1, CR2, CR3, CR4 e CR5) quanto os clientes SOAP-WSDL (identificadores CS1, CS2, CS3, CS4 e CS5) por meio dos protocolos SOAP e HTTP. Ambas as aplicações dos web services se comunicam através de arquivos XML por meio dos métodos HTTP-GET para as aplicações cliente-servidor RESTful e HTTP-POST para as aplicações desenvolvidas em SOAP-WSDL. 
CAPÍTULO 6. PREPARAÇÃO DO AMBIENTE E EXECUÇÃO DO EXPERIMENTO

Após a execução da tarefa no lado dos clientes dos web services estudados cada participante preencheu um formulário com o tempo de início da tarefa e o tempo final de cada tarefa.

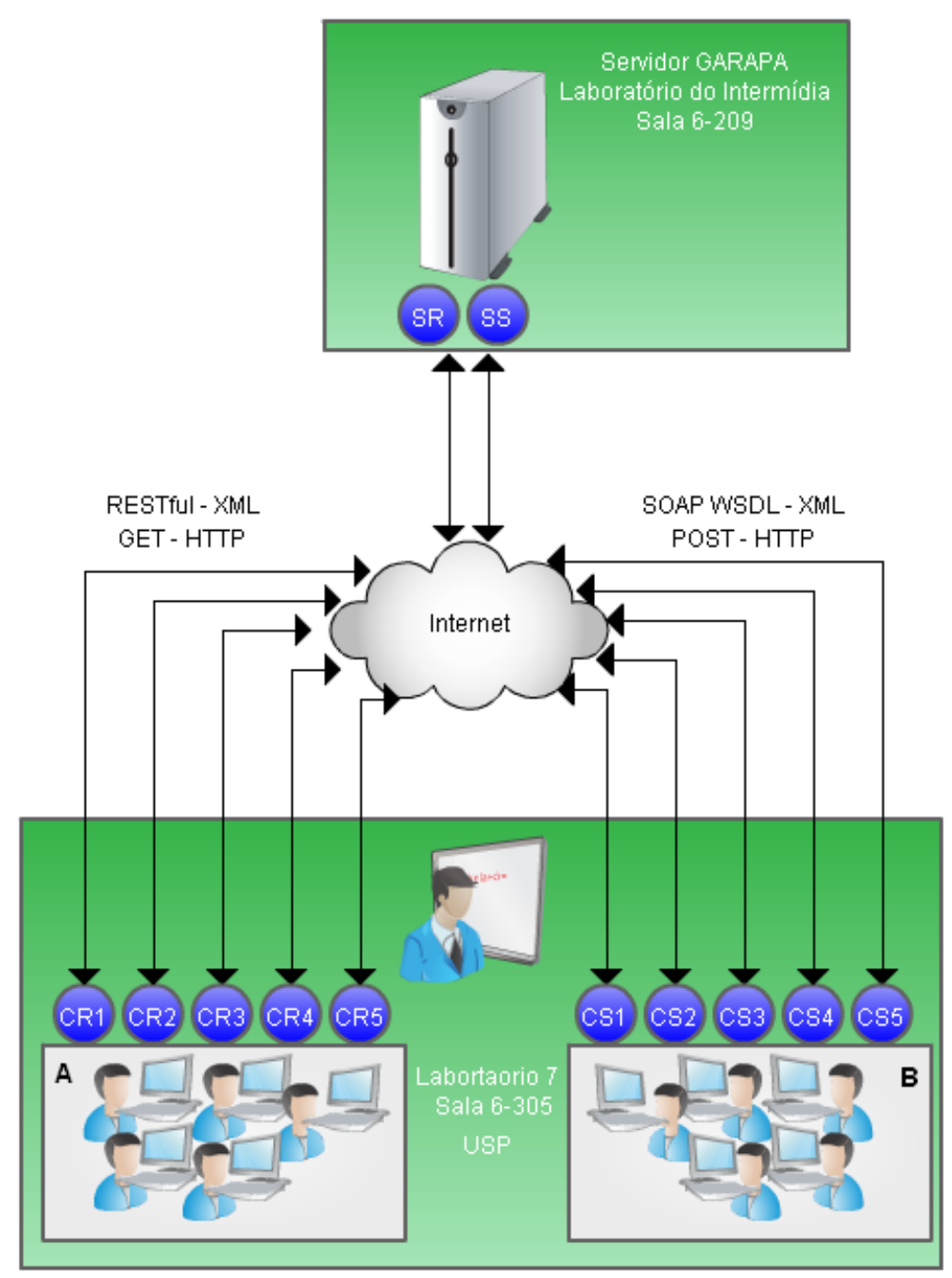

Figura 6.10: $3^{\circ}$ dia do curso de web services 
Além disso, foi criado um repositório SVN para cada cópia dos clientes RESTful

e SOAP-WSDL, e após o término de cada tarefa os alunos eram obrigados a fazer o commit das modificações realizadas para posterior análise do código-fonte conforme mostra a Figura 6.11.

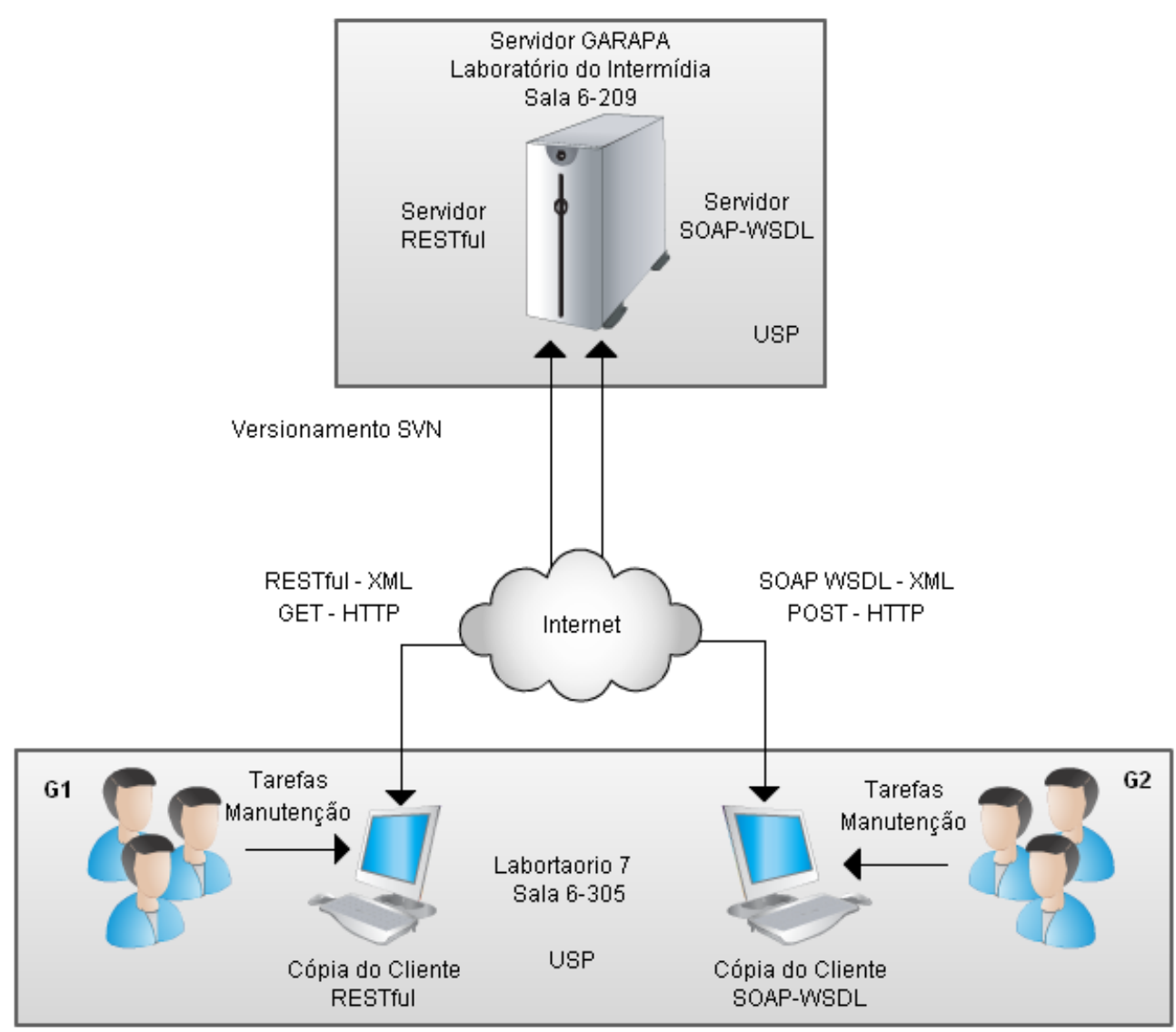

Figura 6.11: Organização do Experimento no $3^{\circ}$ dia de curso

\subsection{Considerações Finais}

Neste capítulo foi detalhado todo o processo de execução do experimento, desde a preparação do ambiente até os critério de Análise dos web services. A descrição dos passos executados no experimento é importante, pois permite a outros pesquisadores analisarem com mais detalhes o estudo e replicarem o experimento com uma maior facilidade. No Capítulo 7 serão apresentados os resultados após a condução do experimento controlado. 



\section{Capítulo 7 \\ Análise dos Resultados e Avaliação da Hipótese}

\subsection{Considerações Iniciais}

O estudo empírico (ou experimento controlado) apresentado neste capítulo se destina a avaliar e comparar a relação entre as métricas e as subcaracterísticas específicas de manutenibilidade investigadas. Especificamente, existem dois objetivos principais deste estudo, definidos de acordo com o quadro GQM de Basili (Mashiko e Basili, 1997):

1 - Avaliar a manutenibilidade dos web services SOAP-WSDL e RESTful no que diz respeito a modificabilidade do software, do ponto de vista dos engenheiros de software, assim como no contexto de um sistema de Software Orientado a Serviço empírico.

2 - Após a avaliação, comparar os valores do resultado e as relações da manutenibilidade para cada tipo de web service distinto.

Três testes $\mathrm{t}$ bicaudais pareados para amostras independentes foram realizados a fim de examinar o impacto da manutenibilidade em termos da modificabilidade de Software Orientado a Serviço de acordo com as hipóteses definidas na Seção 5.2.5.

Em resumo, os resultados indicam que existe uma associação estatisticamente significativa entre as métricas de modificabilidade (MC) apresentadas no Capítulo 4 para os web services RESTful e SOAP-WSDL. Isto, por sua vez, sugere que todas as métricas 
de manutenibilidade avaliadas podem ser utilizadas como indicadores da modificabilidade dos Softwares Orientados a Serviços (Perepletchikov e Ryan, 2011).

Além disso, neste capítulo são apresentados os resultados obtidos após a execução de toda avaliação e comparação da manutenibilidade entre as diferentes abordagens de web services: RESTful e SOAP-WSDL. Primeiramente, são mostrados os resultados referentes a cada web service, para que então estes dados possam ser comparados em relação ao mesmo programa implementado na outra abordagem de web service de interesse.

Também são descritos os passos realizados para a avaliação das hipóteses do experimento, os testes estatísticos utilizados e os resultados da avaliação de cada hipótese definida no Capítulo 5.

A análise dos resultados e a avaliação das hipóteses, assim como, todas as tabelas desta seção estão de acordo com os estudos de Perepletchikov (Perepletchikov e Ryan, 2011).

\subsection{Resultados no Lado do Servidor}

Para a coleta de dados como mencionado na seção anterior foram utilizadas as ferramentas Simple Code Metrics ${ }^{1}$ versão 6.1 da IDE $^{2}$ de desenvolvimento Netbeans e um servidor de gerenciador de versões por meio de um repositório SVN Server versão 1.6.12 para auxiliar na coleta de dados dos web services.

Para melhor visualizar o comportamento da amostra, considerando o número de elementos requeridos para cada abordagem de web services. A partir da Tabela 7.1 de dados e dos resultados obtidos com a avaliação, foram geradas as Tabelas 7.2 e 7.3 referentes ao segundo dia de curso dos web services. Além disso, por meio da Tabela 7.1, ou seja, a tabela de dados, podemos visualizar o identificador representado por ID, o tempo de início da tarefa representado por T.I., o tempo final representado por T.F., o tempo total gasto na tarefa de manutenção representado por T.T. dado em minutos, o número de modificações representado por No Mod. e por fim a Complexidade de Modificação ou Modification Complexity representado por MC (Perepletchikov e Ryan, 2011).

\footnotetext{
${ }^{1}$ http://plugins.netbeans.org/plugin/9494/simple-code-metrics

${ }^{2}$ Integrated Development Environment
} 
Tabela 7.1: Tabela de dados referentes às Tarefas 1 e 2 do servidor RESTful

\begin{tabular}{ccccccc}
\hline ID & Task & T.I. & T.F. & T.T.(min) & N $^{\text {M Mod. }}$ & MC \\
\hline rest01 & 1 & $19: 05$ & $20: 50$ & 105 & 104 & 1,009615385 \\
& 2 & $21: 00$ & $22: 20$ & 80 & 1010 & 0,079207921 \\
\hline rest02 & 1 & $19: 10$ & $21: 00$ & 110 & 98 & 1,12244898 \\
& 2 & $21: 00$ & $22: 12$ & 72 & 998 & 0,072144289 \\
\hline rest03 & 1 & $19: 08$ & $20: 56$ & 108 & 101 & 1,069306931 \\
& 2 & $21: 00$ & $22: 18$ & 78 & 978 & 0,079754601 \\
\hline rest04 & 1 & $19: 15$ & $21: 10$ & 115 & 107 & 1,074766355 \\
& 2 & $21: 10$ & $22: 17$ & 77 & 987 & 0,078014184 \\
\hline rest05 & 1 & $19: 07$ & $20: 59$ & 112 & 108 & 1,037037037 \\
& 2 & $21: 00$ & $22: 15$ & 75 & 996 & 0,075301205 \\
\hline
\end{tabular}

Tabela 7.2: Estatística básica referente à Tarefa 1 do servidor RESTful

\begin{tabular}{|cc|}
\hline Informação & Valor \\
\hline Mínimo & 1,009615385 \\
Média & 1,062634937 \\
Mediana & 1,069306931 \\
Máximo & 1,12244898 \\
Desvio Padrão da Média & 0,019020689 \\
Desvio Padrão & 0,042531553 \\
Variância & 0,001808933 \\
LI (IC Média) & 1,00982504 \\
LS (IC Média) & 1,115444835 \\
\hline
\end{tabular}

Tabela 7.3: Estatística básica referente à Tarefa 2 do servidor RESTful

\begin{tabular}{|cc|}
\hline Informação & Valor \\
\hline Mínimo & 0,072144289 \\
Média & 0,07688444 \\
Mediana & 0,078014184 \\
Máximo & 0,079754601 \\
Desvio Padrão da Média & 0,001412239 \\
Desvio Padrão & 0,003157862 \\
Variância & $9,9721 \mathrm{E}-06$ \\
LI (IC Média) & 0,072963436 \\
LS (IC Média) & 0,080805444 \\
\hline
\end{tabular}


Ao observar a Tabela 7.1 pode-se verificar que o tempo gasto na primeira tarefa de manutenção do servidor do web service RESTful foi muito maior em relação ao tempo gasto na segunda tarefa do mesmo serviço web. Isso pode ter acontecido devido ao primeiro contato do Grupo A com o código-fonte, pois ao implementar uma nova funcionalidade os alunos precisaram entender primeiro todo o código-fonte para executar a tarefa de manutenção.

A seguir a Tabela 7.4 mostra os dados obtidos da tarefa de manutenção do servidor SOAP-WSDL. Em seguida, as Tabelas 7.5 e 7.6 apresentam os resultados dos cálculos da estatística básica referentes às Tarefas 1 e 2 respectivamente do servidor SOAP-WSDL. Além disso, é possível observar que todas as amostras analisadas obtiveram uma variância pequena, aumentando dessa forma a confiança do experimento controlado.

Tabela 7.4: Tabela de dados referentes às Tarefas 1 e 2 do servidor SOAP-WSDL

\begin{tabular}{ccccccc}
\hline ID & Tarefa & T.I. & T.F. & T.T.(min) & N $^{\mathbf{0}}$ Mod. & MC \\
\hline soap01 & 1 & $19: 10$ & $21: 23$ & 133 & 81 & 1,641975309 \\
& 2 & $21: 30$ & $22: 58$ & 88 & 1001 & 0,087912088 \\
\hline \multirow{2}{*}{ soap02 } & 1 & $19: 15$ & $21: 38$ & 143 & 80 & 1,7875 \\
& 2 & $21: 40$ & $23: 00$ & 80 & 960 & 0,083333333 \\
\hline \multirow{2}{*}{ soap03 } & 1 & $19: 07$ & $21: 27$ & 140 & 82 & 1,707317073 \\
& 2 & $21: 30$ & $22: 53$ & 83 & 974 & 0,085215606 \\
\hline soap04 & 1 & $19: 12$ & $21: 27$ & 135 & 79 & 1,708860759 \\
& 2 & $21: 30$ & $22: 55$ & 85 & 954 & 0,089098532 \\
\hline soap05 & 1 & $19: 17$ & $21: 38$ & 141 & 83 & 1,698795181 \\
& 2 & $21: 38$ & $23: 00$ & 82 & 978 & 0,083844581 \\
\hline
\end{tabular}

Tabela 7.5: Estatística básica referente à Tarefa 1 do servidor SOAP-WSDL

\begin{tabular}{|cc|}
\hline Informação & \multicolumn{1}{c|}{ Valor } \\
\hline Mínimo & 1,641975309 \\
Média & 1,708889664 \\
Mediana & 1,707317073 \\
Máximo & 1,7875 \\
Desvio Padrão da Média & 0,023196431 \\
Desvio Padrão & 0,051868797 \\
Variância & 0,002690372 \\
LI (IC Média) & 1,644486047 \\
LS (IC Média) & 1,773293282 \\
\hline
\end{tabular}


Tabela 7.6: Estatística básica referente à Tarefa 2 do servidor SOAP-WSDL

\begin{tabular}{|cc|}
\hline Informação & Valor \\
\hline Mínimo & 0,083333333 \\
Média & 0,085880828 \\
Mediana & 0,085215606 \\
Máximo & 0,089098532 \\
Desvio Padrão da Média & 0,001130447 \\
Desvio Padrão & 0,002527756 \\
Variância & $6,38955 \mathrm{E}-06$ \\
LI (IC Média) & 0,082742205 \\
LS (IC Média) & 0,089019451 \\
\hline
\end{tabular}

Podemos perceber que o tempo gasto na primeira tarefa de manutenção no serviço web no lado do servidor SOAP-WSDL, foi também, maior em relação à segunda tarefa. Isso pode ter acontecido pelo mesmo motivo do web service do servidor RESTful comentado anteriormente, ou seja, devido ao primeiro contato do Grupo B com o código-fonte, ocasionou inicialmente uma certa dificuldade, pois ao implementar uma nova funcionalidade os alunos precisaram entender primeiro todo o código-fonte para executar a tarefa de manutenção.

Além disso, é importante mencionar que o número de modificações foi calculado por meio da nova funcionalidade incluindo o número de linhas, todas as classes, interfaces, métodos, serviços e pacotes modificados no repositório SVN em relação ao código fonte originais. Para auxiliar no cálculo do número de modificações foi utilizado o plugin do Netbeans Simple Code Metrics ${ }^{3}$ juntamente com o repositório SVN.

\subsection{Resultados no Lado do Cliente}

A Tabela 7.7 mostra os dados obtidos por meio da avaliação dos web service do lado do cliente RESTful.

Tabela 7.7: Tabela de dados referentes às Tarefas 1 do cliente RESTful

\begin{tabular}{cccccc}
\hline ID & T.I. & T.F. & T.T.(min) & N $^{\mathbf{c}}$ Mod. & MC \\
\hline rest01 & $19: 50$ & $21: 50$ & 120 & 341 & 0,351906158 \\
rest02 & $19: 42$ & $21: 53$ & 131 & 394 & 0,33248731 \\
rest03 & $19: 40$ & $21: 50$ & 130 & 503 & 0,258449304 \\
rest04 & $19: 45$ & $22: 35$ & 170 & 408 & 0,416666667 \\
rest05 & $20: 00$ & $23: 25$ & 205 & 426 & 0,481220657 \\
\hline
\end{tabular}

As Tabelas 7.9 e 7.10 mostram os resultados dos dados obtidos por meio da avaliação dos web services do lado do cliente SOAP-WSDL.

\footnotetext{
${ }^{3}$ http://plugins.netbeans.org/plugin/9494/simple-code-metrics
} 
Tabela 7.8: Estatística básica referente à Tarefa 1 do cliente RESTful

\begin{tabular}{|cc|}
\hline Informação & Valor \\
\hline Mínimo & 0,258449304 \\
Média & 0,368146019 \\
Mediana & 0,351906158 \\
Máximo & 0,481220657 \\
Desvio Padrão da Média & 0,037887183 \\
Desvio Padrão & 0,084718317 \\
Variância & 0,007177193 \\
LI (IC Média) & 0,262954335 \\
LS (IC Média) & 0,473337703 \\
\hline
\end{tabular}

Tabela 7.9: Tabela de dados referentes à Tarefa 1 do cliente SOAP-WSDL

\begin{tabular}{cccccc}
\hline ID & T.I. & T.F. & T.T.(min) & N $^{\circ}$ Mod. & MC \\
\hline soap01 & $19: 38$ & $22: 21$ & 163 & 1432 & 0,113826816 \\
soap02 & $20: 08$ & $23: 17$ & 189 & 1416 & 0,133474576 \\
soap03 & $19: 38$ & $22: 51$ & 193 & 981 & 0,196738022 \\
soap04 & $19: 40$ & $21: 00$ & 80 & 1140 & 0,070175439 \\
soap05 & $19: 40$ & $22: 00$ & 140 & 1177 & 0,118946474 \\
\hline
\end{tabular}

Tabela 7.10: Estatística básica referente à Tarefa 1 do cliente SOAP-WSDL

\begin{tabular}{|cc|}
\hline Informação & Valor \\
\hline Mínimo & 0,070175439 \\
Média & 0,126632265 \\
Mediana & 0,118946474 \\
Máximo & 0,196738022 \\
Desvio Padrão da Média & 0,020459788 \\
Desvio Padrão & 0,045749477 \\
Variância & 0,002093015 \\
LI (IC Média) & 0,069826787 \\
LS (IC Média) & 0,183437744 \\
\hline
\end{tabular}




\subsection{Comparação dos Resultados}

Os resultados obtidos no estudo revelam que os web services RESTful são mais manuteníveis do lado do servidor em contrapartida os web services SOAP-WSDL são mais manuteníveis do lado do cliente. Os estudos realizados no experimento controlado são promissores e podem auxiliar na redução de custo na manutenção dos serviços web, melhorando dessa forma a qualidade do Software Orientado a Serviço no geral.

Levando o debate em curso os web services RESTful e SOAP-WSDL (Pautasso et al., 2008) como exemplo, o argumento de ser "mais" ou "menos" flexível foi apresentado por cada lado. Por exemplo, dando uma descrição explicita de uma interface de serviço em um documento WSDL pode ser considerado com baixo acoplamento, pois permite a interoperabilidade dos clientes de web services serem implementados em qualquer linguagem de programação. No entanto, ele também pode ser considerado como acoplamento forte, porque as alterações feitas no WSDL pode quebrar os clientes que são construídos usando o código gerado automaticamente a partir de uma versão anterior da descrição do serviço.

\subsubsection{Comparação no Lado do Servidor}

Após a avaliação foi realizada a comparação entre a manutenibilidade dos web services obtida do lado do servidor e do lado do cliente, por meio da métrica da complexidade de modificação da norma ISO 9126 descrita no final do Capítulo 4, além disso, foi utilizado o teste de hipótese conhecido por teste- $t$ com nível de significância no valor de $5 \%$. Todos os testes realizados nesta pesquisa são os mesmo testes abordados por Perepletchikov (Perepletchikov e Ryan, 2011) no seu experimento controlado para avaliar o impacto do acoplamento na manutenção de Software Orientado a Serviço.

Para verificar se as variâncias são iguais ou diferentes, entre os dois conjuntos de amostras de dados, foi realizado o teste- $f$ descrito a seguir. O resultado obtido foi $p=$ 0,507331466, ou seja, as variâncias entre as duas amostras são iguais. Após o teste- $f$, podemos realizar o teste- $t$ para os dois conjuntos de dados de cada amostra.

\section{TESTE- $F$ - DUAS VARIÂNCIAS}

- $P$-valor MAIOR do que 0.05 VARIÂNCIAS IGUAIS.

- $P$-valor MENOR do que 0.05 VARIÂNCIAS DIFERENTES.

Após aplicar o teste- $t$, como explicado a seguir:

\section{TESTE- $T$}

- P-valor MAIOR do que 0.05 NÃO-REJEITA (aceita) hipótese nula. 
- P-valor MENOR do que 0.05 REJEITA a hipótese nula.

Como o resultado do teste- $f$ foi maior do que 0.05 , podemos considerar as variâncias iguais e aplicar o teste- $t$ para comparar a manutenibilidade dos web services no lado do servidor.

A Tabela 7.11 exibe todos os dados referente a Tarefa 7.11 realizada no lado do servidor RESTful e comparação com o servidor SOAP-WSDL.

Tabela 7.11: Teste- $T$ da Tarefa 1 do lado do Servidor

\begin{tabular}{|cc|}
\hline Informação & Valor \\
\hline T & $-21,54348778$ \\
Graus de Liberdade & 8 \\
$P$-valor & $2,26969 \mathrm{E}-08$ \\
Média no grupo 1: & 1,062634937 \\
Média no grupo 2: & 1,708889664 \\
& \\
Desvio padrão amostral do grupo 1: & 0,042531553 \\
Desvio padrão amostral do grupo 2: & 0,051868797 \\
Desvio padrão agrupado: & 0,047430502 \\
& \\
Hipótese Alternativa: Diferente de & 0 \\
Intervalo de Confiança & $95 \%$ \\
Limite Inferior & $-0,715429509$ \\
Limite Superior & $-0,577079945$ \\
\hline
\end{tabular}

O teste- $t$ paramétrico combinando dos pares de dados entre os dois conjuntos da amostra indicam uma variação significativa $(p<0.05)$ em todos os grupos examinados, como mostrado na Tabela 7.11. Por isso, aceitamos a hipóteses alternativa experimental $H_{1}$ e concluímos que os web services RESTful são mais manuteníveis evolutivamente em relação aos web services SOAP-WSDL no lado do servidor, pois a média do grupo 1 ou Grupo A do servidor RESTful é de 1,062634937, ou seja, menor do que a média do grupo 2 ou grupo B do servidor SOAP-WSDL que é de 1,708889664. Quanto menor o valor da Complexidade de Modificação (MC) explicada no final do Capítulo 4 mais manutenível é o web service de acordo com Perepletchikov (Perepletchikov e Ryan, 2011).

Após analisar a manutenibilidade da tarefa evolutiva, o resultado da análise da tarefa de manutenção adaptativa será detalhado. Com o resultado do cálculo obtido do teste- $f$ foi igual à $p=0,978506443$, ou seja, as variâncias entre as duas amostras são iguais. Após o teste- $f$, podemos realizar o teste- $t$ para os dois conjuntos de dados de cada amostra como ilustrado na Tabela 7.12. A Tabela 7.12 exibe o resultado do teste- $t$ referente a Tarefa 2 realizada no lado do servidor. 
Tabela 7.12: Teste- $T$ da Tarefa 2 do lado do Servidor

\begin{tabular}{|cc|}
\hline Informação & Valor \\
\hline T & $-4,973243567$ \\
Graus de Liberdade & 8 \\
P-valor & 0,001088667 \\
Média no grupo 1: & 0,07688444 \\
Média no grupo 2: & 0,085880828 \\
& \\
Desvio padrão amostral do grupo 1: & 0,003157862 \\
Desvio padrão amostral do grupo 2: & 0,002527756 \\
Desvio padrão agrupado: & 0,002860214 \\
& \\
Hipótese Alternativa: Diferente de & 0 \\
Intervalo de Confiança & $95 \%$ \\
Limite Inferior & $-0,013167852$ \\
Limite Superior & $-0,004824924$ \\
\hline
\end{tabular}

O resultado do teste- $t$ paramétrico combinando dos pares de dados entre os dois conjuntos da amostra indicam uma variação significativa $(p<0.05)$ em todos os grupos examinados, como mostrado na Tabela 7.11. Por isso, aceitamos a hipóteses alternativa experimental $H_{1}$ e concluímos que os web services RESTful são mais manuteníveis adaptativamente em relação aos web services SOAP-WSDL no lado do servidor.

\subsubsection{Comparação no Lado do Cliente}

Para a análise da hipótese da manutenibilidade do lado cliente relacionada à manutenibilidade obteve-se o resultado do teste- $f$ com $p$-valor $=0,25981874$, indicando que a variância dos dois conjuntos de dados são iguais. Dessa forma, os resultados do teste- $t$ paramétrico estão apresentados na Tabela 7.13. A análise dessa tabela segue as mesmas instruções citadas nas análise anterioes.

Para este resultado observa-se que a utilização do arquivo WSDL para descrever uma interface de serviço ajuda a abstrair o protocolo de comunicação e os dados de serialização, bem como a plataforma de implementação do serviço (sistema operacional e linguagem de programação). Além disso, os contratos WSDL fornecem uma descrição de processamento da sintaxe e da estrutura do pedido correspondente e mensagens de resposta para as máquinas, além de definir um caminho evolutivo e flexível para o serviço.

Portanto, os motores SOAP e as ferramentas WSDL efetivamente encapsulam a complexidade do programador da aplicação e do integrador. De acordo com a sua experiência pessoal, Pautasso (Pautasso et al., 2008) enfatiza que não é necessário estudar as especificações para ser capaz de desenvolver serviços interoperáveis, assumindo que o tempo 
Tabela 7.13: Teste- $T$ da Tarefa 1 do lado do Cliente

\begin{tabular}{|cc|}
\hline Informação & Valor \\
\hline T & 5,608957297 \\
Graus de Liberdade & 8 \\
P-valor & 0,000504946 \\
Média no grupo 1: & 0,368146019 \\
Média no grupo 2: & 0,126632265 \\
& \\
Desvio padrão amostral do grupo 1: & 0,084718317 \\
Desvio padrão amostral do grupo 2: & 0,045749477 \\
Desvio padrão agrupado: & 0,068081598 \\
& \\
Hipótese Alternativa: Diferente de & 0 \\
Intervalo de Confiança & $95 \%$ \\
Limite Inferior & 0,142220483 \\
Limite Superior & 0,340807024 \\
\hline
\end{tabular}

de execução e ferramentas selecionadas mantenham o perfil básico WS-I ${ }^{4}$. Uma característica importante é que os clientes podem ser gerados a partir dos contratos WSDL automaticamente.

O resultado do teste- $t$ paramétrico combinando dos pares de dados entre os dois conjuntos da amostra indicam uma variação significativa $(p<0.05)$ em todos os grupos examinados. Por isso, aceitamos a hipóteses alternativa experimental $H_{1}$ e concluímos que os web services SOAP-WSDL são mais manuteníveis adaptativamente em relação aos web services RESTful no lado do cliente. Consequentemente, podemos concluir que as ferramentas WS-* atuais favorecem a transformação dos componentes de software existentes em consumidores da web (Pautasso et al., 2008).

A IDE do Netbeans possibilita gerar código para ambas as API do METRO e JAX-RS, porém por causa da descrição em WSDL dos web services SOAP-WSDL, facilitou a tarefa de manutenção do lado cliente com a geração automática de código por meio dos stubs. Pois, a geração de código automática ajudou os alunos a reduzir os erros cometidos nas tarefas de manutenção, além de agilizar a tarefa manual de manutenção do código fonte.

\subsection{Considerações Finais}

Lembrando que a tecnologia de web services RESTful não substitui a tecnologia dos web services SOAP-WSDL, além disso a manutenibilidade é influenciada pelas linguagens de programação e que um cliente RESTful pode ser construído por um simples código JavaS-

\footnotetext{
${ }^{4}$ WS-I. web services Interoperability. http://www.ws-i.org.
} 


\section{CAPÍTULO 7. ANÁLISE DOS RESULTADOS E AVALIAÇÃO DA HIPÓTESE}

cript. Porém, a linguagem de programação Java foi escolhida também por ser amplamente aceita e utilizada no meio empresarial e por estar inserida no contexto de grandes empresas.

Neste capítulo foram apresentadas as análises dos dados obtidos com o experimento conduzido. Duas hipóteses foram analisadas no decorrer do capítulo, resultando nas relações entre as informações sobre o custo e a qualidade do software desenvolvido, contribuindo para o esclarecimento dos critérios para a obtenção de uma boa relação entre o custo da manutenção e a evolução dos serviços web. Os resultados aqui apresentados fornecem subsídios para as conclusões do trabalho, apresentadas no próximo capítulo. 



\section{Conclusão}

\subsection{Caracterização da Pesquisa Realizada}

este trabalho foram apresentados os resultados de um experimento controlado examinando a relação entre a manutenibilidade das abordagens RESTful e SOAP-WSDL, medida pelos indicadores propostos na norma ISO-9126 focando na subcaracterísticas específicas de manutenção de software da modificabilidade. Foi estabelecida uma estratégia que pode ser usada para avaliar futuros trabalhos na área.

Com a análise usando estatística descritiva foi possível observar relações entre a manutenibilidade dos web services RESTful e SOAP-WSDL. Observou-se por meio da avaliação e da comparação obtida do experimento que os web services RESTful são mais manuteníveis do lado do servidor em contrapartida aos web services SOAP-WSDL que são mais manuteníveis do lado do cliente. 


\subsection{Contribuições}

Podem-se destacar como principais contribuições deste trabalho:

1. Comparação da manutenibilidade do lado servidor ou fornecedor do web service RESTful.

2. Comparação da manutenibilidade do lado cliente ou consumidor do web service RESTful.

3. Comparação da manutenibilidade do lado servidor ou fornecedor do web service SOAP-WSDL.

4. Comparação da manutenibilidade do lado cliente ou consumidor do web service SOAP-WSDL.

5. Identificação de uma arquitetura para avaliar a manutenibilidade com base em dois sistemas funcionalmente equivalentes.

6. Geração de um conjunto de artefatos contendo a documentação de toda atividade da manutenibilidade que pode servir como material de auxílio ao ensino e treinamento de técnicas de manutenibilidade de Software Orientado a Serviço.

Este trabalho apresentou os resultados de um experimento controlado comparando a relação entre a manutenibilidade entre as abordagens de web services RESTful e SOAP-WSDL, mensurada por meio das métricas de qualidade de software propostas na norma ISO 9126 (ISO9126, 2003) focando na subcaracterística específica da modificabilidade e manutenção de software.

A análises estatísticas efetuada, revelou as relações entre a manutenção de web services RESTful e SOAP-WSDL. Depois de avaliar e comparar os resultados, foi possível garantir que os web services RESTful são mais sustentável no lado do servidor em contrapartida o SOAP-WSDL, é mais manutenível no lado do cliente.

Portanto, as empresas interessadas em disponibilizar ou fornecer um serviço web por meio da internet, vão obter um menor custo com os gastos de manutenção dos seus serviços por meio dos web services RESTful. Em contrapartida, se o objetivo da empresa é consumir um serviço web por meio da internet, o SOAP-WSDL apresentou um menor custo com os gastos de manutenção.

\subsubsection{Produção Científica}

Este projeto de mestrado resultou na publicação de alguns artigos em eventos científicos que são listados a seguir: 
1. OliveirA, R. R. ; SANCHEZ, R. V. V. ; ESTRELlA, J. C.; BRUSAMOLIN, V.; FORTES, R. P. M. Evaluation of Maintainability among RESTful and SOAP-WSDL web services pproaches. Submetido ao 14th International Conference on Information Integration and Web-based Applications \& Services - iiWAS 2012. Bali Indonésia.

2. OLIVEIRA, R. R. ; SANCHEZ, R. V. V. ; FORTES, R. P. M. . Desenvolvimento de web services RESTful e SOAP-WSDL utilizando as Implementações de Referência JAX-RS e JAX-WS. Material de Treinamento do Curso de web services RESTful e SOAP-WSDL em Java. 2011. Universidade de São Paulo. São Carlos - SP.

3. OLIVEIRA, R. R. ; SANCHEZ, R. V. V. ; FORTES, R. P. M. . Introdução aos web services Axis 2. Material introdutório de desenvolvimento de web services utilizando o Apache Axis 2. 2011. Universidade de São Paulo. São Carlos - SP.

4. SANCHEZ, R. V. V. ; OLIVEIRA, R. R. ; FORTES, R. P. M. . Persistência em Banco de Dados utilizando a Java Persistence API. Material da API do JPA para persistência em Banco de Dados e desenvolvimento Java. 2011. Universidade de São Paulo. São Carlos - SP.

5. OLIVEIRA, R. R. ; SANCHEZ, R. V. V. ; Fernandes Neto, David ; FROTA, P. C. ; FORTES, R. P. M. . Notificação de Wiki por meio de Mensageiros Instantâneos via bot reforçando a colaboração na Web.. In: Simpósio Brasileiro de Sistemas Multimídia e Web WebMedia. Companion Proceedings of the XIV Brazilian Symposium on Multimedia and the Web. New York, NY, USA : ACM, 2008., 2011, Florianopolis SC. Anais do Webmedia 2011, 2011. v. v. 1. p. 1-7.

6. SANCHEZ, R. V. V. ; OLIVEIRA, R. R. ; Fernandes Neto, David ; FORTES, R. P. M. ; PIMENTEL, M. G. C. . Services Mobile: Incorporando serviços da Web 2.0 aos dispositivos móveis mediante o uso de informações de contexto.. In: Simpósio Brasileiro de Sistemas Multimídia e Web WebMedia. Companion Proceedings of the XIV Brazilian Symposium on Multimedia and the Web. New York, NY, USA : ACM, 2008., 2011, Florianopolis SC. Anais do Webmedia 2011, 2011. v. v. 1. p. $1-4$.

\subsection{Dificuldades e Limitações}

O presente trabalho apresentou algumas dificuldades e limitações durante seu planejamento e execução:

1. A primeira dificuldade encontrada foi durante a escolha das ferramentas de manutenção, pois a quantidade de ferramentas disponíveis open source para a auxiliar 
na avaliação da manutenibilidade e prover qualidade do software desenvolvido é bastante limitada. Além disso, muitas dessas ferramentas ou plugins possuem um conjunto limitado de métricas diretas obtidas a partir do código fonte.

2. Outra dificuldade foi encontrar as métricas adequadas devido a grande quantidade de métricas diretas em relação as métricas indiretas. Espera-se que os artefatos gerados neste estudo possam servir para a avaliação e comparação de novas ferramentas que venham a ser desenvolvidas para a manutenibilidade dos Softwares Orientados a Serviços e garantir maior qualidade dos web services desenvolvidos no mercado.

3. Também foi identificada como uma limitação do experimento a quantidade de indivíduos participantes. Com a replicação do experimento com uma quantidade maior de participantes os resultados obtidos neste estudo podem ser comparados e o impacto do fator humano pode ser melhor avaliado.

\subsection{Trabalhos Futuros}

Como trabalhos futuros decorrentes dessa dissertação destacam-se: a replicação desse estudo, considerando outros domínios de programas, tarefas e mais participantes envolvidos, a realização de um estudo teórico sobre as métricas qualitativas com influência da padronização na manutenibilidade dos web services SOAP-WSDL. A arquitetura do experimento pode ser replicada para avaliar e comparar a manutenibilidade por meio da estatística descritiva o padrão de segurança WS-Security com o protocolo HTTPS utilizados para a segurança de transferência de dados dos web services SOAP-WSDL e RESTful respectivamente. Além disso, o Design Rationale poderia ser utilizado para a coleta de dados e registrar as informações de DR por meio de uma rede do tipo argumentação. Um outro trabalho futuro seria avaliar a manutenibilidade evolutiva dos clientes RESTful e SOAP-WSDL. Por fim, poderia ser realizada uma pesquisa da influência da linguagem de programação na manutenibilidade de Softwares Orientados a Serviços. 


\section{Referências}

Adam, N. R.; Atluri, V.; Adiwijaya, I. Si in digital libraries. Commun. ACM, v. 43, p. $64-72,2000$.

Disponível em http://doi.acm.org/10.1145/336460.336476

Aggarwal, K.; Singh, Y.; Chhabra, J. An integrated measure of software maintainability. In: Reliability and Maintainability Symposium, 2002. Proceedings. Annual, 2002, p. 235 -241 .

Avadhesh Kumar, R. K.; Grover, P. S. An evaluation of maintainability of aspect-oriented systems: a practical approach. International Journal of Computer Science and Security, v. 1, n. 3, 2007.

de Barros Neto, B.; Scarminio, I.; Bruns, R. Como fazer experimentos: pesquisa e desenvolvimento na ciência e na indústria. Coleção Livro-Texto. Editora da Unicamp, 2003.

BASCI, D., M. S. Data complexity metrics for xml web services. Advances in Electrical and Computer Engineering, v. 9, p. 9 - 15, 2009.

Basili, V. R.; Caldiera, G.; Rombach, H. D. The goal question metric approach. In: Encyclopedia of Software Engineering, Wiley, 1994.

Basili, V. R.; Selby, R. W.; Hutchens, D. H. Experimentation in software engineering. IEEE Trans. Softw. Eng., v. 12, n. 7, p. 733-743, 1986.

Disponível em http://dl .acm.org/citation. cfm?id=9775.9777

Basili, V. R.; Shull, F.; Lanubile, F. Building knowledge through families of experiments. IEEE Trans. Softw. Eng., v. 25, n. 4, p. 456-473, 1999.

Disponível em http://dx.doi.org/10.1109/32.799939 
Berander, P. Using students as subjects in requirements prioritization. In: Proceedings of the 2004 International Symposium on Empirical Software Engineering, ISESE '04, Washington, DC, USA: IEEE Computer Society, 2004, p. 167-176 (ISESE '04, ).

Disponível em http://dx.doi.org/10.1109/ISESE. 2004.34

Bih, J. Service oriented architecture (soa) a new paradigm to implement dynamic e-business solutions. Ubiquity, v. 2006, p. 4:1-4:1, 2006.

Disponível em http://doi .acm.org/10.1145/1159402.1159403

Canfora, G.; Mancini, L.; Tortorella, M. A workbench for program comprehension during software maintenance. In: Program Comprehension, 1996, Proceedings., Fourth Workshop on, 1996, p. $30-39$.

Carlo Ghezzi, Mehdi Jazayeri, D. M. Fundamentals of software engineering. Prentice Hall, 1991.

Carver, J.; Jaccheri, L.; Morasca, S.; Shull, F. Issues in using students in empirical studies in software engineering education. In: Proceedings of the 9th International Symposium on Software Metrics, METRICS '03, Washington, DC, USA: IEEE Computer Society, 2003, p. 239-(METRICS '03, ).

Disponível em http://dl .acm.org/citation. cfm?id=942804.943760

Cerami, E. Web services essentials. 1st ed. Sebastopol, CA, USA: O'Reilly \& Associates, Inc., 2002.

Colan, M. The business value of web services: improving it stability, agility, and flexibility. WebSphere Developer's Journal, achieving ROI, 2003.

Coleman, D.; Ash, D.; Lowther, B.; Oman, P. Using metrics to evaluate software system maintainability. Computer, v. 27, n. 8, p. $44-49,1994$.

Coleman, D.; Lowther, B.; Oman, P. The application of software maintainability models in industrial software systems. J. Syst. Softw., v. 29, p. 3-16, 1995.

Disponível em http://portal.acm.org/citation. cfm?id=209140. 209142

Erl, T. Service-oriented architecture - a field guide to integrating xml and web services. 1st. ed. Prentice Hall, 2004.

Erl, T. Service-oriented architecture: Concepts, technology, and design. Upper Saddle River, NJ, USA: Prentice Hall PTR, 2005. 
Erlikh, L. Leveraging legacy system dollars for e-business. IT Professional, v. 2, n. 3, p. 17-23, 2000.

Disponível em http://dx.doi.org/10.1109/6294.846201

Fielding, R. T. Architectural styles and the design of network-based software architectures. Tese de Doutoramento, UC Irvine, 2000.

Halstead, M. H. Elements of software science (operating and programming systems series). New York, NY, USA: Elsevier Science Inc., 1977.

Hayes, W. Research synthesis in software engineering: A case for meta-analysis. In: Proceedings of the 6th International Symposium on Software Metrics, METRICS '99, Washington, DC, USA: IEEE Computer Society, 1999, p. 143-(METRICS '99, ). Disponível em http://dl.acm.org/citation.cfm?id=520792.823955

Henry, S.; Humphrey, M. A controlled experiment to evaluate maintainability of object-oriented software. In: Software Maintenance, 1990., Proceedings., Conference on, 1990, p. $258-265$.

Henry, S.; Selig, C. Predicting source-code complexity at the design stage. IEEE Softw., v. 7, p. 36-44, 1990.

Disponível em http://dx.doi.org/10.1109/52.50772

Höst, M. Introducing empirical software engineering methods in education. In: Proceedings of the 15th Conference on Software Engineering Education and Training, CSEET '02, Washington, DC, USA: IEEE Computer Society, 2002, p. 170- (CSEET '02, ). Disponível em http://dl .acm.org/citation.cfm?id=872751.873477

Höst, M.; Regnell, B.; Wohlin, C. Using students as subjects - a comparative study ofstudents and professionals in lead-time impact assessment. Empirical Softw. Engg., v. 5 , n. 3, p. 201-214, 2000.

Disponível em http://dx.doi.org/10.1023/A:1026586415054

Höst, M.; Wohlin, C.; Thelin, T. Experimental context classification: incentives and experience of subjects. In: Proceedings of the 27th international conference on Software engineering, ICSE '05, New York, NY, USA: ACM, 2005, p. 470-478 (ICSE '05, ). Disponível em http://doi.acm.org/10.1145/1062455.1062539

IBM Standards and web services. Último acesso: 01/03/2011, 2009.

Disponível em http://www-128.ibm.com/developerworks/webservices/ standards/ 
ISO2000 Information technology - software product quality - part 1: Quality model report iso/iec fdis 9126-1:2000 (e). 2000.

ISO9126 Nbr iso/iec 9126-1 - engenharia de software - qualidade de produto. Parte 1: Modelo de Qualidade, 2003.

Josuttis, N. M. Soa in practice the art of distributed system design. 1st. ed. O'Reilly Media, Inc., 2007.

Jun, Y.; Zhishu, L.; Yanyan, M. Json based decentralized sso security architecture in e-commerce. In: Proceedings of the 2008 International Symposium on Electronic Commerce and Security, ISECS '08, Washington, DC, USA: IEEE Computer Society, 2008, p. 471-475 (ISECS'08, ).

Disponível em http://dx.doi.org/10.1109/ISECS. 2008.171

Juristo, N.; Moreno, A. M. Basics of software engineering experimentation. 1 st ed. Springer Publishing Company, Incorporated, 2010.

Kajko-Mattsson, M. Evolution and maintenance of web service applications. In: Proceedings of the 20th IEEE International Conference on Software Maintenance, Washington, DC, USA: IEEE Computer Society, 2004, p. 492-493.

Disponível em http://portal.acm.org/citation. cfm?id=1018431.1021463

Kajko-Mattsson, M. Future of evolution and maintenance in the world of integrated web service systems. In: Integrated Design and Process Technology (IDPT-2005), Society for Design and Process Science, 2005.

Kajko-Mattsson, M.; Tepczynski, M. A framework for the evolution and maintenance of web services. In: Proceedings of the 21st IEEE International Conference on Software Maintenance, Washington, DC, USA: IEEE Computer Society, 2005, p. 665-668.

Disponível em http://portal . acm.org/citation. cfm?id=1090952 . 1091921

Kitchenham, B. A.; Dyba, T.; Jorgensen, M. Evidence-based software engineering. In: Proceedings of the 26th International Conference on Software Engineering, ICSE '04, Washington, DC, USA: IEEE Computer Society, 2004, p. 273-281 (ICSE '04, ).

Disponível em http://dl .acm.org/citation.cfm?id=998675.999432

Laurent, S. S.; Dumbill, E.; Johnston, J. Programming web services with xml-rpc. Sebastopol, CA, USA: O'Reilly \& Associates, Inc., 2001.

Manna, M. Maintenance burden begging for a remedy, p. pp. 53-63. Datamation, 1993. 
Mari, M.; Eila, N. The impact of maintainability on component-based software systems. In: Proceedings of the 29th Conference on EUROMICRO, Washington, DC, USA: IEEE Computer Society, 2003, p. 25-.

Disponível em http://portal . acm.org/citation. cfm?id=942796.943274

Mashiko, Y.; Basili, V. R. Using the gqm paradigm to investigate influential factors for software process improvement. J. Syst. Softw., v. 36, p. 17-32, 1997.

Disponível em http://dl . acm.org/citation. cfm?id=259502 . 257526

McCabe, T. Structured testing: A software testing methodology using the cyclomalic complexity metric. NBS Special Publication, 500-99, 1982.

Meng, J.; Mei, S.; Yan, Z. Restful web services: A solution for distributed data integration. In: Computational Intelligence and Software Engineering, 2009. CiSE 2009. International Conference on, 2009, p. $1-4$.

Miller, J. Can results from software engineering experiments be safely combined? In: Proceedings of the 6th International Symposium on Software Metrics, METRICS '99, Washington, DC, USA: IEEE Computer Society, 1999, p. 152- (METRICS '99, ). Disponível em http://dl .acm.org/citation.cfm?id=520792.823953

Oasis Uddi v3.0 ratified as OASIS standard. Relatório Técnico, 2005. Disponível em http://www.uddi.org/

Papazoglou, M.; Traverso, P.; Dustdar, S.; Leymann, F. Service-oriented computing: State of the art and research challenges. Computer, v. 40, n. 11, p. $38-45,2007$.

Pautasso, C.; Zimmermann, O.; Leymann, F. Restful web services vs. "big"' web services: making the right architectural decision. In: Proceeding of the 17th international conference on World Wide Web, WWW '08, New York, NY, USA: ACM, 2008, p. 805-814 ( $W W W^{\prime} 08$, ).

Disponível em http://doi.acm.org/10.1145/1367497.1367606

Perepletchikov, M.; Ryan, C. A controlled experiment for evaluating the impact of coupling on the maintainability of service-oriented software. Software Engineering, IEEE Transactions on, v. 37, n. 4, p. 449-465, 2011.

Pressman, R.; Pressman, R. Software Engineering: A Practitioner's Approach. 6 ed. McGraw-Hill Science/Engineering/Math, 2004.

Disponível em http://www . worldcat.org/isbn/007301933X 
R. Fraser, T. R.; Woodcock, R. Service oriented grid architecture for geosciences community. Proceeding ACSW' '07 Proceedings of the fifth Australasian symposium on ACSW frontiers, v. 68, 2007.

Rombach, H. D. Design measurement: Some lessons learned. IEEE Softw., v. 7, p. 17-25, 1990.

Disponível em http://dx.doi.org/10.1109/52.50770

SEI Software technology review, maintainability index technique for measuring program maintainability,. 2003.

Disponível em http://www.sei.cmu.edu/

Shull, F.; Basili, V.; Carver, J.; Maldonado, J. C.; Travassos, G. H.; Mendonça, M.; Fabbri, S. Replicating software engineering experiments: Addressing the tacit knowledge problem. In: Proceedings of the 2002 International Symposium on Empirical Software Engineering, ISESE '02, Washington, DC, USA: IEEE Computer Society, 2002, p. 7 (ISESE '02, ).

Disponível em http://dl .acm.org/citation. cfm?id=857197.857885

Sj"berg, D. I. K.; Anda, B.; Arisholm, E.; Dybå, T.; J"rgensen, M.; Karahasanovic, A.; Koren, E. F.; Vokác, M. Conducting realistic experiments in software engineering. In: Proceedings of the 2002 International Symposium on Empirical Software Engineering, ISESE '02, Washington, DC, USA: IEEE Computer Society, 2002, p. 17- (ISESE '02, ) .

Disponível em http://dl .acm.org/citation. cfm?id=857197.857886

Sjoberg, D. I. K.; Hannay, J. E.; Hansen, O.; By Kampenes, V.; Karahasanovic, A.; Liborg, N.-K.; C. Rekdal, A. A survey of controlled experiments in software engineering. IEEE Trans. Softw. Eng., v. 31, n. 9, p. 733-753, 2005.

Disponível em http://dx.doi.org/10.1109/TSE.2005.97

Snell, J.; Tidwell, D.; Kulchenko, P. Programming web services with soap. Sebastopol, CA, USA: O’Reilly \& Associates, Inc., 2002.

SOAP Soap specifications. 2007.

Disponível em http://www.w3.org/TR/2007/REC-soap12-part1-20070427/

Sommerville, I. Software engineering (8th edition). Pearson Addison Wesley, 2007.

Stal, M. Web services: beyond component-based computing. Commun. ACM, v. 45, p. 71-76, 2002.

Disponível em http://doi.acm.org/10.1145/570907.570934 
Staron, M.; Kuzniarz, L.; Wohlin, C. Empirical assessment of using stereotypes to improve comprehension of uml models: A set of experiments. J. Syst. Softw., v. 79, n. 5, p. 727-742, 2006.

Disponível em http://dx.doi.org/10.1016/j.jss.2005.09.014

Thelin, T.; Runeson, P.; Wohlin, C. An experimental comparison of usage-based and checklist-based reading. IEEE Trans. Softw. Eng., v. 29, n. 8, p. 687-704, 2003.

Disponível em http://dx.doi.org/10.1109/TSE.2003.1223644

Travassos, G. Introdução à Engenharia de Software Experimental. Relatório Técnico RT-ES 590/02, COPPE/UFRJ, 2002.

W3C Web services architecture. Último acesso: 10/02/2011, 2004a.

Disponível em http://www.w3.org/TR/2004/NOTE-ws-arch-20040211/

W3C Xml schema. Último acesso: 01/03/2011, 2004b.

Disponível em http://www.w3.org/XML/Schema.html

W3C Web services description language (wsdl). Último acesso: 15/02/2011, 2007.

Disponível em http://www.w3.org/TR/2004/WD-wsdl20-patterns-20040326/

Wang, H.; Huang, J. Z.; Qu, Y.; Xie, J. Web services: Problems and future directions. Journal of Web Semantics, v. 1, n. 3, 2004.

Disponível em http://www. websemanticsjournal .org/ps/pub/2004-19

Weerawarana, S.; Curbera, F.; Leymann, F.; Storey, T.; Ferguson, D. F. Web services platform architecture: Soap, wsdl, ws-policy, ws-addressing, ws-bpel, ws-reliable messaging and more. Upper Saddle River, NJ, USA: Prentice Hall PTR, 2005.

Wei-Chung Hu, Chia Hung Kao, F. P. Y.; Jiau, H. C. Vesta: A view-based software quality assessmentmodel for software evolution management. Proceedings of the 22nd International Conference on Software Engineering and Knowledge Engineering, p. p.345-348, 2010.

Wohlin, C. Empirical software engineering: teaching methods and conducting studies. In: Proceedings of the 2006 international conference on Empirical software engineering issues: critical assessment and future directions, Berlin, Heidelberg: Springer-Verlag, 2007, p. 135-142.

Disponível em http://dl .acm.org/citation. cfm?id=1767399.1767459

Wohlin, C.; Runeson, P.; Höst, M.; Ohlsson, M. C.; Regnell, B.; Wesslén, A. Experimentation in software engineering: an introduction. Norwell, MA, USA: Kluwer Academic Publishers, 2000. 



\section{Base de Dados Utilizada no Experimento} ao esquema do banco de dados, que modela a aplicação web para apoio a Sistema de Informação de Ambiente Universitário (SInAU). O mini-mundo foi modelado com o objetivo de conter as várias formas de relacionamento, M:N, 1:N e 1:1, e alguns dos conceitos mais encontrados em esquemas ER, a saber: herança, atributos multivalorados e compostos, entidade fraca e atributo na relação.

No equema de banco de dados da Figura A.1, uma Universidade possui vários Departamentos, porém um Departamento pode ter vários Professores assim como vários Cursos. Um Curso possui várias Disciplinas. Uma Disciplina pode ter vários Alunos e um Aluno pode estar matriculado em várias Disciplinas. Assim como o relacionamento Aluno-Disciplina, o relacionamento entre as entidades Professor-Disciplina é estabelecido da mesma forma, ou seja, um Professor pode ministrar aula em várias Disciplinas e uma Disciplina pode ser ministrada por mais de um professor. Além disso, um Professor é um Usuário do sistema assim como um Aluno também é um Usuário do sistema. 


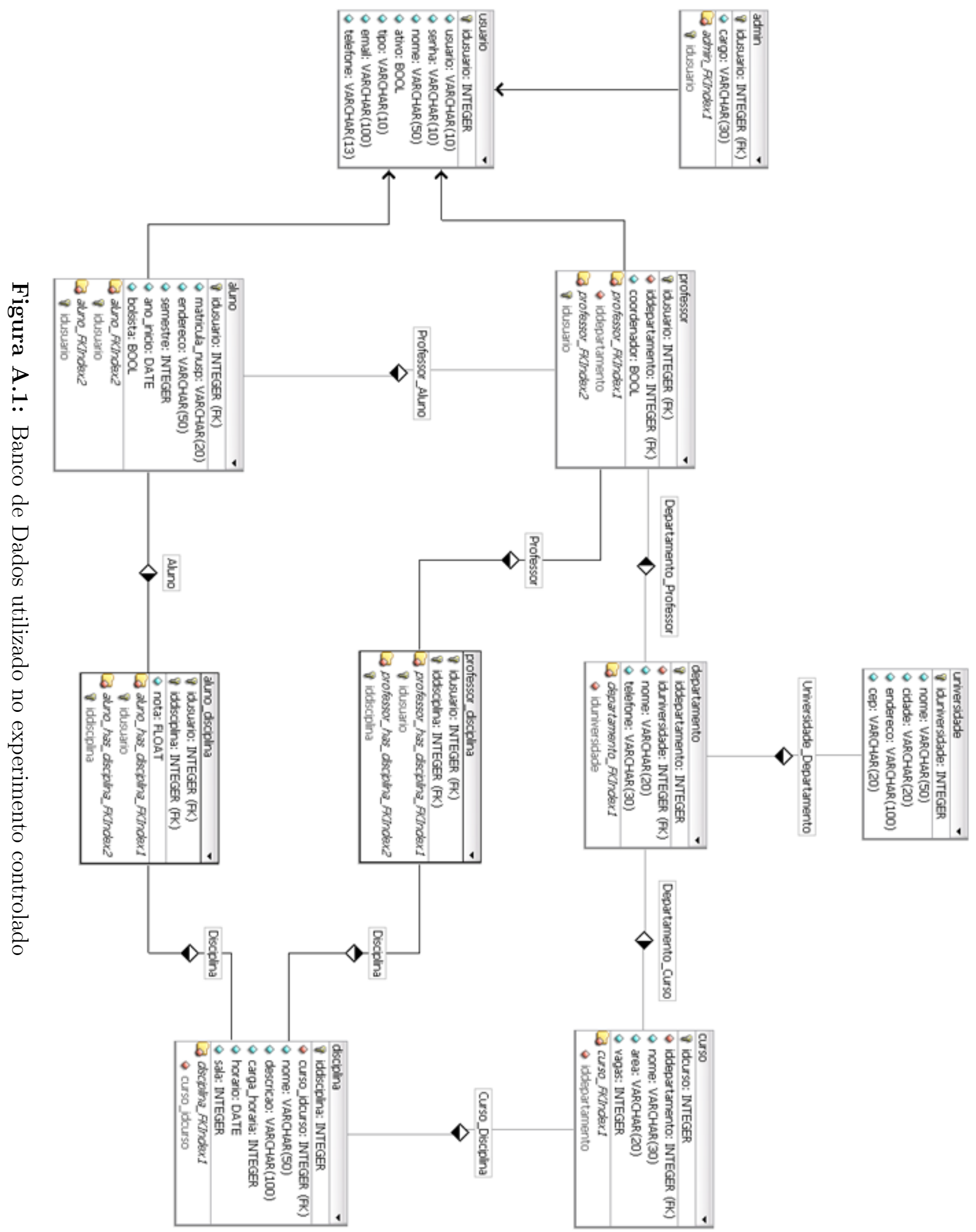


Apêndice

$B$

Modelo Inicial e Provisório da

Arquitetura

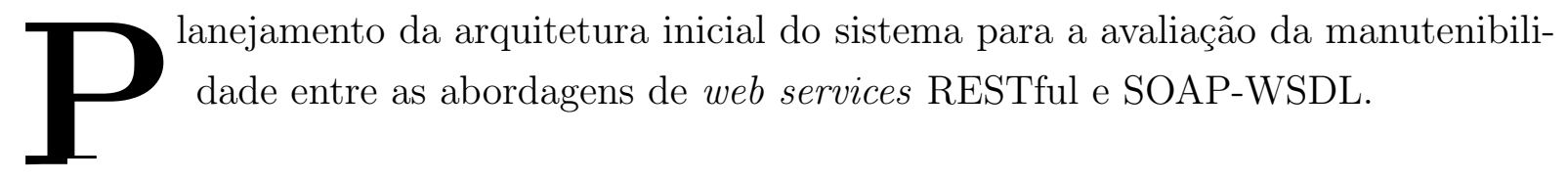

Figura B.1: Arquitetura inicial e provisória do experimento controlado 